VILNIUS GEDIMINAS TECHNICAL UNIVERSITY

Agnè VAICIUKEVIČIŪTÉ

\title{
ASSESSING ECONOMIC IMPACT \\ AND EFFICIENCY OF HIGHER EDUCATION INSTITUTIONS
}

DOCTORAL DISSERTATION

SOCIAL SCIENCES,

ECONOMICS (S 004) 
Doctoral dissertation was prepared at Vilnius Gediminas Technical University in 2014-2019.

\section{Supervisor}

Prof. Dr Jelena STANKEVIČIENĖ (Vilnius Gediminas Technical University, Economics - S 004).

The Dissertation Defense Council of Scientific Field of Economics of Vilnius Gediminas Technical University:

\section{Chairman}

Prof. Dr Daiva JUREVIČIENĖ (Vilnius Gediminas Technical University, Economics - S 004).

\section{Members:}

Prof. Dr Edita GIMŽAUSKIENE (Kaunas University of Technology, Management - S 003),

Assoc. Prof. Dr Egle KAZLAUSKIENE (Vilnius Gediminas Technical University, Economics - S 004),

Prof. Dr Manuela TVARONAVIČIENE (Vilnius Gediminas Technical University, Economics - S 004),

Dr Habil. Malgorzata WARDYN (Kozminski University, Economics S 004).

The dissertation will be defended at the public meeting of the Dissertation Defense Council of Economics in the Senate Hall of Vilnius Gediminas Technical University at $\mathbf{2}$ p. m. on 17 of June 2019.

Address: Saulètekio al. 11, LT-10223 Vilnius, Lithuania.

Tel.: +370 5274 4956; fax +370 5270 0112; e-mail: doktor@vgtu.lt

A notification on the intend defending of the dissertation was send on 16 May 2019. A copy of the doctoral dissertation is available for review at VGTU repository http://dspace.vgtu.lt, at the Library of Vilnius Gediminas Technical University (Sauletekio al. 14, LT-10223 Vilnius, Lithuania), at the Library of Lithuanian Social Research Center (A. Goštauto g. 9, LT-01108 Vilnius, Lithuania) and at the Lithuanian Institute of Agrarian Economics (V. Kudirkos g. 18-2, LT-03101 Vilnius, Lithuania).

VGTU Press TECHNIKA 2019-015-M research publication book ISBN 978-609-476-168-3

(C) VGTU Press TECHNIKA, 2019

(C) Agnè Vaiciukevičiūtè, 2019

agne.vaiciukeviciute@vgtu.lt 
VILNIAUS GEDIMINO TECHNIKOS UNIVERSITETAS

Agnè VAICIUKEVIČIŪTÉ

\section{AUKŠTOJO MOKSLO INSTITUCIJŲ EKONOMINIO POVEIKIO IR EFEKTYVUMO VERTINIMAS}

DAKTARO DISERTACIJA

SOCIALINIAI MOKSLAI,

EKONOMIKA (S 004) 
Disertacija rengta 2014-2019 metais Vilniaus Gedimino technikos universitete.

\section{Vadovas}

prof. dr. Jelena STANKEVIČIENĖ (Vilniaus Gedimino technikos universitetas, ekonomika - S 004).

Vilniaus Gedimino technikos universiteto Ekonomikos mokslo krypties disertacijos gynimo taryba:

\section{Pirmininkas}

prof. dr. Daiva JUREVIČIENÉ (Vilniaus Gedimino technikos universitetas, ekonomika - S 004).

\section{Nariai:}

prof. dr. Edita GIMŽAUSKIENĖ (Kauno technologijos universitetas, vadyba - S 003),

doc. dr. Eglė KAZLAUSKIENE (Vilniaus Gedimino technikos universitetas, ekonomika - S 004),

prof. dr. Manuela TVARONAVIČIENĖ (Vilniaus Gedimino technikos universitetas, ekonomika - S 004),

habil. dr. Malgorzata WARDYN (Kozminski universitetas, ekonomika S 004).

Disertacija bus ginama viešame Ekonomikos mokslo krypties disertacijos gynimo tarybos posedyje 2019 m. birželio 17 d. 14 val. Vilniaus Gedimino technikos universiteto senato posèdžių salëje.

Adresas: Saulètekio al. 11, LT-10223 Vilnius, Lietuva.

Tel.: (8 5) 274 4956; faksas (8 5) 270 0112; el. paštas doktor@vgtu.lt

Pranešimai apie numatomą ginti disertaciją išsiųsti 2019 m. gegužès $16 \mathrm{~d}$.

Disertaciją galima peržiūrèti VGTU talpykloje http://dspace.vgtu.lt, Vilniaus Gedimino technikos universiteto bibliotekoje (Saulètekio al. 14, LT-10223 Vilnius, Lietuva), Lietuvos socialinių tyrimų centro bibliotekoje (A. Goštauto g. 9, LT-01108 Vilnius, Lietuva) ir Lietuvos agrarinès ekonomikos institute (V. Kudirkos g. 18-2, LT-03101, Vilnius, Lietuva). 


\section{Abstract}

Higher Education Institutions (HEIs) have the potential to make a substantial impact on a country's economy. However, at the scientific level, there are lack of tools to assess the internal efficiency of HEIs and their economic impacts on the local economy in a systematic way. This research assumes that the economic activity of HEIs is integral to local economies, and thus, deserves serious study. The research proposes that it is necessary to assess HEIs' measurable impact on the economy, as well as their efficiency, in order to offer an analysis of which HEIs are performing as optimally as possible. The object of this dissertation is to develop a model that allows evaluating economic impact and efficiency of HEIs within the same system.

The dissertation consists of an introduction, three chapters, general conclusions, and seven appendices. Chapter 1 analyses pertinent research on the economic impact of HEIs by considering the most relevant theoretical models. This chapter outlines approaches for evaluating efficiency as they pertain to HEIs' activity. The chapter concludes with a critical synopsis of the current methods of assessing impact and efficiency in HEI research. Chapter 2 details the proposed models for evaluating both the economic impact and the efficiency of HEIs. InputOutput modelling (I-O) will be for its viability as a reliable approach to analysing economic impact. Next, a thorough account of Data Envelope Analysis (DEA) will be performed to justify its theoretical value in assessing HEIs' efficiency. The other part of the chapter brings economic impact and efficiency together by proposing an integrated model. In chapter 3 the study looks at the Lithuanian public universities specifically as an empirical case study. Then the chapter offers an indepth account of the application of the model to Lithuanian context.

Based on this study's empirical research, the findings outlined in Chapter 3 indicate that HEIs have one of the highest type II output multipliers in Lithuania, compared to other educational sectors. Meanwhile, larger universities have higher type II output multipliers than smaller universities. Furthermore, apart from one outlying institution, the largest HEIs were also the most efficient, debunking the common belief that smaller, more specialized universities are more efficient.

Finally, a set of general conclusions and recommendations for further research and application complete the present study. 4 publications focusing on the discussed dissertation are published: 3 in internationally recognized data basis, 1 - in conference material. 


\section{Reziumè}

Aukštojo mokslo institucijos (AMI) turi potencialo daryti didelę ịtaką šalies ekonomikai, tačiau, moksliniame lygmenyje trūksta priemonių kaip sistemiškai ịvertinti AMI efektyvumą ir poveikị šalies ekonomikai bendroje sistemoje. AMI ekonominė veikla yra integrali vietinės ekonomikos dalis ir todėl yra verta išsamaus mokslinio tyrinejjimo. Tyrimo metu paaiškèjo, kad yra būtina vertinti AMI veiklos efektyvumą ir daromą poveiki šalies ekonomikai tam, kad galima būtų išsamiau suprasti kokị poveikị AMI veikla sukuria šalies ekonomikai. Šios disertacijos tikslas yra sukurti modelį, leidžiantị ịvertinti ekonominị AMI poveikị bei šių institucijų efektyvumą bendroje sistemoje.

Disertaciją sudaro įvadas, trys skyriai, išvados ir septyni priedai. Pirmame skyriuje analizuojamas ekonominis AMI poveikis, atsižvelgiant ị pačius aktualiausius teorinius modelius. Skyrius baigiamas kritine AMI ekonominio poveikio ir efektyvumo metodų analize.

Antrame skyriuje detaliau nagrinèjami pasiūlyti tiek AMI poveikio ekonomikai tiek efektyvumo vertinimo modeliai. Siūlomas integralus AMI ekonominio poveikio ir efektyvumo vertinimo modelis, kuris susideda iš dviejų dalių. AMI ekonominiam poveikiui vertinti pasirinktas sąnaudų-rezultatų modeliavimo metodas, o gautų rezulatų efektyvumui vertinti pasirinkta duomenų apgaubimo analizè (toliau - DAA). Antroje skyriaus dalyje pateikiamos prielaidos AMI ekonominio poveikio ir efektyvumo vertinimui, siūlant taikyti vieną integruotą modelị.

Trečiame skyriuje vertinant Lietuvos valstybinių universitetu poveikị ir efektyvumą šalies ekonomikai atliekamas empirinis tyrimas ir modelio aprobavimas. Po to pateikiama nuodugni modelio taikymo eiga vertinant Lietuvos AMI. Gauti rezultatai parodė, jog Lietuvos valstybiniai universitetai turi vieną didžiausių II tipo našumo koeficientų lyginant su kitais švietimo sistemos dalyviais. Rezultatai taip pat parodè, kad, didesni universitetai savo veiklą vykdo efektyviau.

Disertacijos pabaigoje pateikiamos šio tyrimo bendros išvados ir rekomendacijos tolimesniems tyrimams. Šios disertacijos rezultatai paskelbti keturiose publikacijose: 3 publikacijos tarptautiniu mastu pripažintose duomenų bazèse, 1 publikacija konferencijos medžiagoje. 


\section{Abbreviations}

CBA - Cost-Benefit Analysis;

CRS - Constant Returns-to-Scale;

DEA - Data Envelopment Analysis;

DMUs - Decision-Making Units;

EI - Educational Institutions;

FTE - Full Time Equivalent;

HE - Higher Education;

HEI - Higher Education Institution;

HEIs - Higher Education Institutions;

IA $\quad-$ Impact Assessment;

I-O - Input-Output;

OECD - Organization for Economic Co-operation and Development;

VRS - Variable Returns-to-Scale. 



\section{Contents}

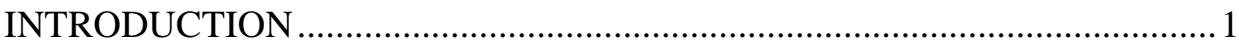

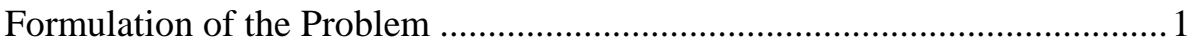

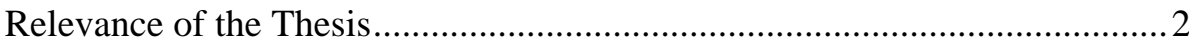

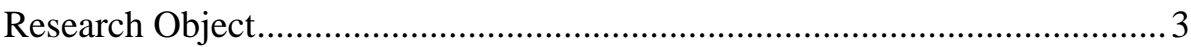

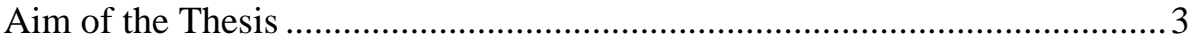

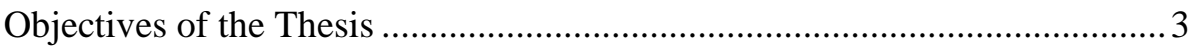

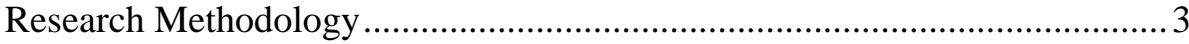

Scientific Novelty of the Thesis ............................................................. 4

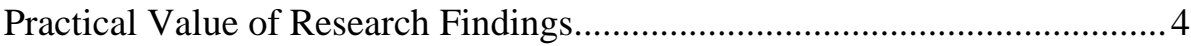

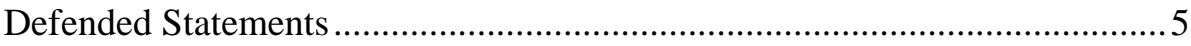

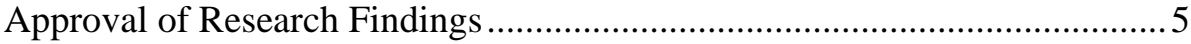

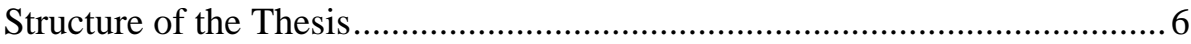

1. THEORETICAL CONCEPTS RELATED TO THE ECONOMIC IMPACT AND EFFICIENCY OF HIGHER EDUCATION INSTITUTIONS.............. 7

1.1. Defining the Key Terms: Economic Impact and Higher Education.........8 8 1.1.1. Theoretical Concepts of Economic Impact Studies in the Context of Higher Education Institutions ................................................... 12

1.1.2. Conceptualizing Different Economic Impact Effects ....................... 14

1.2. Multiply Approaches to the Economic Impact of Higher Education

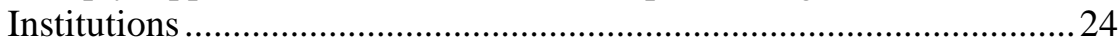


1.2.1. The Single Case Study Approach .................................................... 25

1.2.2. The Multiple Case Study Approach................................................ 28

1.2.3. Knowledge Production Functions .................................................. 30

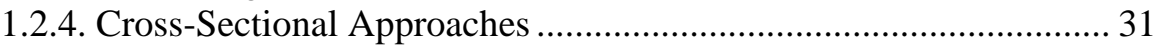

1.3. The Importance to Assess Efficiency of Higher Education

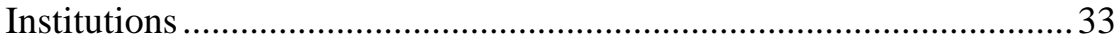

1.4. Chapter Conclusions and Formulation of Dissertation Objectives..........39

2. METHODOLOGY TO ASSESS ECONOMIC IMPACT AND EFFICIENCY OF HIGHER EDUCATION INSTITUTIONS .............................................. 41

2.1. Assessing Economic Impact of Higher Education Institutions .............. 42

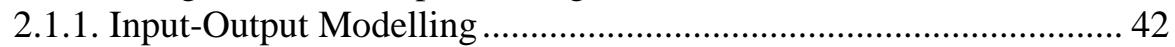

2.1.2. Aggregation of Input-Output Table ................................................ 47

2.1.3. Disaggregation of Economic Impacts of Higher Education Sector . 48

2.2. Assessing the Efficiency of Higher Education Institutions .................... 50

2.2.1 Data Envelopment Analysis for Efficiency of Higher Education

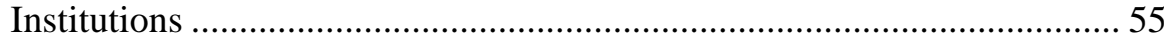

2.2.2. Cross-Efficiency Evaluation in Data Envelopment Analysis .......... 59

2.2.3. Dynamic Data Envelopment Analysis ............................................. 61

2.3. Proposing a Model to Address Economic Impact and Efficiency of

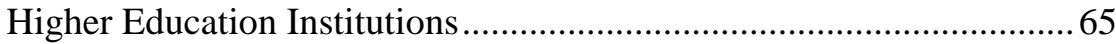

2.4. Incorporating Results in the Higher Education Institutions Assessment

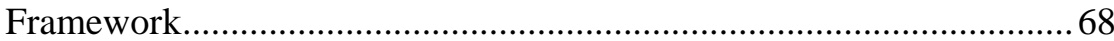

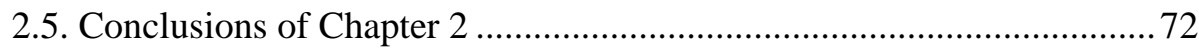

3. ASSESSING ECONOMIC IMPACT AND EFFICIENCY OF HIGHER

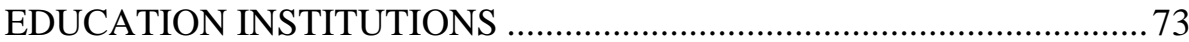

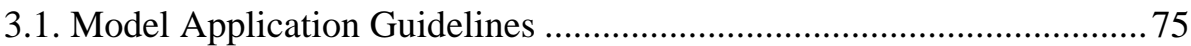

3.2. Economic Impact of Higher Education Institutions …............................ 79

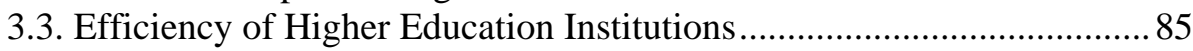

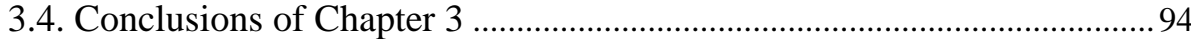

3.5. Future Research Directions ............................................................ 96

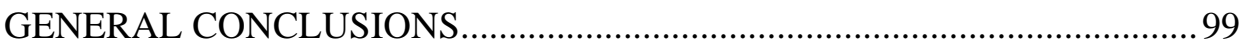

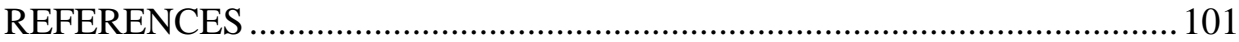

LIST OF PUBLICATIONS BY THE AUTHOR ON THE TOPIC

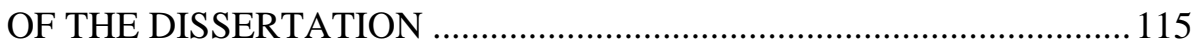

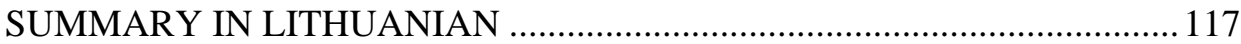




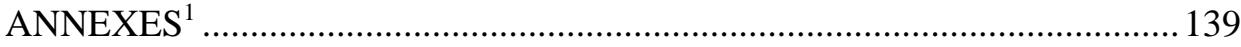

Annex A. Data of Public Universities in Lithuania (2010-2016) ............... 141

Annex B. Input-Output Table Disaggregation .......................................... 148

Annex C. Public Universities Output Multiplier Calculations .................... 150

Annex D. Cross Efficiency and Dynamic Data Envelopment Analysis

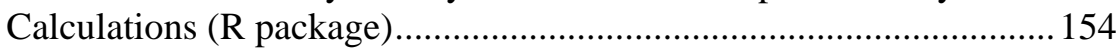

Annex E. Author's Declaration of Academic Integrity ............................... 158

Annex F. The Co-Authors' Agreements to Present the Material of

Publications as a Part of the Doctoral Dissertation

Annex G. Copies of Scientific Publications by the Author

on the Topic of the Dissertation ............................................................. 160

${ }^{1}$ The annexes are supplied in the attached compact disc. 



\section{Introduction}

\section{Formulation of the Problem}

The value of empirical and theoretical research on economic impact and efficiency has been proven in the context of tightened government budget constraints and mounting pressure on fund recipients to ensure the value on investments is growing. HEIs are not exempt from this challenge, since they generally derive some income from government bodies. The case examined in this dissertation - public universities in Lithuania - showcase an example of institutions that receive a large proportion of their income from government bodies.

However, analyses on the economic impact and efficiency of HEIs have been conducted in isolation, without a bridge connecting these two complementary analyses. Together, they can expose a more pragmatic and perceptive understanding of the impacts of the HE sector on the economy. A better understanding of this economic problem generates huge potential for governments to use a systematic approach. The application of such an approach towards a fundamental economic problem can lead to a better allocation of resources. Moreover, a critical analysis of the literature has indicated the following important economic problems:

1. Existing systematic economic impact and efficiency assessment reflect a poor understanding of the impact of HEIs on the economy. There are no systematic methodologies to assess the impact and efficiency of HEIs simultaneously; therefore, assessments of economic impacts and efficiency are not conducted, or are not conducted in a systematic way. 
2. The lack of a comprehensive system of assessment leads to an inability to compare HEIs operating within the same region or country, in terms of the economic impact and efficiency to the economy.

3. The lack of economic impact and efficiency measurement methods impedes HEIs, government and other stakeholders from understanding whether investment in the HE sector creates a sufficient economic effect.

4. Existing quantitative assessment methods to measure economic impact in modern economies have limited application possibilities in the HE sector. Qualitative assessment methods are dominant in literature on the efficiency of HEIs and are very difficult to apply, due to insufficient data.

\section{Relevance of the Thesis}

The dissertation investigates the assessment of economic impact and efficiency of HEIs' in order to evaluate HEIs' impact to the country's economy. The economic activity of HEIs is presumed integral to local economies, however, the degree to which these institutions impact the local economy and the efficiency with which they operate is inadequately understood. The author investigates the economic influence of HEIs on local economies and the efficiency with which such institutions function. At the scientific level, there is a lack of different tools to assess the impact and efficiency of HEIs as well as to understand those impact in a systematic way.

This dissertation contributes to scientific research by proposing a model that integrates economic impact and efficiency simultaneously. Economic impact of HEIs can be understood as the various ways that these institutions have an impact on the economy as a whole. This factor considers their external impact, or their economic impact outside of the boundaries of the institution itself. These impacts are experienced on both micro (the local economy) and macro levels (the national or even the global economy). One salient example of economic impact is job creation at the institution itself (faculty, academic staff, etc.), as well as ripple effects that occur in the rest of the economy to meet the economic needs of the institution. Efficiency refers to making the best possible use of resources that are allocated to the institution. In the most general sense, high efficiency means that an institution creates the highest outputs from relatively low inputs. This factor thus refers to the internal economic workings of the institution. For example, if an institution is able to minimize facility maintenance costs while generating more income, this represents an efficient use of resources. Therefore, efficiency is an important internal metric that situates the institution's economic activities within a broader understanding of a proper ratio of economic inputs and outputs. Neither factor by 
itself is adequate for a government to decide on the relative expenditures it should make at an individual HEI, or in the HE sector as a whole. Taken together, these two elements offer a viable model that the government can deploy in order to make appropriate investments in the Higher Education sector.

\section{Research Object}

The object of research - economic impact and efficiency of higher education institutions.

\section{Aim of the Thesis}

The goal of this thesis is to design and empirically test a model for assessing economic impact and efficiency of Higher Education Institutions.

\section{Objectives of the Thesis}

In order to achieve the specified aim of research, the following tasks should be completed:

1. To systemize existing theoretical concepts to assess HEIs' economic impact and efficiency.

2. To theoretically rationalize the choice of methods and methodology for assessing HEIs' economic impact and efficiency.

3. To propose a model to assess economic impact and efficiency of HEIs within one system.

4. To conduct empirical research on assessing the economic impact and efficiency of HEIs in Lithuania and test the relevance of the proposed model.

\section{Research Methodology}

In order to formulate the picture of the current assessments used of economic impact and efficiency in the HE sector, this study includes a critical literature analysis, followed by an overview of the methods of interpretation and conceptualization of economic impact and efficiency in HEIs. 
In the dissertation different methods were used for analysis of the economic impact of the HE sector first, and then for measuring the efficiency of HEIs. The study uses disaggregation methods to normalize the sectors of the economy follow the Nace 2 classification. The I-O analysis is applied for computing the economic impact of the HE. In the next step, the computed impact is disaggregated using two methods: proportional estimation and linear regression.

After arriving at the quantitative measures of the impact multipliers of HEIs, various data envelope analysis (DEA) methods such as cross efficiency DEA and dynamic DEA were implemented to estimate efficiencies. Consistencies between the results of proposed model were justified by checking the correlation of the results obtained through alternative models. The obtained results have been scientifically interpreted with reference to graphical analysis and logical abstraction methods.

\section{Scientific Novelty of the Thesis}

In developing this thesis, the study has achieved the following significant results for the science of economics:

1. Suggested parameters for measuring economic impact and efficiency in the context of public HEIs.

2. Proposed a quantitative input-output modelling procedure that allows for evaluating each HEI's economic impact by using linear regression.

3. Created a unique integrated assessment model that considers I-O and DEA methods together to comprehensively evaluate the economic effect of HEIs to the economy.

4. Developed an algorithm for assessing economic impact and efficiency for higher education institutions.

\section{Practical Value of Research Findings}

The research results are relevant for:

1. The government of Lithuania, who is currently contemplating a consolidation of the nation's public universities from fourteen to nine.

2. Public representatives who provide government funds for HEIs. The proposed methods of measurement present accountability measures, since 
they offer a way to prove whether these contributions provide significant value and an acceptable return on investment.

3. Informing local and national government bodies on investment decisions and related policy matters. For instance, the method offered in this study may reveal that public investment has yielded sufficient value to justify a continuing of current funding levels. Alternatively, the model could show insufficient value, which could be used as a justification for discontinuing further investment or consolidating low-value HEIs.

4. For individual HEIs, these results may provide a rationale to explore additional output streams to increase the value each HEI adds to the local economy. For example, such outputs could come from enhanced specialized program offerings, research incentives, job creation, and/or labour income. Each HEI can consider adopting new programmatic and enrolment goals to increase their impact on the economy.

5. For the government, comprehensive assessment of economic effects of HEIs creates the conditions for developing and achieving the government's strategic goals for HEIs.

\section{Defended Statements}

The following statements, based on the results of the present investigation, serve as the official hypotheses to be defended:

1. Assessing economic impact and efficiency of HEIs together gives more comprehensive insight to the contribution of each HEI to the country's economy.

2. In order to assess economic impact and efficiency of HEIs, modelling tools such as I-O (to assess economic impact multiplier) and DEA (to assess efficiency scores) must be evaluated within one system.

3. The model facilitates identifying the impact of each HEI, both big and small, on the economy, as well as its efficiency. This will help to disclose the position of each HEI within the same HE system.

\section{Approval of Research Findings}

Four publications focusing on the subject of the dissertation have been issued: Three - paper quoted by Clarivate Analytics Web of Science (Vaiciukevičiūtè, 
Stankevičienė, Bračikovienė 2019; Stankevičienė, Kraujalienė, Vaiciukevičiūtė 2017, Stankevičienè, Vaiciukevičiūtė 2016), one paper - in the peer-reviewed proceedings of international conference: (Stankevičienè, Vaiciukevičiūtė 2014). Three presentations on the topic of the thesis were given in the international conferences (one of them were held abroad):

- Vaiciukevičiūtė A.“Assessing Economic Impact and Efficiency of HEIs”, CEPAR research center, Australia, November 21, 2017.

- Vaiciukevičiūtė A., Stankevičienė J., "Value Creation through Internationalization in Higher Education Management", 9th International Scientific Conference “Business and Management, 2016”, Vilnius, May 1213 d., 2016.

- Vaiciukevičiūtė A., "Value Chain Approach in Higher Education Management", "Contemporary Issues in Business, Management and Education, 2015”, Vilnius, November 12-13 d., 2015.

Four scientific presentations have been made: at the scientific seminars for $\mathrm{PhD}$ students at the Faculty of Business Management (one each year from the period of 2014-2018).

Four scientific internships during doctoral studies have been made:

- Internship at CEPAR research center, New South Wales University, Sydney, Australia (period 06/10/2017-06/01/2018);

- Participation in summer school CLUSDEV, Vilnius Lithuania (period 05/09/2016-07/09/2016);

- Internship at European Centre of Studies and Initiatives (CESIE), Palermo, Italy (period 06/06/2015-14/06/2015);

- Internship at New South Wales University, Sydney, Australia (period 13/01/2015-27/01/2015).

\section{Structure of the Thesis}

The dissertation consists of introduction, 3 chapters, general conclusions, references, list of author's publications, summary in Lithuanian and 7 annexes. The total scope of the dissertation is 154 pages, excluding annexes, 8 figures, 25 tables, 29 numbered formulas, 192 references are included in the dissertation. 


\section{1}

\section{Theoretical Concepts Related to the Economic Impact and Efficiency of Higher Education Institutions}

This chapter comprises analysis of the literature pertaining to the concepts of economic impact and efficiency in the educational sector generally, and specifically, the HE context. Equal weight is given to conceptual and methodological issues.

This chapter offers a theoretical analysis of the literature on economic impact and efficiency in the HE sector internationally. The researcher builds on this literature - including the concepts explored by the field's key research - in later chapters through developing a detailed model that combines the best of quantitative methods. Then the researcher applies this unique model in the context of public universities in Lithuania, which is explored in Chapter 3.

The section that follows explores the relationship between $\mathrm{HE}$ and economic performance and development by examining the strategies and metrics used to assess economic impact. More specifically, attention is paid to the first-order effects, the long-term, value creation effects, and the knowledge spill-over effects of HEIs. Section 1.2 attends to the theoretical and methodological approaches to studying HEIs and their economic impact. The methods, addressed individually 
below, include: the single case study approach (Bramwell \& Wolfe, 2008; Garrido-Yserte \& Gallo Rivera, 2010; Goddard \& Vallance, 2013; Eesley \& Miller, 2017; Steinacker, 2005; Tavoletti, 2007), the multiple HEI approach (see Alves et al., 2015; Carlsson \& Fridh, 2003; Elliott, Levin, \& Meisel, 1988; Guerrero, Cunningham, \& Urbano, 2015; Schartinger, Schibany, \& Gassler, 2001), the knowledge production function approach (Anselin, Varga, \& Acs, 1997, 2000; Barrio-Castro \& García-Quevedo, 2005; Fischer \& Varga 2003; Lin, Kung, \& Wang, 2015; Sevinc, 2014), and cross-sectional approaches (Baryla \& Dotterweich, 2001; Florax, 1992; Florax \& Folmer, 1992; Fogarty, 1993; Tornquist \& Hoenack, 1996). Section 1.3 turns its attention to the concept of efficiency, and explores the methodological approaches used to evaluate efficiency in the educational sector.

The findings of Chapter 1 have been published in 2 scientific papers (Vaiciukevičiūtè, Stankevičienè, Bračikovienè 2019; Stankevičienè, Vaiciukevičiūtè 2016).

\subsection{Defining the Key Terms: Economic Impact and Higher Education}

Researchers working within the context of economic development point out that, until recently, attention was focused on the economic returns generated by the primary and secondary sectors of education (Jaeger \& Kopper, 2014; Tilak, 2003; Yusuf, 2007); Higher Education (HE) was considered to yield relatively lower returns, both in economic and social terms.

More recently, the importance of HE to broader economic objectives has been recognized by policymakers and researchers alike (Brennan et al., 2018). It is increasingly acknowledged that the tertiary sector of education is vital to the economic competitiveness of both sub-national regions and nations in the context of a global economy that is increasingly knowledge-driven (Zhang, Larkin, \& Lucee, 2017; Borralho, Feria \& Lopes, 2015; Ciccone \& Peri, 2006; Harris, 1997; Kotosz,; Elliot, Levin \& Mesisel, 1988; Forrant, 2001; Gaunard-Anderson \& Lukovics, 2018; Goddard \& Vallance, 2013; Huggins \& Cooke, 1997; Sieg-fried, Sanderson \& McHenry, 2007; Thanki, 1999; Barra \& Zotti, 2017; Borralho et al., 2015; Garrido-Yserte \& Gallo-Rivera, 2010; Huggins \& Johnston, 2009; Huggins et al., 2012; Johansen \& Arano, 2016; Goldstein \& Re-nault, 2004).

Furthermore, in an age of pressurized budgets, the assessment of the economic impact and efficiency of Higher Education Institutions (HEIs) is important because there is an increased demand upon educational institutions (EI) to offer value for money (Zhang, Larkin, \& Lucee, 2017). While the demand for HE is growing, available resources that drive quality HE is shrinking (Hermansson et. 
al., 2010). This means that there is a need to achieve greater outcomes with less inputs. Economic impact analysis usually assesses the change in economic activity in a specified country or region, caused by a specific organization, policy, business or other economic event (Weisbrod, 1997). These changes presuppose the need for a systematic approach towards assessing the economic impact and efficiency of HEIs. From a theoretical and methodological point of view, there is a need to integrate separately developed economic impact and efficiency-related factors in the HE sector.

Economic impact measurements are a very persuasive and powerful tool for individuals looking to collect and demonstrate the financial benefits of engaging in any activity. Measuring the economic impact of a particular activity allows the public sector bodies to assess the economic return on the investment that they will make and show how the activity will drive economic benefits (Bridge, 2011). The "economic impact" of a particular activity refers to the total amount of extra expenditure generated within a specific area, as a direct consequence of engaging in that particular activity (Elliott, Levin \& Meisel, 1988).

Economic impacts are systematic, and thus, different from an individual's valuation of the user benefits of a specific service or facility; economic impacts also differ from the broader social impacts. The social impacts and user benefits may include the valuation of the changes in quality of life factors or amenities (for instance noise pollution, air quality, recreation, safety, or health) (Bridge, 2011). Nonetheless, while these different kinds of impacts and benefits can be valued in economic terms (money) - and studied by examining society's and an individual's "willingness to pay" for developing them - they cannot be defined as economic impacts as described above unless they also affect the level of economic activity in that area.

However, the notion of economic impact is easily misinterpreted. According to Weisbrod and Weisbrod, (1997), there are "seven deadly sins" to avoid in conducting economic impact studies:

- Confusing the economic role from its net impact on the economy;

- Adding together different measures;

- Confusing the scope (e.g., state and national effects);

- Confusing time periods (e.g., immediate and eventual effects on economic growth);

- Assuming a facility's capacity and its actual level of activity are the same;

- Applying multipliers in situations where they do not apply;

- Ignoring market effects on wages and land/building costs, which can also affect the economic competitiveness of an area.

Now that the idea of economic impact has been addressed, it is necessary to establish a working notion of higher education. Then this literature analysis will 
proceed to look at literature on the economic impact of HEIs specifically, which is the focal point of this study.

HE includes all post-secondary research, training; and educational institutions. For instance, universities are authorized as institutions of HE by the state (Lu, Miller, \& Newman, 2014). It also includes all activities a particular country deems to be of $\mathrm{HE}$ - not only those which occur within ordinary universities and graduate schools. This includes short-term training and education courses such as junior colleges, polytechnics, and technical specialty schools, which are between two and three years in length. It also includes correspondence and online courses which make use of information technology. These are targeted at a broad population of students (Proctor, 2009).

HEIs, particularly universities, have three principal functions. Apart from education, these institutions conduct research and contribute to the development of society (Alzadjali, 2018). The three functions of HE is connected intimately, and they cannot be separated (Bernaoui, Issolah, \& Hassoun, 2015).

The education and research functions are two sides of the same coin; education develops the human resources to carry out research, while research makes a higher level of education possible (Mason, 2014). Recently, contributions to society have been demanded increasingly of HEIs (Cano \& Ion, 2014). This means that HEIs cannot turn into "ivory towers" (Nicholl et al., 2014), and they must make sure that they disseminate accumulated knowledge back to the society.

On the other hand, the term "tertiary education" is more general, and refers to as postsecondary, third level, and third - stage education (Owen, 1981). It is the education level that follows the completion of secondary education (Kalkbrenner, 2015). Usually tertiary education results in the receipt of certificates, diplomas; or degrees (Saiz-Alvarez, 2014). The World Bank’s World Development Report (2018) states that, given the rapidly increasing role of technology in value chains and the future of work, tertiary education will become relevant for workers who wish to compete in the labour market (Airy \& Brown, 2018). Tertiary education is broad and includes all post-secondary education, which can be both private and public tertiary institutions. For instance, it includes distance learning centres, centres of excellence, research laboratories, nursing schools, community colleges, technical training institutions; and colleges.

In contrast, HE can be defined as any post-secondary education that leads to a formal bachelor's degree or higher. HE is restricted to just colleges and universities that grant four-year degrees or higher. The Table 1.1 looks at the different theoretical concepts of HE and tertiary education by different authors. 
Table 1.1. Theoretical Concepts of Higher Education and Tertiary Education (compiled by author)

\begin{tabular}{|c|c|c|}
\hline $\begin{array}{l}\text { Con- } \\
\text { cept }\end{array}$ & Definitions & Authors \\
\hline \multirow[t]{10}{*}{$\begin{array}{l}\text { Higher } \\
\text { Edu- } \\
\text { cation }\end{array}$} & $\begin{array}{l}\text { All education that is beyond the secondary level and leads } \\
\text { to a formal degree. }\end{array}$ & $\begin{array}{l}\text { Bernaoui, Is- } \\
\text { solah \& Has- } \\
\text { soun, } 2015\end{array}$ \\
\hline & $\begin{array}{l}\text { Includes post-secondary education that leads to a bache- } \\
\text { lor's degree or higher. }\end{array}$ & $\begin{array}{l}\text { Cano \& Ion, } \\
2014\end{array}$ \\
\hline & $\begin{array}{l}\text { A system of post-secondary education institutions which } \\
\text { offer learning opportunities for those individuals who } \\
\text { want to get professional qualifications and academic } \\
\text { degrees. }\end{array}$ & $\begin{array}{l}\text { Lu, Miller \& } \\
\text { Newman, } \\
2014\end{array}$ \\
\hline & $\begin{array}{l}\text { Education that is obtained beyond high school and is pro- } \\
\text { vided by professional schools, graduate schools, and col- } \\
\text { leges. This term is interchangeable with post-secondary } \\
\text { education in education discourse and journal articles } \\
\text { (Random House,1987, p. 902). }\end{array}$ & Proctor, 2009 \\
\hline & $\begin{array}{l}\text { Is that phase/stage of learning which is accomplished in } \\
\text { academies, universities, colleges, etc. }\end{array}$ & $\begin{array}{l}\text { Nicholl et al., } \\
2014\end{array}$ \\
\hline & $\begin{array}{l}\text { Learning which takes place at a college, university, or in- } \\
\text { stitute that is beyond a high school level. }\end{array}$ & Mason, 2014 \\
\hline & $\begin{array}{l}\text { Non-compulsory education that is provided after high } \\
\text { school, typically at a university or college. }\end{array}$ & $\begin{array}{l}\text { Alzadjali, } \\
2018\end{array}$ \\
\hline & $\begin{array}{l}\text { Refers to the education that is obtained either formally or } \\
\text { informally at an educational institution of higher learning } \\
\text { usually a university. }\end{array}$ & $\begin{array}{l}\text { Vidal, Vidal- } \\
\text { García \& } \\
\text { Barros, } 2017\end{array}$ \\
\hline & $\begin{array}{l}\text { Two- or four-year institutions that are dedicated to offer- } \\
\text { ing educational degrees and programs. }\end{array}$ & $\begin{array}{l}\text { Clemmons, } \\
\text { Nolen \& } \\
\text { Hayn, } 2014\end{array}$ \\
\hline & $\begin{array}{l}\text { A system of accredited EI that provide formal post-sec- } \\
\text { ondary education. }\end{array}$ & $\begin{array}{l}\text { Hackett, } \\
\text { Lemoine, \& } \\
\text { Richardson, } \\
2017\end{array}$ \\
\hline \multirow{2}{*}{$\begin{array}{l}\text { Ter- } \\
\text { tiary } \\
\text { Edu- } \\
\text { cation }\end{array}$} & $\begin{array}{l}\text { All post-secondary school education which includes but } \\
\text { not limited to colleges and universities. }\end{array}$ & $\begin{array}{l}\text { Kalkbrenner, } \\
2015\end{array}$ \\
\hline & $\begin{array}{l}\text { Refers broadly to all post-secondary education which in- } \\
\text { cludes both private and public tertiary EI such as distance } \\
\text { learning centres, centres of excellence, research laborato- } \\
\text { ries, nursing schools, community colleges, technical train- } \\
\text { ing institutions, and colleges. }\end{array}$ & $\begin{array}{l}\text { Saiz-Alvarez, } \\
2014\end{array}$ \\
\hline
\end{tabular}


End of Table 1.1

\begin{tabular}{|c|c|c|}
\hline $\begin{array}{l}\text { Con- } \\
\text { cept }\end{array}$ & Definitions & Authors \\
\hline \multirow{2}{*}{$\begin{array}{l}\text { Ter- } \\
\text { tiary } \\
\text { Educa- } \\
\text { tion }\end{array}$} & $\begin{array}{l}\text { Education obtained after secondary level which may in- } \\
\text { clude vocational classes, college or university. }\end{array}$ & $\begin{array}{l}\text { Airy \& } \\
\text { Brown, } 2018\end{array}$ \\
\hline & $\begin{array}{l}\text { Also referred to as post-secondary education, it also in- } \\
\text { cludes research laboratories, nursing schools, technical } \\
\text { training institutions, colleges, distant learning centres, and } \\
\text { universities. }\end{array}$ & Owen, 1981 \\
\hline
\end{tabular}

When theoretical concepts of economic impact and higher education have been established, both topics will be combined below in order to offer a review of literature that considers the economic impact of higher education institutions.

\subsubsection{Theoretical Concepts of Economic Impact Studies in the Context of Higher Education Institutions}

Studies of economic impact have a long history in the education sector (Caffrey \& Isaacs,1971; Booth \& Jarrett, 1976; Leslie \& Brinkman, 1988; Elliott et.al., 1988; Brown et.al.,1997; Armstrong \& Grove-White, 1997; Glasson, 2003; Kelly et al., 2004; Blundellet al., 2005; McGregor et. al., 2006; Keller, 2006; 2011; Rabovsky, 2012; Jalil, \& Idrees, 2013; Olivares \& Wetzel, 2014; Drucker, 2015; Humphreys, 2016; Bowen \& Qian, 2017). These scholars are all interested in assessing different types of economic impacts of the HE sector's activities and policies on a local, regional, and national level. In the Table 1.2, the researcher presents some theoretical concepts of economic impacts and the economic impact of HEIs. In the case of this thesis, it is important to distinguish the general notion of economic impact from the impact of HEIs on the economy.

The economic impact of HEIs is considered with increasing frequency by HEIs in their capital campaigns (Levin, 2018; Rabovsky, 2012; Syvertud \& Williams, 2016). These campaigns include requesting support via donations, as well as funding from the government and the private sector. Though the traditional method of economic impact analysis applies to some events such as conventions and conferences, HEIs present a unique challenge (Elliott, Levin \& Meisel, 1988). Apart from the operation of HEIs generating typical impacts such as incremental area spending flows, HEIs, also create extra future impact via enhancements such as human capital formation, and by also increasing the technological base of the area (Hudson, 1974; Greenwood, Sanchez, \& Wang, 2013; Tavoletti, 2007). 
Table 1.2. Theoretical Concepts of Economic Impact and Economic Impact of Higher Education Institutions (compiled by author)

\begin{tabular}{|c|c|c|}
\hline Concept & Definitions & Authors \\
\hline \multirow{4}{*}{$\begin{array}{l}\text { Economic } \\
\text { Impact }\end{array}$} & $\begin{array}{l}\text { Refers to the effects on the level of economic } \\
\text { activity in a particular area. }\end{array}$ & Bridge, 2011 \\
\hline & $\begin{array}{l}\text { In relation to a project or activity, refers to } \\
\text { the amount of additional expenditure that is } \\
\text { generated within a particular area, as a direct } \\
\text { result of taking part in the project or activity. }\end{array}$ & $\begin{array}{l}\text { Elliott, Levin, \& } \\
\text { Meisel, } 1988\end{array}$ \\
\hline & $\begin{array}{l}\text { Refers to positive economic effects based on } \\
\text { the combination of income that is generated } \\
\text { by taxes, wages, employment and businesses. }\end{array}$ & $\begin{array}{l}\text { Nair \& Sáiz Álva- } \\
\text { rez, } 2018\end{array}$ \\
\hline & $\begin{array}{l}\text { Refers to a macroeconomic effect on in- } \\
\text { comes, employment, and commerce that is } \\
\text { produced by a policy, event, or decision. }\end{array}$ & Lee, 2018 \\
\hline \multirow{3}{*}{$\begin{array}{l}\text { Economic } \\
\text { Impact of } \\
\text { Higher } \\
\text { Education } \\
\text { Institutions }\end{array}$} & $\begin{array}{l}\text { HE is an investment in human capital, and } \\
\text { therefore impacts the regional economy to the } \\
\text { extent to which graduates remain in that par- } \\
\text { ticular area and have higher lifetime earnings. }\end{array}$ & Hudson, 1974 \\
\hline & $\begin{array}{l}\text { Tuition revenues derived from both local and } \\
\text { non-local students are converted into income } \\
\text { for staff and faculty, who in turn will use this } \\
\text { money to buy clothing, food, and housing } \\
\text { within the environs of the HEIs. }\end{array}$ & Tavoletti, 2007 \\
\hline & $\begin{array}{l}\text { HEIs also improve the technological base of } \\
\text { the region, which allows for a unique transfer } \\
\text { of knowledge from the research efforts of the } \\
\text { institution if industrial operations are located } \\
\text { nearby. }\end{array}$ & $\begin{array}{l}\text { Greenwood, } \\
\text { Sanchez, \& Wang, } \\
2013\end{array}$ \\
\hline
\end{tabular}

Therefore, in order to offer a methodology for accurately gauging these various levels of economic impact, this section identifies some of the metrics which are used to assess and evaluate economic impact on the regional and national level. More specifically, the section considers the short-term, immediate effects of HEIs, as well as their long-term effects, at both regional and national levels. Ultimately, this section identifies the main dimensions around which there is consensus, with a view to emphasizing the crucial role that HEIs play in a rapidly developing and globalized economy.

It is increasingly recognized that HE, the tertiary sector of education, is vital to the economic competitiveness of both regions and nations in the context of a 
global economy that is increasingly knowledge-driven (Zhang, Larkin, \& Lucee, 2017). However, researchers, and especially those working within the context of economic development, have pointed out that, until recently, attention was focused on the economic returns generated by primary and secondary sectors of education, with HE considered to yield relatively lower returns, both in economic and social terms (Jaeger \& Kopper, 2014; Tilka, 2003; Yusuf, 2007). For example, in their panel study of almost 100 economies, Psacharopoulos and Patrinos (2002) found that the economic return on primary education was 18.9 per cent compared to just 10.8 per cent for tertiary education. This explains why primary and secondary education tend to be the recipients of more public resources compared to public universities and colleges (Psacharopoulos \& Patrinos, 2002).

More recently, however, the importance of HE to broader economic objectives has been recognized by policymakers and researchers alike (Brennan et al., 2018).

\subsubsection{Conceptualizing Different Economic Impact Effects}

Evaluation of the economic impact of HEIs on country/region is undertaken through economic impact assessments. There are two type of assessments or evaluations that are performed globally: performance assessment and impact assessment or evaluation. Their differences depend on the purpose, evaluation questions, and design that is applied (Penfield et al., 2014).

Selection of method or methods for assessment should principally consider the appropriateness of the evaluation design for answering the main evaluation questions. It should also account for balance cost, feasibility, and the level of rigor needed to inform specific decisions. Usually, assessments use methods that generate the highest-quality and most credible evidence that corresponds to the questions being asked, taking into consideration time, budget, and other practical considerations. A combination of quantitative methods applied in a systematic and structured way yields valuable findings.

Impact evaluations measure the change in a development outcome that is attributable to a defined intervention. Impact assessment can be defined as a "formal, evidence-based set of procedures that asses the economic, social and environmental effects of public policies” (Adelle \& Weiland, 2012). Impact evaluation usually uses models of cause and effect and requires the use of counterfactuals to explain which part of the change is caused by the intervention and which occurred due to some other factors. Impact evaluations in which comparisons are made between beneficiaries randomly assigned to either a treatment or a control group provide the strongest evidence of a relationship between the intervention and the outcome (Drucker \& Goldstein, 2007; Huggins, \& Johnston, 2009; Kimenyi, 2011). 
The typical question that represents counterfactual could be formulated as follows "What would have happened to the program participants if the program did not exist"? At its best, impact evaluation includes a cost-benefit analysis (CBA), that can help to decide whether to continue investing in such a policy, or whether a different approach is more appropriate (Quah et al., 2007).

Impact assessments (IAs) serve different purposes, such as to informing policy - and decision-makers about potential economic, social or environmental consequences, improving transparency, increasing public participation, and improving the legitimacy of proposed policies (Adelle \& Weiland, 2012; Legcevic \& Hecimovic, 2016). These assessments indicate how public policies aim to achieve envisioned goals using various indicators. Finally, IAs contribute to continuous learning in policy development by identifying causalities that inform ex-post review of policies (Schwab et al., 2010).

Impact evaluations use experimental methods (randomization) or quasiexperimental methods and may supplement these with other quantitative methods to increase understanding of the impacts of an intervention.

There are several types of impact assessments, based on scope (for example global vs. local), level (policy impact assessment), strategic aim (environmental assessment, for example), orientation (project related assessments), or topic (education, or the higher education sector, for example) (Schwab et al., 2010).

There is far from a consensus on the precise economic yields generated by HEIs, nor on the factors that moderate and mediate relationships between inputs and outputs (Alves, et al., 2015; Anselin, Varga, \& Acs, 1997; Greenwood, Sanchez, \& Wang, 2013; Steinacker, 2005). However, the literature in this area focuses on three major impacts: short-term expenditure effects, knowledge and human capital-based effects, and (long-term) value creation effects and knowledge spill-over effects (see Table 1.3 for a summary of how different authors conceptualize economic impact).

Many of the studies analysed above do not disaggregate fully between these effects and, instead, consider them as complex dynamics arising from the presence and activities of universities and colleges. Nevertheless, it is useful to consider each of these dimensions in turn, and to analyses the pertinent literature.

Short-term expenditure effects, perhaps, the most straightforward means of assessing the economic impact of HEIs is by examining the direct, or first-order, effects that can be directly attributed to their presence and activities (Kotosz, Gaunard-Anderson, \& Lukovics, 2018). Of the considerable outputs that universities, and especially large public universities produce, employment is most commonly considered by researchers (Elliot, Levin \& Mesisel, 1988; Forrant, 2001; Goddard \& Vallance, 2013; Harris, 1997; Huggins \& Cooke, 1997; Siegfried, 
Sanderson \& McHenry, 2007; Thanki, 1999). Universities are typically large employers, especially in urban and suburban areas (Goddard \& Vallance, 2013; Jaeger \& Kopper, 2014). Through their very presence, and importantly, through their expansion (which, in turn, generates more income), universities and colleges make an important contribution to the local employment market. Furthermore, jobs are created through expenditure effects, whereby HEIs' procurement activities extend job creation to third sectors (Ciccone \& Peri, 2006) (see Table 1.4 for summary of the conclusions of studies on the first order effects of HEIs).

Table 1.3. Conceptualizing Economic Impact (compiled by author)

\begin{tabular}{|l|l|l|}
\hline Conceptualization & Definition & Main authors \\
\hline $\begin{array}{l}\text { Short-term } \\
\text { expenditure effects }\end{array}$ & $\begin{array}{l}\text { The direct, or first order } \\
\text { effects that can be di- } \\
\text { rectly attributed to the } \\
\text { presence and activities } \\
\text { of HEIs. }\end{array}$ & $\begin{array}{l}\text { Borralho, Feria \& Lopes, 2015; } \\
\text { Ciccone \& Peri, 2006; Harris, } \\
\text { 1997; Kotosz, Elliot, Levin \& Me- } \\
\text { sisel, 1988; Forrant, 2001; } \\
\text { Gaunard-Anderson \& Lukovics, } \\
\text { 2018; Goddard \& Vallance, 2013; } \\
\text { Huggins \& Cooke, 1997; Sieg- } \\
\text { fried, Sanderson \& McHenry, } \\
\text { 2007; Thanki, 1999 }\end{array}$ \\
\hline $\begin{array}{l}\text { Long-term value } \\
\text { creation effects }\end{array}$ & $\begin{array}{l}\text { The long-term effects } \\
\text { that accrue from the } \\
\text { generation of } \\
\text { knowledge and which } \\
\text { have implications for } \\
\text { the supply side, and } \\
\text { economic growth. }\end{array}$ & $\begin{array}{l}\text { Barra \& Zotti, 2017 } \\
\text { Borralho et al., 2015; Florax, } \\
\text { 1992; Garrido-Yserte \& Gallo-Ri- } \\
\text { vera, 2010; Huggins \& Cooke, } \\
\text { 1997; Huggins \& Johnston, 2009; } \\
\text { Huggins et al., 2012; Johansen \& } \\
\text { Arano, 2016; Psacharopoulos \& } \\
\text { Patrinos, 2002; Goldstein \& Re- } \\
\text { nault, 2004; Siegfried et al., 2007; } \\
\text { Stokes \& Coornes, 1998 }\end{array}$ \\
& $\begin{array}{l}\text { Cox \& Taylor, 2006; Yusuf, 2007; } \\
\text { Goldstein \& Renault, 2004; Guer- } \\
\text { rero et al., 2015; Jaeger and Kop- } \\
\text { per, 2014; Jaeger and Kopper, } \\
\text { 2014; Uyarra, 2010 }\end{array}$ \\
\hline $\begin{array}{l}\text { Knowledge } \\
\text { spill-over effects }\end{array}$ & $\begin{array}{l}\text { The effects that are pro- } \\
\text { duced from the exploi- } \\
\text { tation of the outcomes } \\
\text { of academic research } \\
\text { and the engagement in } \\
\text { knowledge exchange } \\
\text { with research, commer- } \\
\text { cial and corporate part- } \\
\text { ners. }\end{array}$ & \\
\hline
\end{tabular}


Table 1.4. Summary of the Conclusions of Studies on the First Order Effects of Higher Education Institutions (compiled by author)

\begin{tabular}{|l|l|}
\hline Major Finding & Authors \\
\hline $\begin{array}{l}\text { Through their activities and existence (e.g., } \\
\text { hiring practices) universities and colleges } \\
\text { make an important contribution to the local } \\
\text { employment market for HEI staff. }\end{array}$ & $\begin{array}{l}\text { Elliot, Levin, \& Mesisel, 1988; For- } \\
\text { rant, 2001; Goddard \& Vallance, } \\
\text { 2013; Harris, 1997; Huggins \& } \\
\text { Cooke, 1997; Jaeger \& Kopper, } \\
\text { 2014; Siegfried, Sanderson, \& } \\
\text { McHenry, 2007; Thanki, 1999 }\end{array}$ \\
\hline $\begin{array}{l}\text { Universities and colleges boost employment } \\
\text { in third sectors through procurement activi- } \\
\text { ties. }\end{array}$ & Ciccone \& Peri, 2006 \\
\hline $\begin{array}{l}\text { Universities and colleges enhance the em- } \\
\text { ployability prospects of graduates through up- } \\
\text { skilling. }\end{array}$ & Borralho, Feria \& Lopes, 2015 \\
\hline $\begin{array}{l}\text { The employment and employability enhanc- } \\
\text { ing effects of universities and colleges de- } \\
\text { pends on the extent to which the local econ- } \\
\text { omy is already developed. }\end{array}$ & $\begin{array}{l}\text { Moretti, 2004; Psacharopoulos \& } \\
\text { 2015 }\end{array}$ \\
\hline $\begin{array}{l}\text { Through expenditures and the disbursement } \\
\text { of wages salaries, HEIs have a positive effect } \\
\text { on local and regional consumption levels. }\end{array}$ & $\begin{array}{l}\text { Kopper, 2014; Zhang, \&arkin, \& Ooi, } \\
\text { Lucey, 2017 }\end{array}$ \\
\hline $\begin{array}{l}\text { Universities and colleges help to spur local } \\
\text { economic growth through the consumption } \\
\text { activities of student populations. }\end{array}$ & $\begin{array}{l}\text { Beck, Elliott, Meisel, \& Wagner, } \\
\text { 1995; Carroll \& Smith, 2006; Sieg- } \\
\text { fried et al., 2007; Steinacker, 2005 }\end{array}$ \\
\hline $\begin{array}{l}\text { Investments and expenditures undertaken by } \\
\text { the HEI produce positive demand effects. }\end{array}$ & $\begin{array}{l}\text { Drucker, 2016; Huggins \& Cooke, } \\
\text { 1997; Power \& Malmberg, 2008 }\end{array}$ \\
\hline
\end{tabular}

Although job creation is considered here to be a short-term, first order effect, more complex models have demonstrated the longer-term effects that HEIs have upon employment. In addition to hiring faculty, staff, and other key personnel, through their very raison d'etre universities and colleges boost the employability of their students, with long-term employment enhancing effects (Borralho, Feria, \& Lopes, 2015). Many empirical papers have alluded to these long-term direct effects, but as pointed out by Stokes and Coornes (1998), it is difficult to estimate those effects with any accuracy (see also Moretti, 2004; Pastor, Pérez, \& De Guevara, 2013). In addition to the time lag associated with knowledge-based supplyside impacts, there are practical problems. For example, many studies on economic impact focus on specific localities or regions; however, students and others who benefit from the employability effects of HEIs are a transient group, such that 
it may be difficult to attribute local employment attributes to specific colleges and universities in the area (Siegfried et al., 2007).

One line of reasoning discussed in the literature is that the increases in innovativeness, competitiveness, and productivity that arises because of HEI activity should increase employment levels, both in the medium and the long-term (Ciccone \& Peri, 2006). However, several authors note that this relationship between inputs and outputs is likely to be confounded by several mechanisms and variables (Stokes \& Coornes, 1998; Garrido-Yserte \& Gallo-Rivera, 2010; Schubert \& Kroll, 2016). Furthermore, there are contextual factors relating to the nature of the local external environment which should be considered in determining HEI's employment effects (Moretti, 2004). In developing regions with a limited or embryonic knowledge economy, for example, HEIs seem to have limited impact on the lesser skilled labour force. It is precisely this labour force which is necessary to help spur economic performance (Psacharopoulos \& Patrinos, 2002; Yen, Ong, \& Ooi, 2015).

Consumption effects are also related to HEI expenditures (Zhang, Larkin, \& Lucey, 2017). Through the disbursement of wages and expenditures, HEIs are said to exert a positive effect on local and regional consumption levels - a key factor in growth (Jaeger \& Kopper, 2014). In addition, the presence of the student population itself can also spur economic growth through the demand side effects propagated by consumption (Beck, Elliott, Meisel, \& Wagner, 1995; Carroll \& Smith, 2006; Siegfried et al., 2007). This seems to be especially true of urban colleges with significant student populations (Steinacker, 2005). These demand side effects could have long-term, positive implications for employment levels, causing dynamic and non-linear outcomes. Furthermore, it has been demonstrated that a significant student population can spur sustainable regional development, given students' propensities for high consumption (Carroll \& Smith, 2006). This effect could compensate for any crowding out effects of student acquisition of local jobs.

Finally, there are demand effects caused by the investment undertaken by the HEI, which can yield significant effects in terms of local value (Drucker, 2016; Huggins \& Cooke, 1997; Power \& Malmberg, 2008). With regards to regional development, the investment of colleges and universities in local infrastructure (e.g., buildings and transportation links) and communities should be expected to trigger demand and, thereby, wider multiplier effects. As a demanding customer, the HEI could also generate further positive supply side effects over the short to medium term (Drucker, 2016).

To summarize, several authors have adopted an approach to economic impact that places emphasis on the direct effects that can be directly attributed to the work, presence, and activities of HEIs. This is the most straightforward approach to measure economic impact. Researchers have focused their attention upon outcomes such as a job creation, overall employment levels, consumption effects, and 
demand effects. Typically, a short-term timeframe is adopted, and the focus is on long-term value, although some of the more sophisticated forms of analyses are conducted over a longer time frame and consider a wider environmental impact. The next section examines studies which have considered the longer term, valuecreation effects of HEIs.

Long-term economic effects are those that accrue from the generation of knowledge and which have implications for the supply side, as well as economic growth (Garrido-Yserte \& Gallo-Rivera, 2010; Florax, 1992; Stokes \& Coornes, 1998). Production function models incorporated endogenous variables as a means of measuring economic growth. However, later, more complex models have operationalized growth in broader, and perhaps more meaningful ways, considering the social and other developmental aspects of growth (Moretti, 2004).

A key variable of long-term effects is human capital. Human capital can be understood as the stock of knowledge, know-how, and skills which are embodied within an individual (Johansen \& Arano, 2016). The fundamental assertion of human capital theory is that as the demand for skilled labour increases, so does investment in education. Therefore, individuals are induced to increase their pursuit of education until the opportunity costs of additional investment in education exceeds the benefit that it is expected to yield (Johansen \& Arano, 2016). Given Solow's ideas about the importance of knowledge to economic development, human capital theory, also argues that advancements in society are contingent upon the knowledge and skills possessed by individual workers. Therefore, educational policy that has productivity in mind should be designed in such a way as to help to develop human capital in individuals (Psacharopoulos \& Patrinos, 2002).

Given this, the economic effect of HEIs has been examined from the perspective of human capital theory, and with knowledge and skill building in mind (Barra \& Zotti, 2017; Borralho et al., 2015; Florax, 1992; Garrido-Yserte \& GalloRivera, 2010; Goldstein \& Renault, 2004; Huggins \& Cooke, 1997; Huggins \& Johnston, 2009; Huggins et al., 2012; Johansen \& Arano, 2016; Siegfried et al., 2007; Stokes \& Coornes, 1998). In line with the propositions of human capital theory, this research contends that the stream of skilled graduates produced by universities and colleges can yield positive supply side effects for the local and regional economy if those graduates decide to remain in the local area (Siegfried et al., 2007). Imbued with transferable, managerial, and technical skills, HEI graduates have the potential to increase the creativity, productivity, and innovativeness of local enterprises. These direct effects have multiplier outcomes since higher revenues, profit margins, and higher wages, are all consequences of innovation, productivity, and creativity (Huggins \& Cooke, 1997; Huggins \& Johnston, 2009; Huggins et al., 2012). 
A further strand of research has also explored the role that universities and colleges play in generating entrepreneurial intentions and developing entrepreneurial knowledge (Lilies \& Rõigas, 2017; Tilka, 2003). For example, some graduates use their human capital to establish new enterprises in the local area, which injects additional dynamism into the local economic environment (Florax, 1992).

However, there are some contrary findings. The positive relationship between graduate human capital skills and economic development is neither linear not guaranteed. As pointed out by Goldstein and Renault (2004), for instance, there is a time lag between graduation and the ability of graduates to transfer their skills and knowledge to the workplace (see also, Hayter, 2016). In the period that immediately follows graduation, for instance, it is common for graduates to experience frictional unemployment and even unemployment. Therefore, the direct and immediate impact of graduating students upon their local economic environment might be detrimental, rather than positive (Huggins et al., 2012; Johansen \& Arano, 2016; Lilies \& Rõigas, 2017). In a similar argument, Goldstein and Renault (2004) suggested there might be a structurally negative correlation between the average level of earnings observed in an economy and the number of degrees awarded by HEIs in the local area, which suggests that these institutions might contribute to oversupply.

Studies (see Table 1.5) that have explored the broader, national (as opposed to regional) impact of HEIs through the human capital channel seem to be more conclusive. Using production functions or longitudinal regression methods, these studies have shown that there is a relationship between inputs such as enrolment in, or graduation from, HEIs and economic development (Tilak, 2003). Using a panel approach, for instance, and analysing data on 50 Asian Pacific countries, Tilak (2003) demonstrated a strong, positive relationship between tertiary human capital stock in the population and the potential for economic growth. Data from the World Bank and other global institutions also confirms these results (Psacharopoulos \& Patrinos, 2002; Yusuf, 2007). For example, countries with high enrolment rates in tertiary education are more likely to score high on the United Nations Development Index's (UNDP) Technology Achievement Index (TAI), which measures the extent to which an economy creates and innovates in new technologies (Tilak, 2003).

There is a corpus of research that has focused on the long term, value-creation effects of HEIs. The long-term effects are those that accrue from the generation of knowledge, which have implications for the supply side and for overall levels of economic growth. These studies tend to adopt a longer time frame compared to studies of the short-term effects, which in turn necessitates a more sophisticated methodological framework. In general, there is a consensus among this body of research that the graduates produced by HEIs can yield long-term, positive outcomes, through multiplier effects on outcomes such as revenues, profit margins, 
and wages. The next section continues to look at the long-term, human capital effects of HEIs by drawing on the literature that examines the spill-over of knowledge to individuals and institutions outside of the focal HEI itself.

Table 1.5. Summary of the Conclusions of Studies on the Long-Term Economic Effects of Higher Education Institutions (compiled by author)

\begin{tabular}{|c|c|}
\hline Major Finding & Authors \\
\hline $\begin{array}{l}\text { The major economic benefit of HEIs are } \\
\text { in terms of the human capital that they } \\
\text { embed in graduates. }\end{array}$ & $\begin{array}{l}\text { Barra \& Zotti, 2017; Borralho et al., } \\
\text { 2015; Florax, 1992; Garrido-Yserte \& } \\
\text { Gallo-Rivera, 2010; Goldstein \& Re- } \\
\text { nault, 2004; Huggins \& Cooke, 1997; } \\
\text { Huggins \& Johnston, 2009; Huggins et } \\
\text { al., 2012; Johansen \& Arano, 2016; } \\
\text { Siegfried et al., 2007; Stokes \& } \\
\text { Coornes, } 1998\end{array}$ \\
\hline $\begin{array}{l}\text { The positive supply side effects of gradu- } \\
\text { ates can be measured at the local level in- } \\
\text { sofar as those graduates decide to remain } \\
\text { in the local area. }\end{array}$ & Siegfried et al., 2007 \\
\hline $\begin{array}{l}\text { The positive supply side and value crea- } \\
\text { tion effects of graduates can be assessed } \\
\text { over the long-term through multiplier ef- } \\
\text { fects. }\end{array}$ & $\begin{array}{l}\text { Huggins \& Cooke, 1997; Huggins \& } \\
\text { Johnston, 2009; Huggins et al., } 2012\end{array}$ \\
\hline $\begin{array}{l}\text { HEIs create entrepreneurial opportunities } \\
\text { which can stimulate the local economy. }\end{array}$ & $\begin{array}{l}\text { Florax, 1992; Lilies \& Rõigas, 2017; } \\
\text { Tilka, } 2003\end{array}$ \\
\hline $\begin{array}{l}\text { There is positive relationship between the } \\
\text { stock of individuals in the population } \\
\text { with a tertiary level of education and the } \\
\text { potential for economic growth. }\end{array}$ & $\begin{array}{l}\text { Psacharopoulos \& Patrinos, 2002; } \\
\text { Tilak, 2003; Yusuf, } 2007\end{array}$ \\
\hline $\begin{array}{l}\text { There is a time lag between the time im- } \\
\text { mediately following graduation and the } \\
\text { ability of graduates to transfer their skills } \\
\text { and knowledge to the workplace, making } \\
\text { it difficult to identify a positive economic } \\
\text { impact of graduates in the short term. }\end{array}$ & $\begin{array}{l}\text { Goldstein \& Renault, 2004; Hayter, } \\
2016\end{array}$ \\
\hline $\begin{array}{l}\text { There is a structurally negative correla- } \\
\text { tion between the average level of earnings } \\
\text { observed in an economy and the number } \\
\text { of degrees awarded by local HEIs. }\end{array}$ & Goldstein \& Renault, 2004 \\
\hline
\end{tabular}


Earlier literature on the economic impact of HEIs has focused on the impact of the two traditional roles of HEIs - their role as educators and their role in producing research outputs (Drucker, 2016). More recently, however, greater emphasis has been placed upon the 'third stream' objective of HEIs - to promote regional and national economic growth and development (Cox \& Taylor, 2006; Guerrero et al., 2015; Jaeger \& Kopper, 2014; Uyarra, 2010). For administrators of HEIs themselves, this specific mission is rising on their own agenda because of greater pressure placed upon their finances, in the context of limited access to public resources (Drucker, 2016). As the gap between academic units of research and the marketplace has narrowed, HEIs have become increasingly adept at commercially exploiting the outcomes of academic research and engaging in knowledge exchange (Cox \& Taylor, 2006; Yusuf, 2007). For example, a number of enormously successful high technology companies, including Google, Yahoo and Cisco, grew directly out of research conducted at Stanford University.

These knowledge spill-over effects, which arise because of the interactions between HEIs, industry, and science occur over the medium to long term (Goldstein \& Renault, 2004). There are likely to be multiplier effects here too, which spill over into various other constituent elements of regional economic growth and development. For example, it has been suggested that as universities become increasingly cognizant and convinced of their third mission, the potential for knowledge spill-over increases (Cox \& Taylor, 2006; Goldstein \& Renault, 2004; Guerrero et al., 2015; Jaeger \& Kopper, 2014; Uyarra, 2010). It is also suggested that there are circuitous and dynamic transfer channels between knowledge spillovers to improved performance and competitiveness to employment effects (Siegfried et al., 2007).

To summarize, knowledge spill-over effects are produced from the exploitation of the outcomes of academic research, as well higher levels of knowledge exchange among research, commercial, and corporate partners. This is the more recent of the three strands of research that have been explored in the extant literature. This body of research argues that the economic impact of HEIs is far from straightforward, direct, and static; rather, universities and colleges have dynamic and circuitous economic effects because of their increased willingness to work with industry partners. Given that economic impact may be difficult to directly attribute to HEI presence and activity, it is possible that there are certain variables which moderate the relationship between HEIs (and their inputs) and economic outcomes. In the section that follows, the literature exploring moderating variables in HEIs and economic outcomes is critically reviewed.

Over the past decade, attention has turned to understanding the contextual factors that smooth over and/or disrupt the relationship between HEI activity and economic outcomes (Lilles \& Rõigas, 2017). A key factor that has emerged is the 
external framework conditions surrounding the HEI, and specifically, their position within their local and regional ecosystem. Key factors of prime importance are interactions between the HEI and key industry partners in the region, as well as the density of industry networks in the broader business ecosystem (Huggins \& Johnston, 2009; Huggins, Johnston, \& Thompson, 2012; Smilor \& Matthews, 2004). Huggins and Johnston (2009) and Power and Malmberg (2008) agree that in the absence of actual linkages between industry and HE, the positive effects of knowledge spill-overs are unlikely to occur because universities do not generate knowledge that can be absorbed quickly by local firms.

Empirical research by Huggins and colleagues has specifically focused upon this area. Huggins and Johnston (2009) contend that for a HEI to have an impact on regional development, there must be opportunities for universities and colleges to produce outputs that are economically and commercially meaningful and useful. In addition, local firms must have the capacity to make effective use of those outputs. From an empirical perspective, however, there is considerable variance in the extent to which universities and colleges are able to transfer their knowledge to local industry, and for local firms to be able to absorb that knowledge (Brennan et al., 2018; Cox \& Taylor, 2006; Hayter, 2016; Jaeger \& Kopper, 2014; Smilor \& Matthews, 2004). Factors which might impact knowledge and technology transfer include the extent to which the HEI is knowledgeable about, and interacts with, the local business sector and the knowledge- orientation of local industries.

According to Huggins et al. (2012), mismatches between the outputs of HEIs and the needs of local industry are more common than might be considered. Power and Malmberg (2008) build upon this observation to argue that the impact of HEIs is contingent upon the extent to which local firms have technological capabilities, because only those firms can capitalize upon complex academic knowledge. At the same time, however, Huggins et al. (2012) pointed out that decision makers in HEIs are apt to select the partners with whom they are willing to cooperate based upon their reputation and relevance, rather than upon their geographic location.

Summarising almost forty years of scholarly debate, there is now a broad recognition that HEIs generate a variety of outcomes that are beneficial for societies. HEIs play a key role in developing knowledge, human capital, and building knowledge bases, in the dissemination and deployment of knowledge. They accomplish this through their interactions with industry stakeholders, and in direct and often tangible ways such as the development of partnerships, the undertaking of cooperative and contract research, consulting, technology licensing and employment creation. Those outcomes can be classified into short-term (e.g., employment creating) and long-term (e.g., value creating) effects, and into tangible (e.g., patents and publications) and intangible (e.g., creativity and leadership) effects. 
However, the mechanisms by which HEI activities and inputs translate into external effects tend to be highly complex and dynamic in nature and may be challenging to estimate. First order effects, such as employment, local consumption, local expenditure, and investment effects are the most straightforward to quantify and calculate. These immediate, or short-term impacts, are expected to spur second order, supply side effects such as regional economic effect and knowledge spill-over, but these areas of activity may be difficult to quantify. In the next part of the literature analysis, the theoretical approaches used to conduct economic impact studies of HEIs is overviewed.

\subsection{Multiply Approaches to the Economic Impact of Higher Education Institutions}

In line with the growing emphasis on the economic impact of HEIs, HE has attracted growing attention, although some studies have also applied measurement and evaluation techniques to the secondary and primary sectors (Agasisti \& Bonomi 2014; Bayraktar et al., 2013, De Witte \& Hudrlikova 2013; De Witte et al., 2013, Duh et al., 2014; Johnes, 2013, Lu \& Chen, 2013; Mainardes et al., 2014; Nazarko \& Saparauskas, 2014; Zoghbi et al., 2013). When examining the literature on the economic effects produced by HEIs, one is struck by the level of consensus in the literature. Generally speaking, and aside from a few detracting views (e.g., Goldstein \& Renault, 2004), it is acknowledged that the effects that universities and colleges yield on the economic environment are largely positive in nature. While the focus of study differs between the short-, medium- and longterm, and on the local and regional environment, these papers agree that the presence of HEIs, including their activities and personnel, is beneficial for economies. Where consensus is lacking, however, is how these conclusions might best be reached.

From a theoretical and methodological perspective, it is possible to identify at least four approaches to studying HEIs and their economic impact on the economy. The time periods in which each approach dominated, as well as an overview of some of the key authors, is provided in Table 1.6.

Table 1.6. Timeline of Theoretical Approaches to Economic Impact Studies in the Higher Education Institutions Context (compiled by author)

\begin{tabular}{|l|l|l|}
\hline Approach & Period & Key Papers and Authors \\
\hline $\begin{array}{l}\text { The single case study } \\
\text { method }\end{array}$ & $\begin{array}{l}\text { 1970s to 1990s, and again } \\
\text { 2000s }\end{array}$ & $\begin{array}{l}\text { Felsentein, 1996, 1999; } \\
\text { Glasson, 2003; Steinacker, } \\
\text { 2005; Thanki, 1999 }\end{array}$ \\
\hline
\end{tabular}


End of Table 1.6

\begin{tabular}{|c|c|c|}
\hline Approach & Period & Key Papers and Authors \\
\hline $\begin{array}{l}\text { The multiple HEI ap- } \\
\text { proach }\end{array}$ & 2000-present & $\begin{array}{l}\text { Alves, Carvalho, Car- } \\
\text { valho, Correia, Cunha, } \\
\text { Farinha, \& Nicolau, 2015; } \\
\text { Carlsson \& Fridh, 2003; } \\
\text { Guerrero, Cunningham, } \\
\text { \& Urbano, 2015; Guer- } \\
\text { rero, Urbano, \& Cunning- } \\
\text { ham, 2016; Motohashi, } \\
\text { 2005; Schartinger, Schi- } \\
\text { bany, \& Gassler, 2001 }\end{array}$ \\
\hline $\begin{array}{l}\text { The knowledge produc- } \\
\text { tion function approach }\end{array}$ & $\begin{array}{l}\text { Largely } 1995-2005 \text {, with a } \\
\text { few scattered studies post } \\
2013 .\end{array}$ & $\begin{array}{l}\text { Anselin, Varga, \& Acs, } \\
\text { 1997; 2000; Barrio-Cas- } \\
\text { tro \& García-Quevedo, } \\
\text { 2005; Fischer \& Varga, } \\
2003\end{array}$ \\
\hline $\begin{array}{l}\text { The cross-sectional } \\
\text { approach }\end{array}$ & $\begin{array}{l}\text { Mid to late 1990s to early } \\
\text { 2000s }\end{array}$ & $\begin{array}{l}\text { Florax, 1992; Florax \& } \\
\text { Folmer, 1992; Baryla \& } \\
\text { Dotterweich, } 2001 ; \\
\text { Tornquist \& Hoenack, } \\
\text { 1996; Fogarty, 1993; } \\
\text { Goldstein \& Renault, } \\
2004\end{array}$ \\
\hline
\end{tabular}

The theoretical insights below considers the following four approaches: the single case study approach, which examines the myriad impacts of a single institution and makes use of input-output modelling; a multiple institution approach, which examines the impact of more than one institution, albeit within a narrowly defined geographical area; the knowledge production function approach; and cross-sectional approaches, which take a more comparative view.

\subsubsection{The Single Case Study Approach}

One of the earliest, and hence most commonly used, approaches to assessing the economic impact of HEIs involves the in-depth analysis of a single case study institution. Individual approaches use economic forecasting models and input-output models to estimate both the direct and indirect impacts of individual universities. These models take into account variables such as HEIs' impacts upon local and regional employment, as well as their investment in the local economy (Bramwell \& Wolfe, 2008; Garrido-Yserte \& Gallo Rivera, 2010; Goddard \& Vallance, 2013; Eesley \& Miller, 2017; Steinacker, 2005; Tavoletti, 2007). Blackwell, Cobb 
and Weinberg (2002) note that the popularity of this approach from the 1970s to the 1990s can be attributable to a white paper issued by the American Council of Education that advocated for a tailored approach to estimating economic impact. However, as noted by Guerrero, Urbano, and Cunningham (2016), this approach was also long popular in the European context (see also, Lilles \& Rõigas, 2017). As with case studies more generally, the advantage of this approach lies in the ability of the researcher to gather a broad range of input data (e.g., student numbers and HEI expenditures) and to attempt to relate to observable economic outputs. In this sense, case studies focused on single HEIs offer perhaps the most comprehensive account of the economic impact of individual universities on their local economic environment and beyond.

One illustrative example is Steinacker's (2005) case study. Using a locally focused, input-output approach and based on data gathered five years' previously, Steinacker (2005) reached the conclusion that the HEI's activities were worth some USD \$10.5 million. A similar approach was employed by Felsenstein (1999) based on a case study analysis of Ben Gurion University in Israel, and earlier in an in-depth analysis of the impact of Northwestern University in Chicago (Felsenstein, 1996). This latter paper, however, attempted to introduce a more sophisticated approach into the analysis, through the estimation of a Keynesian multiplier. This approach assumes that the value of outputs is some multiplier of the value of inputs. Based on his empirical analysis, Felsenstein (1996) calculated an output multiplier of 3.11 for Northwestern University, with the HEI directly responsible for contributing half a billion dollars to the Chicago Metropolitan region. Taking a similar approach, Glasson (2003) suggested that Sunderland University transforms its inputs up to 1.12 times to contribute to the local region in which it is based.

While the input-output and multiplier approaches are found in abundance in the literature prior to 2005, detractors maintain that these approaches are too simplistic in their ability to be able to adequately capture and compute the impact of HEIs (Thanki, 1999). Critics emphasise three points. First, analysts tend to cherry pick the inputs that are used to perform the analysis. Based upon a synthesis of the literature, there is limited guidance as to the appropriate set of inclusion and exclusion criteria for such an analysis. For example, Felsenstein (1999) concerns himself with the migration levels of student, faculty, and administrators, while Glasson (2003) gathers data on the value of the HEI expenditures and employment levels. Without a standardized set of inputs to form the basis of such analyses, comparison between individual cases is invalid. Thanki (1999) also argues that there has been too much of a focus on the causal relationship between the expenditures and other pecuniary activities performed by the HEI and HEI outputs, with limited attention paid to the specific nuances of HEIs (as distinguished from other institutions who undertake economic activities). 
A second criticism is the static nature of input-output analyses. This approach, and those that integrate multiplier effects, imply a fixed relationship between inputs to HEI activity and economic output. In fact, the economic impact of HEIs has been found to be the result of dynamic activities. The production of knowledge is one such dynamic activity, which produces long-term effects, as well as effects that cannot easily be traced back to individual universities (Thanki, 1999). This is the consequence of methodological limitations; due to data limitations, analysts generally perform economic impact studies in short to medium time frames and limit their focus to a local or regional geographical study area. In fact, impact may occur over a longer timeframe or a wider geographical area (Siegfried, Sanderson, \& McHenry, 2007).

Thirdly, few studies, except for the work by Felsenstein (1996; 1999) provide counterfactual analysis to substantiate their claims of a causal relationship between economic inputs and outputs. Counterfactual analysis demonstrates economic development in the absence of the HEI. However, by its very nature, counterfactual analysis is challenging to undertake, and from a methodological point of view, it often lacks validity (Goldstein \& Renault, 2004). Nevertheless, without it, it can be difficult to accept the conclusions of analysts using the individual approach.

As a direct response to the criticism that these analyses are too static in nature, some researchers have attempted to calculate economic impact not by translating HEI inputs into economic outputs, but instead by quantifying those outputs or conducting a qualitative assessment of the economic impacts of their activities. A relatively large corpus of research has examined linkages between the individual HEI and industry through, for example, evaluating the number and quality of spin-off firms produced through research and knowledge exchange activities (see, Cheah \& Yu, 2016; Eesley \& Miller, 2017; Goddard \& Vallance, 2013; Rogers et al., 1999; Siegfried et al., 2007). Other research has measured the impact of technology transfer activities such as licensing agreements (e.g., Charles, 2011; Glasson, 2003; Hermannsson, Lisenkova, McGregor, \& Swales, 2013; Langford, 2002; Mayer, 2007; Zhang, Larkin \& Lucey, 2017). For example, Rogers et al. (1999) found that 19 spin-off enterprises can be directly attributed to the research activities of the University of New Mexico.

Others have attempted to correct for the over-simplistic nature of quantified outputs by addressing a broader and more qualitative range of economic outputs such as urban regeneration, citizenship and social justice (e.g., Brennan, Cochrange, Lebeau, \& Williams, 2018; Gaffikin \& Morrissey, 2008; Goddard \& Vallance, 2013; Guerrero et al., 2016; Shah \& Pahnke, 2014; Taylor, 2007; Turner, 1997).

Regardless of these attempts to offer a more refined and nuanced approach to the analysis of the economic impact of individual universities, there are still 
some deficiencies in this body of literature. The main problem is the inability to state with confidence that observed economic outcomes are causal outcomes of HEI activity. Given what has been noted about the dynamism of the activities of universities, this is particularly problematic. Universities are both embedded in, and are affected by, the local and regional environment. However, there are a host of other institutions (education-oriented, as well as social and economic focused) that interact with, and impact upon, the HEI (Goddard \& Vallance, 2013). Disentangling the effects of these other institutions from those of the individual HEI is, therefore, a major challenge. In addition, while the single case study involves indepth analysis of the impact of the individual HEI, breadth of analysis is sacrificed and, therefore, the results of these analyses cannot be generalized more widely to other contexts.

To conclude, there is a large corpus of research that has adopted the single case study method (Felsentein, 1996, 1999; Glasson, 2003; Steinacker, 2005; Thanki, 1999). This approach focuses attention on a single HEI and seeks to attribute myriad economic outcomes to that focal institution's activities. From a methodological perspective, the approach has made use of input output approaches, and the estimation of a Keynesian multiplier. On the one hand, focusing one's attention on the activities of a single institution makes attributing outcomes to that institution somewhat more straightforward than if multiple institutions were to be evaluated (this is discussed in further detail in the next section). However, there are three main criticisms of the approach: poor causal explanatory power; the dynamism of HEI activity is not adequately captured using this approach; and few authors supply the results of a counterfactual analysis to bolster their claims of a causal relationship between economic inputs and outputs. In the next section, the body of literature taking a multiple HEI approach is examined, with a view to assessing the power of these studies in correcting for those deficiencies.

\subsubsection{The Multiple Case Study Approach}

A second strand of research has employed data collection techniques common in quantitative research (e.g., auditing or questionnaires) to gather data from a broader range of HEIs (e.g., Alves et al., 2015; Carlsson \& Fridh, 2003; Elliott, Levin, \& Meisel, 1988; Guerrero, Cunningham, \& Urbano, 2015; Guerrero, Urbano \& Cunningham, 2016; Motohashi, 2005; Schartinger, Schibany, \& Gassler, 2001). These studies gather information from HEIs in a variety of geographical contexts in order to reach conclusions about the broad economic impact of HEIs that can be widely generalized.

In addition to overcoming the lack of generalizability of single case studies, this approach also addresses the difficult in being able to fully attribute changes 
in economic development to the HEI (Elliot et al., 1988). Using a survey methodology, for instance, researchers try to elicit information about the role that the HEI plays in bringing out economic change compared to other important institutions from key players, such as firms. In their study of the effects of publicly funded research universities on economic development in Germany, Beise and Stahl (1999) ask local firms to describe the importance of proximity to a local research focused HEI on their decision to relocate to the area. They also inquire about aspects associated with innovation, such as their productivity. Studies adopting similar methodologies include Carlsson and Fridh (2003) in the US, Guerrero et al. (2016) in the UK, Schartinger et al. (2001) in the Austrian context, Monjon and Waelbroeck (2003) in France, and Motohashi’s (2005) Japanese study. This approach identifies key agents of economic development and then asks questions about the outcomes that HEIs have upon the economic environment, such as the development of HEI industry linkages, the impact of knowledge spill-overs, human capital effects, and employment creation. Therefore, this approach is perhaps better placed than the single case study approach to attribute economic change directly to the focal HEI.

Of course, approaches that gather data from a broader range of actors, and with a broader set of institutions in mind, also suffer from validity threats such as social desirability, bias, respondent ignorance, and poor recall. Thus, the economic impact of HEIs could potentially be over- or under-estimated using this approach. The ability to generalize the results of these studies beyond the study context could also be under question. Most of the studies that have been published in this area have a narrowly defined (usually nation-level) geographical focus (e.g., Beise \& Stahl, 1999; Carlsson \& Fridh, 2003; Guerrero et al., 2016; Monjon \& Waelbroeck, 2003; Motohashi, 2005; Schartinger et al., 2001). There are certainly factors that differ according to geographical context which could affect the conclusions. For example, studies such as that by Beise and Stahl (1999) ask firms to determine the importance of proximity to HEI on their relocation decisions. However, they tend not to ask about other factors which play a role in decision making, such as having proximity to a skilled workforce, or their proximity to competitors. Since these aspects tend to vary according to local context and region, it is possible that economic impact studies using a broader, survey or auditbased approach generate conclusions that are no more generalizable than single case study methodologies.

In conclusion, since the 2000s, there have been a plethora of studies that have attempted to correct for the deficiencies of the single case study approach by examining the impact of multiple institutions on economic impacts. Typically, these studies are conducted within a narrowly defined geographical area, such as a certain region or country. Both quantitative approaches are evident in this body of research. While this approach means that it is less important for 
researchers to attribute economic outcomes to specific HEIs, there are validity threats given that this approach tends to rely on primary data collection methods with firms and other institutions deemed to be impacted by the HEIs. In the next section, a third approach is discussed, which makes use of knowledge production functions.

\subsubsection{Knowledge Production Functions}

Since the work of Solow (1957) and Arrow (1962), economists have recognised the importance of technological inputs to economic development and change. Neoclassical models of the production function have therefore long included a role for knowledge and technology. It is perhaps unsurprising that there is a strand of economic impact studies that have employed this approach in determining the economic impact of HEIs. The specific knowledge production model that has been most often used is the Griliches-Jaffe model (which, in itself is based on the standard Cobb-Douglas model) that seeks to understand the extent to which HEI and corporate Research \& Development (R\&D) spills over to the broader economic setting in which it takes place (Goldsein \& Renault, 2004). The model specifies innovation as the dependent variable, measured by the quantity of patents, new products, or licenses produced. Two independent variables capture the HEI inputs: the institution itself and industry $\mathrm{R} \& \mathrm{D}$ expenditures.

A host of research has employed either the generic form of the GrilichesJaffe model, or a refined, modified, or extended version in their work on the economic impact of HEIs (Anselin, Varga, \& Acs, 1997, 2000; Barrio-Castro \& García-Quevedo, 2005; Fischer \& Varga 2003; Lin, Kung, \& Wang, 2015; Sevinc, 2014). It is possible to gather a significant amount of outcome data (e.g., patent citations) and to apply the model to determine localization patterns and the importance of spatial proximity to the HEI. For example, Fischer and Varga (2003) find that patterns in patent citations tend to be clustered around industry and HEIs with substantial R\&D activities and expenditures. One stream of research has focused on the agglomeration effects of R\&D activities (Anselin et al., 1997; Sevinc, 2014; Varga, 2001). Agglomeration is a kind of economy of sales which occurs when firms and institutions locate near one another in industrial clusters. Varga's (2001) work emphasises the importance of agglomeration effects in the economic impact of HEIs. This be a counter to the work of the single case study enthusiasts, who view economic impact as the consequence of the activities of individual HEIs, rather than clusters. Essentially, what Varga (2001) demonstrates and later confirms with colleagues (Anselin et al., 1997) is that firms that establish themselves in populous regions 
that already have a strong constellation of employment opportunities with already existing industry clusters are in a better position to use the knowledge generated by HEIs to their production advantage. This could undermine conclusions regarding the causal linkages between HEI activity and economic impact, for it would suggest a kind of cyclical relationship between the activities of regions, industry, and HEI that might be challenging to disentangle.

Despite this, these research studies have generally demonstrated the unique qualities of institutions that specialize in knowledge production, compared to other institutions with economic-producing outputs. This approach has confirmed the dynamism of the spill-over effects of HEIs, and thereby serves as the greatest challenge to the more simplistic input-output approach common in single case studies. Nevertheless, and certainly in the context of agglomeration effects, methodological constraints do prevent researchers from being able to reach conclusions that would enable them to attribute economic outcomes to individual HEIs and their different activities (e.g., employment creation, research and development, innovation, skills development). Furthermore, most of the research that has been undertaken in this vein has focused on specific types of HEI (namely, researchoriented universities and publicly funded research institutions), overlooking other types of HEIs.

To summarize, informed by neoclassical models of the production function, there is a body of studies that has applied knowledge production functions (typically, the Griliches-Jaffe model, or some variant of it) to assess the economic impact of HEIs. This approach, championed by Anselin, Varga (2000), and colleagues, represents a more sophisticated and dynamic method of assessing economic impact. It is also the approach that helped to establish that HEIs do produce dynamic spill-over effects. However, this approach has focused its attention on research-oriented universities to the detriment of other types of HEIs. Cross-sectional approaches, which are the final theoretical approach to be considered in this section, attempt to address this weakness.

\subsubsection{Cross-Sectional Approaches}

Given that economic impact studies seek to generate conclusions about the causal effect of HEI activity, it may seem surprising that several studies have adopted a cross-sectional, rather than longitudinal, approach. However, given the flexibility of this approach, a few earlier studies have adopted the method. Typically, researchers identify a sampling framework, gather data on knowledge and HEI inputs and activities and regional outcomes, and use multivariate modelling procedures (regression and similar techniques tend to be common in these kinds of studies) to seek to determine a relationship between the inputs and outcomes. Examples of papers utilising this approach are Baryla and Dotterweich (2001), 
Tornquist and Hoenack (1996), Florax (1992), Florax and Folmer (1992), and Fogarty (1993, 2001).

In two related studies focused on the Netherlands region, for example, Florax (1992) and Florax and Folmer (1992) examine the knowledge effects of universities on investments in manufacturing firms in the local region. These twin studies are examples of the few studies that have demonstrated there to be no effect of proximity to HEIs on economic outputs. Fogarty (1993) undertook a similar study focused on the US but with the focus of analysis on new firm births. That study suggested that, indeed, having an HEI in a metropolitan area could stimulate the birth of new firms in certain industries, such as the electronic equipment industry.

Goldstein and Renault (2004), also working in the US context, use a very different approach in their study. Those authors collected wage data and attempted to correlate this data to the entrepreneurial activities of research-oriented universities. Based on their analysis, the researchers conclude that research universities do have a positive influence on entrepreneurial activity in the economic region, a finding that has been replicated more recently by Guerrero et al. (2015), and by Roberts and Easley (2011) in their study of the Massachusetts Institute of Technology (MIT).

Table 1.7. The Strengths and Limitations of the Four Conceptual Approaches to Economic Impact Studies in Higher Education Context (compiled by author)

\begin{tabular}{|l|l|l|}
\hline Approach & Strengths & Weaknesses \\
\hline $\begin{array}{l}\text { The single case study } \\
\text { method }\end{array}$ & $\begin{array}{l}\text { Depth of analysis } \\
\text { Simplicity }\end{array}$ & $\begin{array}{l}\text { Lack of causal explana- } \\
\text { tory power } \\
\text { Difficult to attribute eco- } \\
\text { nomic outcomes to a sin- } \\
\text { gle institution where } \\
\text { other institutions are pre- } \\
\text { sent }\end{array}$ \\
\hline $\begin{array}{l}\text { The multiple HEI } \\
\text { approach }\end{array}$ & $\begin{array}{l}\text { Breadth of analysis } \\
\text { No need to try to attribute } \\
\text { effects to specific institutions }\end{array}$ & $\begin{array}{l}\text { Ignores HEIs that are not } \\
\text { research intensive } \\
\text { May be subject to meth- } \\
\text { odological constraints }\end{array}$ \\
\hline $\begin{array}{l}\text { The knowledge pro- } \\
\text { duction function } \\
\text { approach }\end{array}$ & High casual explanatory power & $\begin{array}{l}\text { May be difficult to im- } \\
\text { plement }\end{array}$ \\
\hline $\begin{array}{l}\text { The cross-sectional } \\
\text { approach }\end{array}$ & Breadth of analysis & $\begin{array}{l}\text { Lack of causal explana- } \\
\text { tory power }\end{array}$ \\
\hline
\end{tabular}


A smaller set of studies concentrated between 1995 and 2001 have adopted a cross-sectional approach to economic impact analysis. Researchers will typically draw a sample of institutions and gather a range of inputs and output data, which is then assessed using multivariate modelling techniques to attempt to demonstrate whether there exists a relationship between the inputs and outcomes captured. The breadth of analysis should be a benefit of these approaches, but this is sacrificed for causal power.

As the examples highlight, while there are benefits to each approach, no approach has yet fully been able to solve the key problems associated with economic impact analysis. A summary of the strengths and limitations of the four major approaches is supplied in Table 1.7.

Based on the above literature, is has been established that there is a long tradition, dating back to the 1970s at least, of researchers looking to examine the economic impact of HEIs. HEIs are key institutional actors in knowledge production and economic growth. Above, four key methodological approaches have been discussed: single case study, the multi-case study, the knowledge production function, and finally, the cross-sectional approach. Not yet assessed is the extent to which these approaches are able to capture the efficiency of HEIs. This is the subject of the next chapter.

\subsection{The Importance to Assess Efficiency of Higher Education Institutions}

In the previous chapters, the focus of attention has been placed upon economic impact assessments, the methodology for undertaking such assessments, and the types of outcome that are assessed. One specific outcome which may be either implicitly or explicitly assessed through evaluative activities is efficiency. More likely, however, is that efficiency is absent from economic impact analyses and treated exogenously. There are, however, specific models and approaches used to assess efficiency in education. This subsection of the literature therefore turns its attention to the concept of efficiency, examining the methods and strategies that have been used to assess for it in the educational context. Specifically, the section examines the way in which the concept of efficiency has been operationalized in education, and the main methods of assessing for it, including both parametric and non-parametric models. Finally, this chapter ends with a critical review of the literature on economic impact and efficiency, with suggestions for further research in this area outlined.

In recent years, the importance of efficiency in education has attracted increased attention by governments and intergovernmental bodies (Stiglitz \& Rosengard, 2015). For instance, a 2013 report published by the Organisation for 
Economic Co-operation and Development (OECD) emphasized that it if economies are to survive and thrive, it is increasingly crucial that countries carefully consider "how to allocate [education] spending and the policies they design [so as to] to improve the efficiency and relevance of the education they provide" (OECD, 2013, p. 15).

HEIs can be seen as enterprises whose inputs and outputs are difficult to measure, since the majority of them do not have market prices. Dixit (2002) points out that the education system has multi-period, multi-principal, and multi-task organizations and operates in a way similar to the monopolies. With the multiple objectives of HE, it is difficult to apply a simple criterion in measuring failure or success in achieving the specified objectives. It follows that there are no perfect criteria for measuring the efficiency of an HEI.

There are several reasons for this growing interest in efficiency. The OECD report (2013) that placed emphasis on the concept was published just as Europe and North America were emerging from one of the deepest and most prolonged recessions in recent history. In the context of an austerity-driven economy, and especially given the rising cost of education, it is increasingly important that educational systems make the most efficient use of their considerable investments (OECD, 2013).

Public universities are heavily reliant on funding from the government. They will likely continue to be a key area of government spending over the coming decades. Therefore, assessment and monitoring of how efficient these HEIs are is necessary. Efficiency is often mentioned in national education planning documents; however, these document rarely clearly state whether efficiency itself is the ultimate goal, or whether it is a channel to achieve specific educational goals (Abbott \& Doucouliagos, 2009.

To proceed to examine efficiency in HEIs, it is important to understand what an efficient system of education provision looks like. The fundamental theoretical work in this area was undertaken by Bessent, Bessent, and colleagues (Bessent \& Bessent, 1980; Bessent, Bessent, Kennington, \& Reagan, 1982). These papers established that broadly speaking, efficiency in education occurs where those agencies and institutions responsible for the production and implementation of education make the best possible use of all available inputs. Said differently, an inefficient system is one where there are possibilities to bolster outputs with current inputs held constant, or where there are opportunities to reduce inputs with outputs ceteris paribus (Gralka, 2018).

Therefore, we will narrow in on the dominant ideas of efficiency in the context of education in order to create a framework for understanding the literature on the subject. McMahon (1983) discusses four ideas of efficiency in education provision: technical, price, exchange, and allocative efficiency. Technical effi- 
ciency looks at the resources and time used in the production of an output. Examples of such resources include students' learning activities, instructional materials, and teaching methods (Boughey, 2003). Price efficiency is described as an extension of technical efficiency, as it takes into consideration the relative costs of the resources; for example, this metric considers whether the educational services in the HEIs are priced in a manner that is cost-efficient (Furková, 2013). Exchange efficiency represents the ability of educational services to meet the needs of other institutions (religious, civic, and business organizations). It concerns questions like whether the credentials are valuable in the market or whether employees are overqualified (Cowan, 1985). Lastly, allocative efficiency is attained in cases where there is technical, exchange, and (factor) price efficiency.

In the Table 1.8, we shall look at some of the theoretical concepts of efficiency and efficiency of HEIs.

Table 1.8. Theoretical Concepts of Efficiency and Efficiency of Higher Education Institutions (compiled by author)

\begin{tabular}{|c|c|c|}
\hline Concept & Definition & Authors \\
\hline \multirow{8}{*}{ Efficiency } & $\begin{array}{l}\text { Is the ability to avoid the wastage of time, money, } \\
\text { efforts, energy, and materials in doing something } \\
\text { or producing a specific desired result }\end{array}$ & $\begin{array}{l}\text { Abbott \& Dou- } \\
\text { couliagos, } 2009\end{array}$ \\
\hline & $\begin{array}{l}\text { Is the ability to carry out tasks successfully with- } \\
\text { out any wastage }\end{array}$ & Lowe Boyd, 2004 \\
\hline & $\begin{array}{l}\text { It is a measure of the extent in which input is uti- } \\
\text { lized well for the intended function or task(output) }\end{array}$ & Waldo, 2007 \\
\hline & $\begin{array}{l}\text { The extent to which effort, time or cost is well } \\
\text { used for an intended purpose or task }\end{array}$ & $\begin{array}{l}\text { Agasisti \& } \\
\text { Haelermans, } \\
2015\end{array}$ \\
\hline & $\begin{array}{l}\text { The ability to accomplish a certain task with mini- } \\
\text { mal resources }\end{array}$ & Furková, 2013 \\
\hline & $\begin{array}{l}\text { The degree of how well an organization or system } \\
\text { works }\end{array}$ & Mikušová, 2017 \\
\hline & $\begin{array}{l}\text { Describes the degree to which a performance is } \\
\text { achieved in terms of productivity }\end{array}$ & Granzow, 1979 \\
\hline & $\begin{array}{l}\text { The optimal expenditure of resources by a user in } \\
\text { using a particular product to achieve the desired } \\
\text { objective in a particular context of use }\end{array}$ & Rapple, 1992 \\
\hline $\begin{array}{l}\text { Efficiency } \\
\text { of Higher } \\
\text { Education } \\
\text { Institutions }\end{array}$ & $\begin{array}{l}\text { A comparison of a higher education institution and } \\
\text { their related outputs. An efficient institution gets } \\
\text { more output for a set of resource inputs, or it } \\
\text { achieves comparable levels of output for much } \\
\text { fewer inputs }\end{array}$ & Marginson, 1991 \\
\hline
\end{tabular}


End of Table 1.8

\begin{tabular}{|c|c|c|}
\hline \multirow[t]{2}{*}{ Concept } & Definition & Authors \\
\hline & $\begin{array}{l}\text { The amount of time that is spent on the successful } \\
\text { use of a learning object compared to the benefits } \\
\text { that are received by the learner. }\end{array}$ & Hoenack, 1982 \\
\hline \multirow{3}{*}{$\begin{array}{l}\text { Efficiency } \\
\text { of Higher } \\
\text { Education } \\
\text { Institutions }\end{array}$} & $\begin{array}{l}\text { The degree to which outputs are produced from in- } \\
\text { puts }\end{array}$ & Cowan, 1985 \\
\hline & $\begin{array}{l}\text { The use of fewest resources(inputs) to produce the } \\
\text { most outputs (services or products) }\end{array}$ & $\begin{array}{l}\text { Powell, Gilleland, } \\
\text { \& Pearson, } 2012\end{array}$ \\
\hline & $\begin{array}{l}\text { The resources used by the institution in relation to } \\
\text { the completeness and accuracy of the objectives } \\
\text { achieved. }\end{array}$ & Boughey, 2003 \\
\hline
\end{tabular}

The education sector offers a challenging context for assessment when compared to other sectors (Johnes, 2014). The institutions in that sector make use of multiple inputs which are not priced. In addition, as a sector, it produces multiple outputs which cannot easily be discerned over both the short- and the long-run. Finally, since education is often not-for-profit, it is impossible to determine how inputs are used to produce largely intangible outcomes.

Below this analysis looks at three factors that are important in relation to understanding the efficiency of HEIs: the level of analysis, the inputs, and the outputs. The level of analysis refers to the geographical focus of the analysis, which generally includes an individual (student), institutional, regional, or national scope. Then this review looks at the four-common level of inputs: inputs pertaining to the HEI itself, environment-level inputs, inputs related to the student, and inputs relating to the family. Finally, at the level of outputs, assessments look at quantitative measures, including the numbers of graduate, test scores, and other measures of student performance, as well as qualitative measures such as technology transfer from the HEI to industry, patents, citations, and research quality. This research takes all three of these factors in mind in its analysis of the efficiency of Higher Education Institutions. In Chapter 3, the relevance of these factors to efficiency in the Lithuania's HEIs is explored.

Level of analysis. One way to categorise studies on efficiency in education is according to the level at which analysis is undertaken. As with the literature on the economic impact of HE more generally, this literature tends to adopt a narrow geographical focus. Here we consider national, regional, institutional, and individual level (student) approaches.

Most studies adopt a case study approach, focusing on either specific countries or regions (e.g., Aristovnik, 2013; Gralka, 2018; Johnson \& Ruggiero, 2014; Ouellette \& Vierstraete, Naper, 2010; Wolszczak-Derlack, 2014;) or on specific HEIs (Agasisti \& Bonomi, 2014; Duh et al., 2014; Kong \& Fu, 2012; Lu \& Chen, 
2013; Mainardes et al., 2014; Nazarko \& Saparauskas, 2014; Zoghbi et al., 2013). It is rarer for studies to be undertaken at the individual (i.e. student) level, but increasingly, this approach is becoming popular (see, for example, Crespo-Cebada et al., 2014; De Witte \& Kortelainen, 2013; Deutsch et al., 2013; Podinovski et al., 2014; Portela et al., 2013, Thieme et al., 2013).

Given growing access to national datasets that can be used to compare the efficiency of education provision at the national level (a good example is the Trends in International Mathematics and Science Study, or TIMSS or the European University Data Collection), a comparative approach between countries could be facilitated. Comparisons could also take place within-country and between institutions or narrowly defined geographical areas. These comparisons would facilitate knowledge about the inputs and transformation strategies that generate efficiency.

In addition to comparative perspectives, there is room for more holistic approaches that would integrate analysis at multiple levels. This multi-level analysis could offer a more sophisticated and complex understanding of the drivers of efficiency and inefficiency. Such studies might integrate analysis undertaken at the national, institution and individual level, for example. These are some ideas for addressing gaps in future research into efficiency in education.

Inputs assessed. Efficiency is essentially about the strategies used to transform inputs into educational outputs and outcomes (Bessent et al., 1982). Therefore, it is important to consider the various inputs analysts have considered as drivers of efficiency in education. The literature focuses on four different types of inputs: inputs pertaining to the HEI itself, environment-level inputs, inputs related to the student, and inputs relating to the family.

With respect to inputs pertaining to the institution, studies have focused on factors such as the level of expenditure, educational equipment and other resources, enrolment levels, and size and characteristics of the teaching force such as teacher quality, teacher absences, and teacher experience (Crespo-Cebada et al., 2014; Deutsch et al., 2013; Haelermans \& Blank, 2012; Johns, 2013; Kong \& Fu, 2012; Thieme et al., 2012). These tendencies build upon a strong theoretical foundation within the literature.

Bessent and Bessent (1980) saw characteristics such as the ratio of educators to students, teacher mobility and expenditures on faculty, research staff, and administrators as key to understanding how efficiency works in education. Interestingly, however, the research that has been conducted in the last two decades or so often fails to identify a strong empirical relationship between these aspects of the educational institute and efficiency outcomes. The problem, however, is that these inputs are often considered without taking into account the individual institution's ability to transform those inputs into efficient outcomes. Next, we explore the second factor in efficiency: of the environmental level inputs. 
Researchers have pointed out that a key issue driving efficiency or inefficiency is the context or environment in which the HEI is embedded (De Witte et al., 2013). McEwan and Carnoy (2000) point out that the geographical location of the HEI can exert an impact on efficiency through mediating channels, such as student performance or the availability of local resources. For example, Dolton et al. (2003) point out that there are likely to be differences in the availability of resources between institutions in urban and rural areas. Heshmati and Kumbhakar (1997) argue that these characteristics influence the number of households that contain individuals who demand education. If the location is rural and has a low number of such households, it may be difficult to translate existing resources and inputs into efficient outcomes.

Of equal importance is the degree of competition that exists in the locality (Nazarko \& Saparauskas, 2014). Typically, analysts will use some extension or refinement of the Herfindahl Index to assess the size of the HEI compared to the size of the industry (Stiglitz \& Rosengard, 2015). The presence of competitors can undermine the ability of the organization to translate its inputs into efficient gains. Other important characteristics at the environmental level include the number and size of local taxes, and the nature of the local and regional employment market (Dolton et al., 2003; Grosskopf et al., 2014; Nazarko \& Saparauskas, 2014).

The third factor we consider is the student level of inputs. These assessments are evident in the growing number of studies on students, rather than on the institutions themselves (Crespo-Cebada et al., 2014; De Witte \& Kortelainen, 2013; Deutsch et al., 2013; Podinovski et al., 2014; Portela et al., 2013, Thieme et al., 2013). These studies tend to measure behavioural and psychological variables, especially academic achievement prior to entering the institute of education, or in the previous academic years (Crespo-Cebada et al., 2014; Portela et al., 2013; Thieme et al., 2013;). This is important because it provides a measure of the 'distance travelled' with regards to achievement and the other, institute-level resources that have been invested in the institute. Other factors which have been assessed include individual levels of motivation, the predicted level of achievement, and the demographic characteristics of either the focal student, or their classmates (De Witte et al., 2010; Dolton et al., 2003).

The fourth factor under consideration is the demographic, behavioural, and psychological attributes of students' household and family. The highest level of education of the parents and the socio-economic status or household income of the family often serve as proxies for motivation and propensity to undertake education (Kong \& Fu, 2012). Parental involvement and support and family structure are known to be predictors of student outcomes. In addition, access to resources that aid in educational success (such as personal tutors or access to computers and reading materials) is driven by familial socio-economic status and income, which drives educational outcomes (Deutsch et al., 2013; Mongan et al., 2011). 
Now that examined the four main inputs assessed are examined in educational efficiency - at the level of the institutions, the environment, the student, and the family - we will proceed to examine the outputs commonly assessed in HEIs.

Outputs assessed. Outputs can be assessed into measures of quantity and quality (Stiglitz \& Rosengard, 2015). For example, it is common for researchers to assess the number or percentage of graduates emerging from the HEI (see, for example, Burney et al., 2013; Haelermans \& Ruggiero, 2013; Johnes, 2013; Misra et al., 2012; Wolszczak-Derlacz \& Parteka, 2011). Test scores and other measures of student performance are also commonly used. Measures of quality include technology transfer, patents, citations, and research quality (Duh et al., 2014; Nazarko \& Saparauskas, 2014). When both types of measures are considered together, studies are able to provide a comprehensive assessment of the outputs of the educational system.

However, this does not mean that such measures are without criticism. Detractors such as Gronberg et al. (2012) have argued that absolute measures are less successful in measuring output compared to relative measures because education does not necessarily produce immediate effects. For example, value-added approaches, which assess the degree of change in research outputs or in student performance across a specified period are able to show the level of value that changes in educational inputs add from one year to the next (Gronberg et al., 2012; Kong \& Fu, 2012).

Researchers have employed a myriad of approaches to economic impact and efficiency analyses, making use of a variety of different theoretical frameworks, and employing different echoic tools. The literature analysis has examined a range of issues, including: the rationale for undertaking economic impact and efficiency analyses in the first place; the theoretical and methodological approaches to studying the economic impact and efficiency of HEIs; and the range of different approaches to evaluating economic impact and efficiency in the HE sector.

\subsection{Chapter Conclusions and Formulation of Dissertation Objectives}

Based on the analysis above, the following conclusions can be made:

1. From general perspective, it is evident in the literature that HEIs, whether research-oriented or not, can yield positive outcomes for economies. This reflects recognition of the knowledge-producing and economy-enhancing roles of these key institutional actors. Conceptually, however, there seems to be a lack of agreement as to what constitutes economic impact.

2. From the economic impact and efficiency assessment perspective the research has indicated a need for considering assessment of HEIs along two focal points: economic impact and efficiency. 
3. Three major issues can be observed in different approaches toward assessment of economic effects within HE context. First, there is an inability to monitor the effective use of financial resources in terms of HEIs impact on outcomes. Second, there is a lack of tools and instruments for measuring the economic impact and efficiency of HEIs in general. Third, there is a lack of methods to obtain data on the performance of the human resources in HEIs. This strand of literature agrees that HEIs make an important contribution to the local and regional economy, but there are diverse views about where that impact lies.

4. Currently there is no singular methodology which covers all areas needed to make assessment of economic impact and efficiency of HEIs sufficiently rigorous. Therefore, researchers are forced to make a trade-off in the depth and breadth of the data analysis by selecting a single case study or cross-sectional approach. Another trade-off is between the explanatory power and simplicity of the research analysis, which involves using the complex data analysis in the form of multi-HEI analysis, or the data analysis of a singular HEI, which is difficult to manage and conduct.

5. Finally, the analysis revealed that limited attempts have been made to integrate efficiency analysis into economic impact assessment. Given the importance of both efficiency and economic impact to educational investment, this seems to be an oversight. A gap in the literature therefor exists that could be filled by research that adopts an integrative approach towards assessing economic impact and efficiency of HEIs. Therefore, in order to correspond to the need for a systematic approach, integrated model that enables assessment of economic impact and efficiency of HEIs within one system is designed and suggested in the following chapter. Afterwards the relevance of the proposed model is tested in the empirical study of Lithuanian HEIs. 


\section{2}

\section{Methodology to Assess Economic Impact and Efficiency of Higher Education Institutions}

This chapter proposes a novel practical combination of the Input-Output (I-O) model and the Data Envelopment Analysis (DEA) model in order to evaluate the efficiencies of HEIs. This study combines DEA and I-O models in order to maximize the positive attributes of both quantitative methods. Below each one is explained in detail, before a model for combining the two is proposed.

The combination works by considering the economic impacts resulting from the I-O model as one of the outputs to be used in the DEA model. The combination is practical, since it considers the impact on the national (regional) economy, in addition to other artefacts such as the number of graduates or the weighted points of scientific papers. The analysis is thus detailed and insightful, providing a valuable guidance for strategic policy makers.

The findings of Chapter 2 have been published in 4 papers (Vaiciukevičiūtè, Stankevičienè, Bračikovienè 2019; Stankevičienė, Kraujalienè, Vaiciukevičiūtė 2017, Stankevičienè, Vaiciukevičiūtė 2016; Stankevičienè, Vaiciukevičiūtė 2014). 


\subsection{Assessing Economic Impact of Higher Education Institutions}

HEIs are diverse in terms of their scale and characteristics. For example, while some HEIs focus intensively on research with a relatively small number of students, others are more driven by student enrolment. Incomes and expenditures are thus, by nature, diverse. As a result, the economic impacts are diverse too. This section evaluates such impacts of HEIs on the national economy by using multipliers in Input-Output (I-O) models.

The researcher starts with the formalization of the Input-Output model in the context of measuring economic impact of HEIs in relation to other sectors in the national economy. Before presenting two ways to disaggregate the economic impact of the HE sector into the impacts of individual HEIs, the researcher shows how to aggregate the I-O table for sectors according to Nace 2 classification.

\subsubsection{Input-Output Modelling}

The I-O model serves as an appropriate method for assessing the overall impact of different economic sectors (e.g., agriculture, manufacturing, services, etc.) on national economic growth, thus they form an essential part of an economic impact analysis. It has several advantages that are considered.

- Input-output models utilize supply chain linkages (the flow of money) to assess the impact of sectors within one economic system.

- Input-output models capture the full effects of not only planned but also the sudden and unpredicted changes within the economic system.

- Input-output models are simple and straightforwardly transparent, capturing the relations between sectors with the overall economy.

Input-output models are based on evidence and reliable data, providing a detailed analysis on inter-sectorial connections; thus, they produce detailed sectorial results.

The I-O analysis has become one of the most applied methods in economics. It considered a useful tool to understand the impact of individual sectors, industries, or institutions on the entire economy (Zhang et al., 2017). One of those who modified and applied Leontief's model was Gosh (1958), but his approach and model was rather supply-driven. He suggests a model which assumes that fixed allocation coefficients are not affected by final demand changes and scarce capacity for all industrial sectors, except the sectors targeted (Park 2006). Other authors found that I-O, as well as another econometric models, should be considered as a supplement rather than a complementary methodological approach. For example, 
Miller et al. (1991) considered early empirical work and applications of Leontief's model to serve mostly industry-related subjects and actors.

Although the mathematics of I-O is straightforward, what makes the process more complex is the enormous set of data related to the expenditures and revenues of each sector or institution under scrutiny. Therefore, the creation of I-O tables represents a useful tool for sorting and analysing a large set of data. In some countries, and very often in research attempts, the economic "snapshot" of certain sector is represented through I-O tables.

The central part of an I-O analysis involves input-output tables. Each table includes specific, sector-related data that are sorted in columns and rows. When observing tables or an inter-industry matrix, which represent the main tool of the I-O model, there are several columns indicating different economic parameters. For example, column 'entries' usually indicate inputs to a specific industrial sector, and rows stand for a given sector. This format clearly indicates inter-dependency of different sectors and enables analysis and estimations in a clearer way. Additionally, specific industries are listed or indicated in the headers of each row and column. For example, the OECD uses I-O tables that present matrices of interindustrial flows of goods and services (produced domestically and imported) in current prices (USD million), for all OECD countries and 27 non-member economies (OECD, 2018).

When constructing tables, authors usually employ a methodology that assumes two types of spending - exogenous and endogenous. Exogenous refers to a government's spending, exports, and investment; it is considered independent from the level of economic activity within the host economy. On the other hand, endogenous spending has been determined by the overall level of economic activity within the host economy or within the institutions as a reaction to shocks to the sectors. Additionally, demand for intermediate inputs and sometimes household consumption demands are taken to be endogenous. The key assumption in the I-O model is that a system, such as an HEI, is demand-determined, and not supply-determined (Zhang et al., 2017). Assuming that exogenous expenditure determines endogenous activities, multipliers can be derived.

All HEIs are considered as a sector of the national economy. Suppose that denotes the HE sector and denote other economic sectors. The computation of the economic impact of is done through the following three steps.

- Construct the I-O table.

- Compute the Leontief inverse matrix.

- Derive the output multiplier.

Those three steps are described in detail through the following example. 
Step 1: Construct the I-O Table

Table 2.1 illustrates the I-O table for our example. While each row of the table represents the distribution of the output (income) that each sector gives to the other sectors, each column describes the distribution of the input (expenditure) that each sector receives from other sectors.

Table 2.1. I-O Table of HEIs and Other Economic Sectors (Miller et al., 2009)

\begin{tabular}{|c|c|c|c|c|c|c|}
\hline Sectors & $H$ & $S_{2}$ & $\ldots$ & $S_{m}$ & Final Demand & Total \\
\hline$H$ & $X_{11}$ & $X_{12}$ &.. & $X_{1 m}$ & $F_{1}$ & $O_{1}$ \\
\hline$S_{2}$ & $X_{21}$ & $X_{22}$ &.. & $X_{2 m}$ & $F_{2}$ & $O_{2}$ \\
\hline$\ldots$ & $\ldots$ & $\ldots$ &.. & $\ldots$ & $\ldots$ & $\ldots$ \\
\hline$S_{m}$ & $X_{m 1}$ & $X_{m 2}$ &.. & $X_{m m}$ & $F_{m}$ & $O_{m}$ \\
\hline Other sources & $Y_{1}$ & $Y_{2}$ & $\ldots$ & $Y_{m}$ & $Y_{m+1}=F_{m+1}$ & $O_{m+1}$ \\
\hline Total & $O_{1}$ & $O_{2}$ & $\ldots$ & $O_{m}$ & $O_{m+1}$ & $O_{s}$ \\
\hline
\end{tabular}

Consider the rows, for example, the institute $H_{1}$ would distribute its total output $O_{1}$ as

- $X_{11}$ for $H$ (itself),

- $X_{12}$ for $S_{2}$,

$-\ldots$,

- $X_{1 m}$ for $\mathrm{S}_{m}$, and

- $F_{1}$ as the exogenous output (final demand) such as consumption, investment, government expenditure, or exports.

As a result, the following formulas from 2.1 to 2.12 was proposed by Miller and Blair (2009).

$$
O_{1}=X_{11}+X_{12}+\ldots+X_{1 m}+F_{1} .
$$

More generally, for each $j=1, \ldots, n+m$, the following equation holds.

$$
O_{j}=X_{j 1}+\ldots+X_{j m}+F_{j} \text {. }
$$

Consider the columns, for example, the institute $H_{1}$ would receive as its input total amount of $O_{1}$ in which

- $X_{11}$ is from $H$,

- $X_{21}$ is from $S_{2}$, 
- $X_{m 1}$ is from $S_{m}, Y_{1}$ is from other sources such as imports, labour, and capital.

It should be noted that the total of input and output for each sector are the same. As a consequence, there is the following equation.

$$
O_{1}=X_{11}+\ldots+X_{m 1}+Y_{1} \text {. }
$$

Or more generally, for each $j=1 \ldots, n+m$, the following equation holds.

$$
O_{j}=X_{1 j}+\ldots+X_{m j}+Y_{j} \text {. }
$$

Finally, the total amount of input and output for all sectors are the same and is denoted as $O$ in the table.

$$
O_{s}=O_{1}+\ldots+O_{m+1} .
$$

Step 2: Compute the Leontief Inverse Matrix

Given the I-O table, the following relation exsist.

$$
X\left[\begin{array}{c}
1 \\
\ldots \\
1
\end{array}\right]+F=O,
$$

where

$$
\mathbf{X}=\left(\begin{array}{ccc}
X_{11} & \cdots & X_{1 m} \\
\vdots & \ddots & \vdots \\
X_{m 1} & \cdots & X_{m m}
\end{array}\right) ; \quad \mathbf{F}=\left[\begin{array}{c}
F_{1} \\
\ldots \\
F_{m}
\end{array}\right] ; \quad \mathbf{O}=\left[\begin{array}{c}
O_{1} \\
\cdots \\
O_{m}
\end{array}\right] .
$$

Consider the matrix $\mathbf{A}$ as following.

$$
\mathbf{A}=\left(\begin{array}{ccc}
X_{11} / O_{1} & \cdots & X_{1 m} / O_{m} \\
\vdots & \ddots & \vdots \\
X_{m 1} / O_{1} & \cdots & X_{m m} / O_{m}
\end{array}\right)
$$

Then,

$$
A O+F=O .
$$

The formula is equivalent to

$$
F=O-A O
$$




$$
F=(I-A) O
$$

Multiplying the inverse of $(I-A)$ results in the following equation.

$$
O=(I-A)^{-1} F
$$

Here $(I-A)^{-1}$ is called the Leontief inverse matrix.

Step 3: Derive the Output Multiplier

The output multipliers are derived from the above formula. Specifically, the vector $\left[\begin{array}{c}M_{1} \\ M_{2} \\ \ldots \\ M_{m}\end{array}\right]$ defined as following,

$$
\left[\begin{array}{c}
M_{1} \\
M_{2} \\
\ldots \\
M_{m}
\end{array}\right]=\left((I-A)^{-1}\right)^{T}\left[\begin{array}{c}
1 \\
\ldots \\
1
\end{array}\right]
$$

defines the output multipliers for $H, S_{2}, \ldots, S_{m}$, respectively. The output multipliers estimate how much the total economic output will change with respect to a unit change in final demand for the corresponding sector. In other words, there is the following estimation for each $\mathrm{j}=1 \ldots, n+m$.

$$
O_{j} \approx M_{j} F_{j} \text {. }
$$

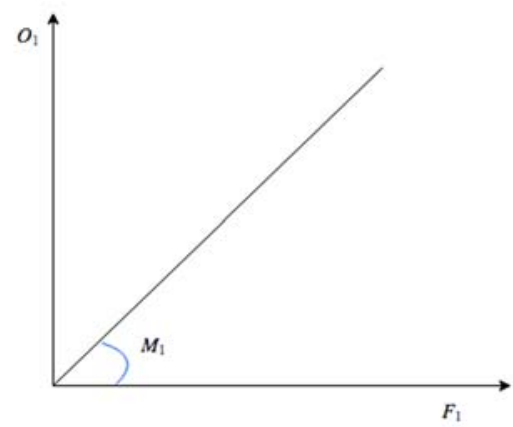

Fig. 2.1. Multiplier M1 Estimates the Linear Relation Between $O_{1}$ and $F_{1}$ (Miller et al., 2009) 
Figure 2.1 illustrates such a relation between $O_{1}$ and $F_{1}$ via $M_{1}$. Output multipliers are widely used as an estimation for the national economic impact of sectors (here we are interested in HEIs).

\subsubsection{Aggregation of Input-Output Table}

In the Input-Output table received from the government, the economy often be broken-down into many activities (e.g., 98 activities in the case of Lithuania). For comparability, there is a need to follow a standard analysis, where a certain fixed number of categories of activities are considered. Following the Nace 2 classification, the aggregated Input-Output table with breakdown of 11 economic activities should be constructed. The breakdown is described in Table 2.2.

Table 2.2. Classifications of Activities to 11 Groups Following the Nace 2 Classification (Eurostat, 2008)

\begin{tabular}{|l|l|}
\hline Nr. & Classifications of Activities \\
\hline 1 & A-Agriculture, forestry and fishing \\
\hline 2 & $\begin{array}{l}B+C+D+E-\text { Mining and quarrying; manufacturing; electricity, gas, steam } \\
\text { and air conditioning supply; water supply; sewerage, waste management, and } \\
\text { remediation activities }\end{array}$ \\
\hline 3 & $F-$ Construction \\
\hline 4 & $\begin{array}{l}G+H+I-\text { Wholesale and retail trade; repair of motor vehicles and motorcy- } \\
\text { cles; transportation and storage; accommodation and food service activities }\end{array}$ \\
\hline 5 & $J-$ Information and communication \\
\hline 6 & $K-$ Financial and insurance activities \\
\hline 7 & $L-$ Real estate activities \\
\hline 8 & $\begin{array}{l}M+N-\text { Professional, scientific and technical activities; administrative and } \\
\text { support service activities }\end{array}$ \\
\hline 9 & $\begin{array}{l}O+Q-\text { Public administration and defence; compulsory social security; human } \\
\text { health and social work activities }\end{array}$ \\
\hline 10 & $P-$ education \\
\hline 11 & $\begin{array}{l}R+S+T-\text { Arts, entertainment and recreation, repair of household goods, and } \\
\text { other services }\end{array}$ \\
\hline
\end{tabular}

The estimation of the aggregated Input-Output table is computed by summation of the corresponding constituting economic sectors. For $i, j \in\{1, \ldots, 11\}$ the 
value of the cell $(i, j)$ in the aggregated Input-Output table is computed as the following formula (Zhang et al., 2017).

$$
X_{i j}=\sum_{\text {Activity } a_{i} \text { in group } i} \sum_{\text {Activity } a_{j} \text { in group } j} \text { output that } a_{i} \text { distributes to } a_{j} \text {. }
$$

After having the aggregated Input-Output table, the researcher computes the economic impacts of the HE sector in the whole economy, which consists of the above 11 sectors. Since the aim of this research is to evaluate the impacts of each HEI, the next section proposes two ways to disaggregate the economic impact of the HE sector into impacts of individual HEIs.

\subsubsection{Disaggregation of Economic Impacts of Higher Education Sector}

This section proposes two approaches for disaggregating the economic impact $M_{1}$ (i.e. multiplier) of the HE sector into the impacts of individual HEIs. While the first approach simply takes the proportion of $M_{1}$ based on the expenditures of each HEI to assign multipliers to HEIs, the second approach utilizes the regression method to model the Input-Output linear relationship. It then estimates the multipliers of HEIs using the results of the linear regression model.

Proportion Based on the Expenditure's Method Application.

Suppose that $n$ HEIs: $H_{1}, \ldots, H_{n}$; and their expenditures are $e_{1}, \ldots, e_{n}$ respectively. The estimated multiplier for HEI $H_{h}$ for $h=1 \ldots, n$ is estimated as the following (compiled by author).

$$
M_{H_{h}}=\frac{e_{h}}{e_{1}+\ldots+e_{n}} M_{1} .
$$

This method is selected for its simplicity in calculations and interpretation. This method uses the interpolation of data observed by using a related high-frequency indicator - the expenditure of each HEI operating within one country. The process forces the condition that the sum of the interpolated series must be equal to the initial value of all higher education results in an Input-Output table. An expenditure indicator was selected, because the volumes of gross value added in education are calculated according to the expenditure approach. 
Linear Regression for Input-Output Relationship method Application.

The regression model relates the disaggregated series with a set of known high frequency indicators. Two different sets of high frequency data were used:1) Total income, number of students, and full-time equivalent (staff), 2) Income from the government is disaggregated by purpose, income from exports by purpose, and other income, plus the number of students.

Suppose that each HEI has $p$ frequency indicators as following.

- $H_{1}$ has $\left\{x_{11}, \ldots, x_{1 p}\right\}$ as indicators.

- $H_{2}$ has $\left\{x_{21}, \ldots, x_{2 p}\right\}$ as indicators.

- $H_{n}$ has $\left\{x_{n 1}, \ldots, x_{n p}\right\}$ as indicators.

The relationship between the expenditure and the indicators of $H_{h}$ for $h=1$, $\ldots, n$ is estimated as the following formula (compiled by author).

$$
\widehat{e_{h}}=\sum_{k=1}^{p} \beta_{k} x_{h k},
$$

where $\widehat{e_{h}}$ is the estimated value of $e_{h}$-the expenditure of $H_{h}$. The parameters $\beta_{k}$ for $\mathrm{k}=1, \ldots, p$ is estimated such that the following sum of square errors is minimized (compiled by author).

$$
\sum_{h=1}^{n}\left(e_{h}-\widehat{e_{h}}\right)^{2} .
$$

The problem is solved by the ordinary least square method. The results are used to estimate the multiplier of HEI $H_{h}$ for $\mathrm{h}=1, \ldots, n$ as following (compiled by author).

$$
M_{H_{h}}=\frac{\widehat{e_{h}}}{\widehat{e_{1}}+\ldots+\widehat{e_{n}}} M_{1} .
$$

While I-O modelling gives a way of evaluating HEIs in the big picture of the national economy, it is desirable to have a more direct comparison between HEIs' performances or efficiencies. Moreover, the efficiencies of each HEI over years also provides an informative insight into their performances. Section 2.2 will propose a use of Data Envelopment Analysis in the context of HEIs to provide such other views. 


\subsection{Assessing the Efficiency of Higher Education Institutions}

In the preceding sections, the key literature on methodological approaches to economic impact assessment have been presented, discussed, and critiqued. Multiple studies have been conducted, using a myriad of methodological strategies. From a critical perspective, each of the diverse approaches has strengths, weaknesses, and limited applicability. Trade-offs will need to be made between depth of analysis (which is achievable through the single case study approach) and breadth of analysis (which is achievable through the cross sectional and multiple HEI approach). In addition, there are trade-offs between high causal explanatory power (achievable using knowledge production functions) and simplicity of analysis (achievable through the single case study approach). There appears to be no single method that can achieve all positive goals, while minimizing all weaknesses simultaneously.

When evaluating HEIs, the following two quantitative questions are raised.

- How does each HEI impact the national (regional) economy?

- How efficient are they with respect to their given incomes?

A number of methods have been used to assess efficiency in EI. At the basic level, research can be divided into studies that have adopted a non-parametric approach (e.g., Aristovnik, 2013; Haelermans \& De Witte, 2012; Wolszczak-Derlack, 2014) such as Free Disposal Hull (FDH) or Data Envelopment Analysis (DEA) and those that have preferred to make use of a parametric approach such as stochastic frontier analysis (SFA) (Stiglitz \& Rosengard, 2015).

There are benefits and drawbacks to each approach (see Table 2.3).

Arguably, non-parametric methodologies are the most straightforward approach to employ, for they are able to directly assess the linkages between inputs and outputs. In addition, the analyst does not need to make any a priori assumption about the specification of the error term or of the form of the production function (Hjalmarsson et al., 1996). At the same time, however, it is not always possible to determine statistical significance, and estimate bounds are not always estimable. Stochastic approaches do require that the researcher select a single explanatory variable (Hjalmarsson et al., 1996).

However, these methodological approaches enable the integration of contextual variables, such as those relating to the environmental setting of the HEI (Fried et al., 2008). Below, some studies that make use of these methodological approaches are reviewed in greater detail. 
Table 2.3. Different Non-Parametric Efficiency Methods in Evaluating Higher Education Institutions (compiled by author)

\begin{tabular}{|l|l|l|}
\hline Name & Features & Scholars \\
\hline $\begin{array}{l}\text { Data Envelopment } \\
\text { Analysis (DEA) }\end{array}$ & $\begin{array}{l}\text { A linear methodology or a tool } \\
\text { that is used for measuring the ef- } \\
\text { ficiency of multiple decision- } \\
\text { making units }\end{array}$ & $\begin{array}{l}\text { Charnes et al., 1978; } \\
\text { Jamasb \& Pollitt, 2001; } \\
\text { Din \& Cretan, 2005; } \\
\text { Wolszczak-Derlacz, 2014 }\end{array}$ \\
\hline $\begin{array}{l}\text { Ordinary Least } \\
\text { Squares (OLS) }\end{array}$ & $\begin{array}{l}\text { Useful to estimate the unknown } \\
\text { parameters in a linear regression } \\
\text { model. } \\
\text { Statistic technique that bases } \\
\text { comparison relative to an aver- } \\
\text { age producer }\end{array}$ & $\begin{array}{l}\text { Goldberger, 1964; } \\
\text { Hayashi, 2000 }\end{array}$ \\
\hline $\begin{array}{l}\text { Stochastic Frontier } \\
\text { Analysis (SFA) }\end{array}$ & $\begin{array}{l}\text { For economic modelling } \\
\text { Includes component describing } \\
\text { random shocks } \\
\text { Considered as cost / profit effi- } \\
\text { ciency method }\end{array}$ & $\begin{array}{l}\text { Aigner, Lovell, \& Schmidt, } \\
\text { 1977; } \\
\text { Meeusen \& Van den } \\
\text { Broeck, 1977 }\end{array}$ \\
\hline
\end{tabular}

Below the research considers two main models for assessing efficiency: Data Enveloped Analysis and Stochastic Frontier Models. The section will end by offering the second half of the proposed model for arriving at this study's empirical findings.

Stochastic Frontier models, which first emerged and became popular in the late 1970s, are designed to assess the extent to which the institution can accomplish maximum output with minimal inputs (Hjalmarsson et al., 1996). This is a parametric approach to assessing efficiency in education. It is argued that stochastic frontier models consider inefficiencies which occur at the technical level. They also acknowledge that production is oftentimes impacted by random exogenous shocks, which are out of the control of the producers (Johnes \& Johnes, 2013).

This approach involves the estimation of a model in which an envelope curve is fitted through a series of data points. That curve then serves as a benchmark against which the efficiency with which high education institutions transform inputs into outputs can be compared and measured. Johnes and Johnes (2013) provide an illustrative example of the way this approach might be used in practice. The authors employed a stochastic frontier model to explore efficiency in British HEIs over two observed time periods. Their study found that controlling for the various characteristics of HEIs can reduce the variance that is observed in their efficiency. Thus, in contrast to the Cunha and Rocha (2012) study which made 
use of a different methodological approach, Johnes and Johnes' (2013) work suggests that characteristics of the institutions themselves can account for differences in the relative efficiency of HEIs. This emphasizes the very different findings that can be yielded by studies that make use of different methodological approaches.

It is, however, possible to reach somewhat firmer conclusions about the optimal method of evaluation of efficiency in the context of HE. We can then relate these methods to techniques for performing economic impact assessment. Stochastic frontier models are more appropriate for cross sectional methodological approaches because they tend to make use of a sample panel of universities (Hjalmarsson et al., 1996). In addition, a production function is applied that draws on quantitative data pertaining to the relevant inputs and outputs.

There are at least four key strengths of the stochastic frontier approach when applied to assess the efficiency of HEIs. First, stochastic frontier models can consider random errors, while simultaneously estimating the relative sizes of inefficiencies (Johnes \& Johnes, 2013). This may make for a more comprehensive level of analysis. Second, this approach can be used where environmental factors moderate or mediate the relationship between resource inputs and outputs. These environmental or other factors may influence the ability of institutions to act in an efficient manner (Goldstein \& Renault, 2004; Huggins et al., 2012; Johansen \& Arano, 2016). Stochastic frontier models can model the influence of these factors on efficiency. The third major strength of this approach is that it makes use of more conventional methods of statistical analysis, which are known to bolster validity. This includes sensitivity tests, bootstrapping, and resampling methods. Given this, conclusions yielded through stochastic frontier approaches to efficiency analysis might be treated as reliably significant. Finally, the approach can be used to assess for changes in efficiency over time (Hjalmarsson et al., 1996). Furthermore, these changes can be decomposed into their constituent elements, such that the research analyst is able to point to changes in technological efficiencies, scale efficiencies, technical efficiencies, and the like.

This does not, mean that the approach is without limitations. Importantly, stochastic frontier modelling relies upon a priori assumptions about the functional form of the model and the placement of the error term (Hjalmarsson et al., 1996). These assumptions may be inaccurate. Furthermore, it is not possible to use the approach with multiple outcome indicators. This makes it less useful when the researcher is looking at a myriad of different outcomes pertaining to efficiency, such as when the researcher uses a single case study method. The model requires that the researcher 'price' their inputs, but again, this is not always possible, so that the cost function may be inaccurate (Hjalmarsson et al., 1996).

Data Envelopment Analysis (DEA) is just one of the mathematical optimization models that are popular in analysing productive efficiency. DEA is a linear programming method for estimating maximum potential output for a given inputs 
of Decision-making units (DMUs), proposed by Charnes et al. (1978). It has primarily been used in the estimation of efficiency. A key advantage of DEA over other approaches is that it more easily accommodates multiple inputs and multiple outputs, without any assumption on data distribution.

The popularity of this methodological approach grew in the 1980s and 1990s, such that it soon became the fundamental methodological approach to the study of efficiency (Stiglitz \& Rosengard, 2015). As pointed out by Hjalmarsson, Kumbhakar, and Heshmati (1996) in the mid-1990s, "The nonparametric data envelopment analysis (DEA) model has become increasingly popular in the analysis of productive efficiency, and the number of empirical applications is now very large" (p. 303). Even now, however, in the face of competition from alternative approaches, the DEA, non-parametric approach to the analysis of efficiency remains popular (Aristovnik, 2013; Haelermans \& De Witte, 2012; Johnson \& Ruggiero, 2014).

Taking a comparative methodological approach and using a large dataset, Wolszczak-Derlack (2015) (see also Wolszczak-Derlack, 2017) used the approach. Wolszczak-Derlack used a range of different input-output groupings, such as the number of academic staff and administrative staff, total revenue, and total number of graduates. Wolszczak-Derlack also took a dual-frontier approach by examining the full pool and then disaggregating the pool by geographic location. Finally, Wolszczak-Derlack used a bootstrapped, multistage DEA process. In the end, the researcher found that there are differences in the drivers of efficiency according to the geographic location of the institution. More specifically, in Europe, when government investment in education provision increases, so too does the extent to which the institution becomes inefficient. An increase in funds stemming from student tuition fees, on the other hand, helps to improve the efficiency of European HEIs. In the case of institutions based in North America, however, as the share of the HEI's income from tuition fees increases, so too does inefficiency.

A similar empirical approach was employed by Veiderpass and McKelvey (2016). Those researchers also took a broader, comparative approach, making use of a vast dataset. In their case, they assessed the efficiency of HEIs in 17 different European countries. Like the study by Wolszczak-Derlack (2015), the results of this study indicated differences in efficiency, depending upon the geographical location of HEI. For example, HEIs in the Scandinavian countries exhibited a relatively low level of economic efficiency, while HEIs in the Baltic region and Eastern Europe exhibited relatively high levels of productive efficiency. More empirical research is likely necessary to explain these findings. However, Veiderpass and McKelvey's (2016) work does offer some clues as to these findings. Whereas Wolszczak-Derlack $(2015 ; 2017)$ saw funding structure as crucial to the transformation of inputs into efficient outputs, for Veiderpass and McKelvey (2016) the key driving variables are the intensity of the research being undertaken at the HEI and the overall size of the institution. 
Cretan (2015) employed Data Enveloped Analysis (DEA) in order to determine whether and how the changes in public funding patterns in Romania affect the efficiency scores of publicly funded universities. The DEA model was based on two input and three output measures. The input measures were presented through the institutional level of funding allocated by the ministry, and the percentage of public core funding allocated to universities (used as the control variable). Output measures included the total number of graduates, the level of funds gathered for research projects through competitions from international sources, and the amount of revenues obtained from services and product supply. Cretan (2015) focused on the period prior to and following the economic crisis in 2008. The study considered the changes related to the Romanian public funding mechanisms of HE during the years of 2007, 2009, and 2010 compared with the year of 2006. The study used a content analytic methodological strategy, while assessing the relative efficiency scores of each selected publicly-funded HEI. The results and findings of Cretan's (2015) study point to the fact that the efficiency scores of public universities are improved as a result of more oriented funding mechanisms. The findings of the research emphasized that a more performanceoriented funding mechanism improves the efficiency scores of public universities. As the author indicated, "considering all the facts and results, the more quality/ performance oriented is the funding method of public HEIs, the more operational efficient become public universities" (Cretan, 2015).

Din and Cretan (2005) assessed the value of a DEA application in an investigation of the cross-HEI approach. They analysed different input output variables such as efficiency scores, frontier efficiency, a reference set for each inefficient HEI, an efficiency target, and the number of inefficient units for each benchmark. They also outline the main advantages and shortcomings / or limits of the DEA application. As advantages, they highlight its ability to model multiple-input and multiple-output relationships, also its application to different homogenous set of decision-making units such as schools, hospitals, bank branches, or production plants. It can also potentially be used in the calculation of technical efficiency, which is an important precondition for economic efficiency. Additionally, DEA could be useful for regression analysis, through which it can address multiple inputs and multiple outputs simultaneously and not limit their number. Another advantage of Data Enveloped Analysis is that it can consider the source of inefficiency for each unit. However, these authors did point out one of the limitations of the approach: the lack of testing possibility for the best specification of DEA models (Din \& Cretan, 2005).

Cunha and Rocha (2012) also undertook a comparative approach, but within one single national context. This approach may help to reduce the presence of confounding variables emerging at the national level, which are unaccounted for 
in the DEA. Gathering their data from HEIs in Portugal, the investigators disaggregated their sample according to the type of HEI: high status HEIs, public polytechnics, and public universities. The purpose of the research was to identify which of these types of institution was the most technically efficient in order to provide benchmarks for inputs and transformation strategies. Based upon the results of their Data Envelopment Analysis, Cunha and Rocha (2012) argued that, in fact, most institutions, whatever their type, are working in an inefficient manner. Comparing the results of this study with the results obtained in national-comparative investigations, it might be reasonable to argue that there are characteristics associated with Portugal which are contributing to the relative inefficiency of its education institutions.

DEA is also a frontier method, but its strengths and weaknesses are very different compared to stochastic frontier modelling. The key advantage of this approach is that it provides the research analyst with the opportunity to develop a model with multiple inputs and outputs, which facilitates the estimation of efficiency without the need to calculate the parameters of those input or outputs. Similarly, using this approach there is little need to make an a priori choice about the functional form of the production function. Using Data Enveloped Analysis, the researcher is able to estimate the relative contribution of each of the inputs to the overall efficiency or inefficiency of each institution. The relative level of (in)efficiency of each input can also be estimated. This makes the DEA approach particularly useful where the researcher is adopting a cross sectional or comparative methodological approach.

There are some limitations to the approach, however. Importantly, Data Enveloped Analysis rests upon the assumption that it is not possible to estimate the errors in the original data. The outcome of the model is also highly sensitive to the number of observations in the model, and the number of variables included. For example, when the number of variables in the model rises and the number of observations falls, then the number of HEIs that are found to lie at the efficiency frontier will probably rise. This may make the approach unsuitable for studies using large samples.

\subsubsection{Data Envelopment Analysis for Efficiency of Higher Education Institutions}

Each DEA model has a property of being either input - oriented or output- oriented, and either constant returns-to-scale (CRS) or variable returns-to-scale (VRS). Table 2.4 summarizes the descriptions of such properties.

Given those properties, an DEA model has two properties which are:

- orientation: either input- oriented or output- oriented, and

- type of returns to scale: either CRS or VRS. 
Table 2.4. Properties of Data Envelopment Analysis Models (Zhu, 2015)

\begin{tabular}{|l|l|l|}
\hline Property & Description & Example \\
\hline $\begin{array}{l}\text { Input- } \\
\text { oriented }\end{array}$ & $\begin{array}{l}\text { Efficiency score indicates } \\
\text { how much the firm could } \\
\text { contract its input in order to } \\
\text { achieve the same output } \\
\text { level. }\end{array}$ & $\begin{array}{l}\text { An efficiency score of 0.9 means that the } \\
\text { input should be contracted by 10\% and the } \\
\text { output is kept the same in order to achieve } \\
\text { efficiency. }\end{array}$ \\
\hline $\begin{array}{l}\text { Output- } \\
\text { oriented }\end{array}$ & $\begin{array}{l}\text { Efficiency score determines } \\
\text { the firm's potential output } \\
\text { with the current input level. }\end{array}$ & $\begin{array}{l}\text { Efficiency score of } 0.9 \text { means that the cur- } \\
\text { rent output is at the level 90\% of the effi- } \\
\text { cient output, assuming the given input } \\
\text { does not change. }\end{array}$ \\
\hline $\begin{array}{l}\text { Constant } \\
\text { returns- } \\
\text { to-scale }\end{array}$ & $\begin{array}{l}\text { CRS reflects the fact that the } \\
\text { output will proportionally } \\
\text { change as the input change. }\end{array}$ & $\begin{array}{l}\text { The graph of output and input looks like } \\
\text { this }\end{array}$ \\
\hline $\begin{array}{l}\text { Variable } \\
\text { returns- } \\
\text { to-scale }\end{array}$ & $\begin{array}{l}\text { VRS reflects the fact that the } \\
\text { output may exhibit increas- } \\
\text { ing, decreasing, or constant } \\
\text { returns to scale. }\end{array}$ & $\begin{array}{l}\text { The graph of output and input might look } \\
\text { like this. } \\
\text { output } \uparrow\end{array}$ \\
\hline
\end{tabular}

In order to explain those properties, consider a simple example of eight DMUs $\{A, B, C, D, E, F, G, H\}$ each of which has only one input and one output. Pairs of input-output of DMUs are plotted in Figure 2.2.

The differences between a CRS model and a VRS model are as follows (Zhu, 2015).

- In a CRS model, $\mathrm{C}$ will be the best efficient DMU (the angle between the input axis and the line connecting the origin with $\mathrm{C}$ is larger than with other DMUs). As a result, the efficiency score of $\mathrm{C}$ will be maximum 1 and the efficiencies of others are computed relative to that of $\mathrm{C}$. The line 
connecting the origin and $\mathrm{C}$ is the line of efficient DMUs and all DMUs lie on this line are efficient. In this example, only $\mathrm{C}$ is efficient.

- In a VRS model, on the contrary, all the DMUs which lie on the faces of the convex hull of all the DMUs will achieve the maximum efficiencies. Consequently, the efficiencies of inefficient DMUs (not lie on the faces of the convex hull) will be computed relatively to that of efficient ones. The set of faces of the convex hull are called the border of VRS DMUs.

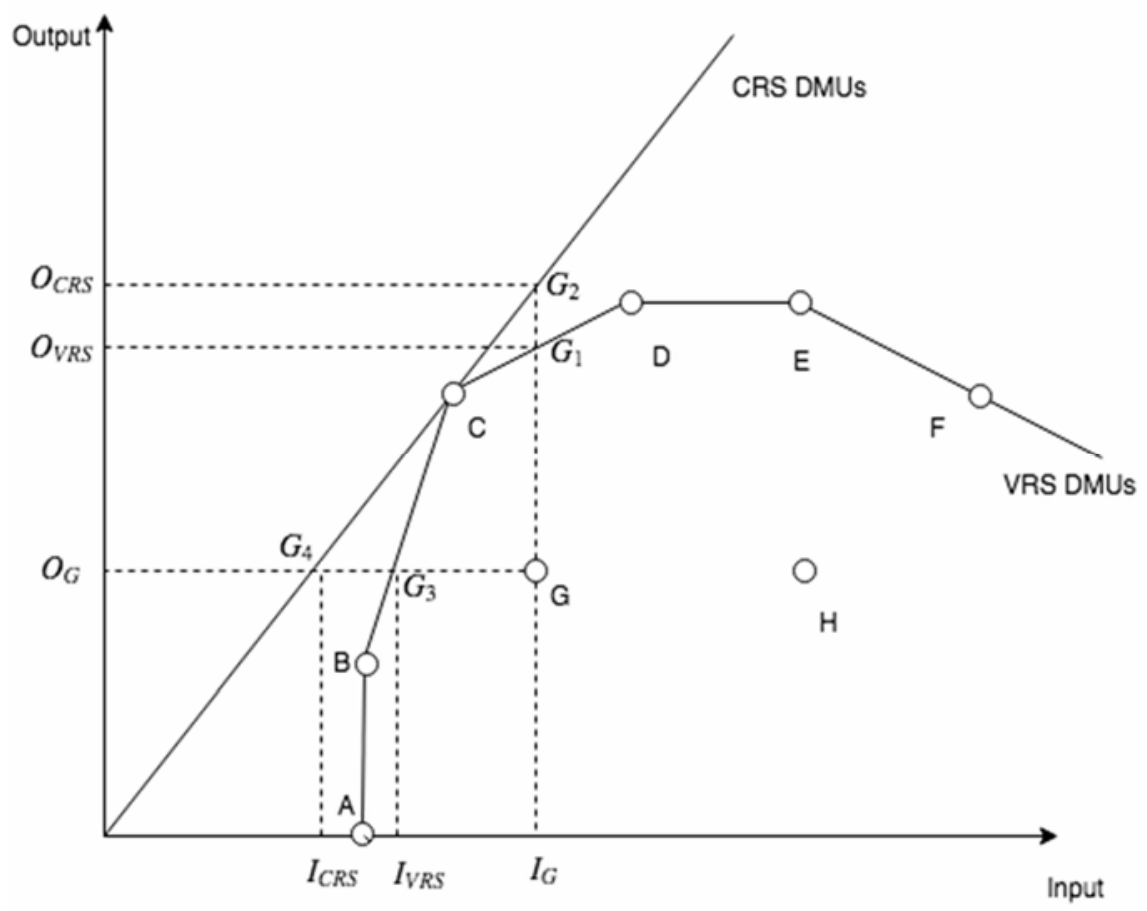

Fig. 2.2. An Example on Input-Orientation, Output-Orientation,

Constant returns-to-scale, and Variable returns-to-scale Models (Zhu, 2015)

Suppose we want to compute the efficiency of $G$ with $I_{G}$ and $O_{G}$ as input and output respectively. Table 2.5 illustrates the efficient point of $G$ and the computation of G's efficiency score in different types of DEA models. While the row of the table shows the returns to scale type of the model, the columns shows the orientation of the model. 
Table 2.5. Efficient Point and Efficiency Score of G in Different Types of Data Envelopment Analysis Model (Zhu, 2015)

\begin{tabular}{|l|l|l|}
\hline & Input-oriented & Output-oriented \\
\hline $\begin{array}{l}\text { Constant } \\
\text { returns- } \\
\text { to-scale }\end{array}$ & Efficient point: $G_{4}$ & Efficient point: $G_{2}$ \\
\hline $\begin{array}{l}\text { Variable } \\
\text { returns- } \\
\text { to-scale }\end{array}$ & Efficiency score: $\frac{I_{C R S}}{I_{G}}$ & Efficiency score: $\frac{O_{G}}{O_{C R S}}$ \\
\hline
\end{tabular}

- In a CRS input- oriented model, we project the point $G$ on the line of CRS DMUs along the input axis, getting the point $G_{4}$ as shown in Figure 2.2 The point $G_{4}$ is consider the efficient point of $G$ in this model and the efficiency score is computed as $\frac{I_{C R S}}{I_{G}}$ where $I_{C R S}$ is the input-axis value of $G_{4}$.

- On the other hand, in a CRS output-oriented model, we project the point $\mathrm{G}$ on the line of CRS DMUs along the output axis, getting the point $G_{2}$ as shown in Figure 2.2.The point $G_{2}$ is consider the efficient point of $G$ in this model and the efficiency score is computed as $\frac{O_{G}}{O_{C R S}}$ where $O_{C R S}$ is the input-axis value of $G_{2}$.

- In a VRS input-oriented model, we project the point $G$ on the border of VRS DMUs along the input axis, getting the point $G_{3}$ as shown in Figure 2.2. The point $G_{3}$ is consider the efficient point of $G$ in this model and the efficiency score is computed as $\frac{I_{V R S}}{I_{G}}$ where $I_{V R S}$ is the inputaxis value of $G_{3}$.

- In contrast, in a VRS output-oriented model, we project the point $\mathrm{G}$ on the border of VRS DMUs along the output axis, getting the point $G_{1}$ as shown in Figure 2.2. The point $G_{1}$ is consider the efficient point of $G$ in 
this model and the efficiency score is computed as $\frac{O_{G}}{O_{V R S}}$ where $O_{V R S}$ is the input-axis value of $G_{1}$.

Generally, as the input cannot be reduced, the input-orientated DEA approach is less relevant in the estimation of capacity utilization, while people often utilize output-orientation models to evaluate the DMUs. Throughout this section, we will focus on output-oriented models to evaluate DMUs.

\subsubsection{Cross-Efficiency Evaluation in Data Envelopment Analysis}

We assume a set $\left\{H_{1}, H_{2}, \ldots, H_{n}\right\}$ of $\mathrm{n}$ HEIs as the set of decision-making units. Each $H_{h}$ has $s$ different outputs $y_{h}=\left(y_{1 h}, y_{2 h}, \ldots, y_{s h}\right)$ and $m$ different inputs $x_{h}=\left(x_{1 h}, x_{2 h}, \ldots, x_{m h}\right)$. Cross efficiency is generally presented as a two-stage process, namely self-evaluation and cross efficiency, for every pair of HEIs.

\section{Stage 1: Self-evaluation}

Suppose $H_{h}$ is under evaluation by the CRS model. Its efficiency score is the optimal value of the following optimization problem (Zhu, 2015).

$$
\begin{gathered}
\min E_{h h}=\frac{\left(v_{h}\right)^{T} x_{h}}{\left(u_{h}\right)^{T} y_{h}} ; \\
\text { s.t. } \quad E_{h j}=\frac{\left(v_{h}\right)^{T} x_{j}}{\left(u_{h}\right)^{T} y_{j}} \geq 1, \quad j=1, \ldots, n, u_{h} \geq 0, v_{h} \geq 0,
\end{gathered}
$$

where $u_{h}=\left(u_{1 h}, u_{2 h}, \ldots, u_{s h}\right)$ and $v_{h}=\left(v_{1 h}, v_{2 h}, \ldots, v_{m h}\right)$ represents the output and input weights for $H_{h}$. Since the above optimization model is a non-linear one, it is usually solved in the equivalent multiplier model (Zhu, 2015).

$$
\begin{gathered}
\min E_{h h}=\left(v_{h}\right)^{T} x_{h} ; \\
\text { s.t. } \quad\left(u_{h}\right)^{T} y_{h}=1 ; \\
\left(v_{h}\right)^{T} \mathrm{x}_{\mathrm{j}}-\left(u_{h}\right)^{T} y_{j} \geq 0, \quad j=1, \ldots, n ; \\
u_{h} \geq 0, v_{h} \geq 0 .
\end{gathered}
$$


By duality of linear programming, the model (2.19) results in the following envelopment form (Charneset al., 1978).

$$
\max \theta_{h} \text { s.t. }-\theta_{h} y_{h}+Y \lambda_{h} \geq 0 x_{h}-X \lambda_{h} \geq 0 \theta_{h} \text { free, } \lambda_{h} \geq 0,
$$

where

$$
\begin{gathered}
\mathbf{X}=\left[\begin{array}{ccc}
x_{11} & \cdots & x_{1 n} \\
\vdots & \ddots & \vdots \\
x_{m 1} & \cdots & x_{m n}
\end{array}\right] ; \\
\mathbf{Y}=\left[\begin{array}{ccc}
x_{11} & \cdots & x_{1 n} \\
\vdots & \ddots & \vdots \\
x_{s 1} & \cdots & x_{s n}
\end{array}\right] ; \\
\lambda_{h}=\left(\lambda_{1 h}, \ldots, \lambda_{n h}\right) ; \\
\theta_{h} \in R .
\end{gathered}
$$

From the optimal solution of (2.20), we can construct the optimal solution of (2.19) (Charnes et al., 1978).

Here the efficiency of the $H_{h}$ is computed by the CRS model (Charnes et al., 1978). Another common model for computing efficiency is called the Variable Returns-to-scale model, in which inputs are minimized and the output are kept at the current levels (Banker et al., 1984).

$$
\begin{gathered}
\max \theta_{h} \text { s.t. }-\theta_{h} y_{h}+Y \lambda_{h} \geq 0 ; \\
x_{h}-X \lambda_{h} \geq 0 ; \\
1^{T} \lambda_{h}=1 \theta_{h} \text { free, } \lambda_{h} \geq 0 .
\end{gathered}
$$

Stage 2: Cross efficiency score of each Higher Education Institution

After having the individual efficiency score for each HEI, we compute the cross efficiency of $H_{j}$, using the weights that $H_{h}$ has chosen in model Figure 2.2., which is given by (Banker et al., 1984)

$$
E_{h j}=\frac{\left(v^{\prime}{ }_{h}\right)^{T} x_{j}}{\left(u_{h}^{\prime}\right)^{T} y_{j}},
$$


where $u_{h}{ }_{h}$ and $v^{\prime}{ }_{h}$ are optimal solutions in model Figure 2.2. The cross-efficiency score of $H_{j}$ is computed as the average of all $E_{h j}$ for $h=1,2, \ldots, n$ as follow (Banker et al., 1984).

$$
\overline{E_{j}}=\frac{1}{n} \sum_{h=1}^{n} E_{h j} .
$$

Identification the scope of the assessment. The number of inputs and outputs and the DMUs determine the variation between efficient and inefficient units. There are two conflicting considerations concerning the size of the data set.

- One approach is to include as many DMUs as possible, with the motivation that a larger population will guarantee a greater probability of capturing high performance units. As a result, this would strongly discriminate against the efficient and inefficient units.

- The other conflicting consideration is that the homogeneity of the data set may decrease. That means that impacts of no interest to the analyst or beyond the control of the manager may affect the results (Golany \& Roll, 1989).

There are some rules of thumb on the number of inputs and outputs to select and their relation to the number of DMUs. While Golany and Roll (1989) establish that the number of inputs and outputs considered should be at most half of the number of units, Bowlin (1998) remarks on the need to have three times the number of DMUs as there are input and output variables. Table 2.6 presents examples of these recommendations on the size of the dataset.

Table 2.6. Examples of Recommendations about Dataset Size (compiled by author)

\begin{tabular}{|l|c|c|l|}
\hline Authors & $\begin{array}{l}\text { Number of } \\
\text { inputs }\end{array}$ & $\begin{array}{l}\text { Number of } \\
\text { outputs }\end{array}$ & Number of units \\
\hline Golany and Roll (1989) & 3 & 4 & At least 12 \\
\hline Bowlin (1998) & 3 & 4 & 21 \\
\hline Dyson et al. (2001) & 3 & 4 & At least 24 \\
\hline
\end{tabular}

Dyson et al. (2001) recommend the number of units to be at least two times the product of the number of input and output variables. The example assumes that each DMU has 3 inputs and 4 outputs.

\subsubsection{Dynamic Data Envelopment Analysis}

While the cross-efficiency score provides a measure for ranking HEIs, it may be necessary to consider the trend in efficiency of each HEI over years. This section 
views each HEI-year pair as a separate decision-making unit, thus allowing for intertemporal comparisons. This allows for learning more about the dynamics of efficiency estimates across and within each HEI.

Let $x_{h}^{t}$ and $y_{h}^{t}$ be the input and output respectively of the HEI $H_{h}$ in the period $t$ for $t=1 \ldots, l$. For judging the performance trend over the periods $t=1 \ldots$, $l$ we consider l DMUs as illustrated in Table 2.7.

Table 2.7. Explanation of inputs and outputs of 1 Decision Making Units Over the Periods $1, l$ with each $H_{h}$ (Zhu, 2015)

\begin{tabular}{|c|c|c|l|}
\hline DMU & Input & Output & Description \\
\hline$H_{h}^{1}$ & $x_{h}^{1}=\left(x_{1 h}^{1}, x_{2 h}^{1}, \ldots, x_{m h}^{1}\right)$ & $y_{h}^{1}=\left(y_{1 h}^{1}, y_{2 h}^{1}, \ldots, y_{s h}^{1}\right)$ & $\begin{array}{l}\text { The HEI } H_{h} \text { along with } \\
\text { its inputs and outputs in } \\
\text { the } 1^{\text {st }} \text { period. }\end{array}$ \\
\hline$\vdots$ & $\vdots$ & $\vdots$ & $\vdots$ \\
\hline$H_{h}^{t}$ & $x_{h}^{t}=\left(x_{1 h}^{t}, x_{2 h}^{t}, \ldots, x_{m h}^{t}\right)$ & $y_{h}^{t}=\left(y_{1 h}^{t}, y_{2 h}^{t}, \ldots, y_{s h}^{t}\right)$ & $\begin{array}{l}\text { The HEI } H_{h} \text { along with } \\
\text { its inputs and outputs in } \\
\text { the } t^{\text {th }} \text { period. }\end{array}$ \\
\hline$\vdots$ & $\vdots$ & $\vdots$ & $\vdots$ \\
\hline$H_{h}^{l}$ & $x_{h}^{l}=\left(x_{1 h}^{l}, x_{2 h}^{l}, \ldots, x_{m h}^{l}\right)$ & $y_{h}^{l}=\left(y_{1 h}^{l}, y_{2 h}^{l}, \ldots, y_{s h}^{l}\right)$ & $\begin{array}{l}\text { The HEI } H_{h} \text { along with } \\
\text { its inputs and outputs in } \\
\text { the } \mathrm{l}^{\text {th }} \text { period. }\end{array}$ \\
\hline
\end{tabular}

Similar to the previous section, the cross-efficiency score for each of those DMUs is computed through two stages.

\section{Stage 1: Self-evaluation}

Suppose $H_{h}^{t}$ is under evaluation by the CRS model. Its efficiency score is the optimal value of the following optimization problem (Zhu, 2015).

$$
\begin{gathered}
\min E_{h}^{t t}=\frac{\left(v_{h}^{t}\right)^{T} x_{h}^{t}}{\left(u_{h}^{t}\right)^{T} y_{h}^{t}} ; \\
\text { s.t. } E_{h}^{t w}=\frac{\left(v_{h}^{t}\right)^{T} x_{h}^{w}}{\left(u_{h}^{t}\right)^{T} y_{h}^{w}} \geq 1, w=1, \ldots, l . u_{h}^{t} \geq 0 ;
\end{gathered}
$$




$$
v_{h}^{t} \geq 0,
$$

where $u_{h}^{t}=\left(u_{1 h}^{t}, u_{2 h}^{t}, \ldots, u_{s h}^{t}\right)$ and $v_{h}^{t}=\left(v_{1 h}^{t}, v_{2 h}^{t}, \ldots, v_{m h}^{t}\right)$ represents the output and input weights for $H_{h}$. Because of the first constraint, this model constrained the efficiency score to be between 0 and 1 .

Since the above optimization model is a non-linear one, it is usually solved in the equivalent multiplier model (Zhu, 2015).

$$
\begin{gathered}
\min E_{h}^{t t}=\left(v_{h}^{t}\right)^{T} x_{h}^{t} ; \\
\text { s.t. }\left(u_{h}^{t}\right)^{T} y_{h}^{t}=1\left(v_{h}^{t}\right)^{T} x_{h}^{w}-\left(u_{h}^{t}\right)^{T} y_{h}^{w} \geq 0, \quad w=1, \ldots, l ; \\
u_{h}^{t} \geq 0 ; \\
u_{h}^{t} \geq 0 .
\end{gathered}
$$

Through duality of linear programming, the model (2.25) results in the following envelopment form (Charneset al., 1978).

$$
\max \theta_{h}^{t} \text { s.t. }-\theta_{h}^{t} y_{h}^{t}+Y_{h} \lambda_{h}^{t} \geq 0 ; x_{h}^{t}-X_{h} \lambda_{h}^{t} \geq 0 ; \theta_{h}^{t} \text { free, } \lambda_{h}^{t} \geq 0 ;
$$

where

$$
\begin{gathered}
X_{h}=\left[\begin{array}{ccc}
x_{11}^{1} & \cdots & x_{1 n}^{l} \\
\vdots & \ddots & \vdots \\
x_{m 1}^{1} & \cdots & x_{m n}^{l}
\end{array}\right] ; \\
Y_{h}=\left[\begin{array}{ccc}
y_{11}^{1} & \cdots & y_{1 n}^{l} \\
\vdots & \ddots & \vdots \\
y_{s 1}^{1} & \cdots & y_{s n}^{l}
\end{array}\right] ; \\
\lambda_{\mathrm{h}}^{\mathrm{t}}=\left(\lambda_{1 h}^{t}, \ldots, \lambda_{n h}^{t}\right) ; \\
\theta_{h}^{t} \in R .
\end{gathered}
$$

From the optimal solution of (2.26), we can construct the optimal solution of (2.25) (Charnes et al., 1978). Here the efficiency of the $H_{h}$ is computed by the CRS model (Charnes et al., 1978). Another common model for computing efficiency is called the Variable Returns-to-Scale model, in which inputs are minimized and the output are kept at the current levels (Banker et al., 1984). 


$$
\begin{gathered}
\max \theta_{h}^{t} \text { s.t. } \quad-\theta_{h}^{t} y_{h}^{t}+Y_{h} \lambda_{h}^{t} \geq 0 ; x_{h}^{t}-X_{h} \lambda_{h}^{t} \geq 0 ; \\
1^{T} \lambda_{h}^{t}=1 ; \theta_{h}^{t} \text { free, } \lambda_{h}^{t} \geq 0 .
\end{gathered}
$$

Stage 2: Cross efficiency score of each Higher Education Institution in one period After having the individual efficiency score for each HEI in one period, we compute the cross efficiency of $H_{h}^{w}$, using the weights that $H_{h}^{t}$ has chosen in model (2.25), which is given by

$$
E_{h}^{t w}=\frac{\left(u_{h}^{t}{ }^{\prime}\right)^{T} y_{h}^{w}}{\left(v_{h}^{t}{ }^{\prime}\right)^{T} x_{h}^{w}},
$$

where $u_{h}^{t}$ ' and $v_{h}^{t}$ ' are optimal solutions in model (2.25). The cross-efficiency score of $H_{h}^{w}$ is computed as the average of all $E_{h}^{t w}$ for $w=1 \ldots, l$ as following

$$
\overline{E_{h}^{w}}=\frac{1}{l} \sum_{w=1}^{l} E_{h}^{t w} .
$$

Identification the scope of the assessment. Similar to the suggestions for cross efficiency between HEIs, the same rules of thumb are applied here on the number of inputs, outputs, and the number of periods. Table 2.8 gives an example of suggested number of inputs and outputs by various authors.

In the previous section, two approaches to evaluate performances of HEIs in either the national economy or in comparison with each other/themselves through time were reviewed. The next section is going to propose a combination of two such approaches, so that we can have a more insightful view about the performance of HEIs.

Table 2.8. Examples of Recommendations about the Dataset Size of Dynamic Evaluation (compiled by author)

\begin{tabular}{|l|c|c|l|}
\hline Authors & $\begin{array}{l}\text { Number of } \\
\text { inputs }\end{array}$ & $\begin{array}{l}\text { Number of } \\
\text { outputs }\end{array}$ & Number of periods \\
\hline Golany \& Roll (1989) & 3 & 4 & At least 12 \\
\hline Bowlin (1998) & 3 & 4 & 21 \\
\hline Dyson et al. (2001) & 3 & 4 & At least 24 \\
\hline
\end{tabular}


This chapter first introduced two methods for evaluating economic impact of HEIs (I-O model) and assessing HEIs efficiencies (DEA model). The summary of the contents is as following.

1. From the I-O table of the national economy, the sectors are classified following the standard of Nace 2 classification. The Input-Output table for the new groups is aggregated from the original table. After that, the standard I-O analyses outputs to the multiplier for HEIs sector, which is interpreted as the economic impact of that sector. Given the economic impact of the HE sector, the impacts of individual HEIs are estimated based on their expenditures and their incomes.

2. From the given incomes and the outcomes of HEIs over several periods, the DEA model is employed to evaluate their efficiencies in two ways: efficiencies between HEIs and efficiencies of each HEI between different periods. It should be noted that these efficiencies are relative, where we consider a set of DMUs and try to figure out which ones are efficient and compute the efficiency scores of others based on the efficient ones.

3. The economic impact of HEIs is further considered to be an output in the DEA model. While the output of the I-O model makes the DEA analysis more detailed, insightful, and practical, the results of the DEA model further gives feedback to HEIs to improve their economic impacts. The combination is simple but clearly introduces a new view of analysing performances of HEIs.

\subsection{Proposing a Model to Address Economic Impact and Efficiency of Higher Education Institutions}

In the literature, while questions about impact can be answered by using the I-O model, questions about efficiency can be answered by the DEA model. In an I-O model, each HEI is considered as a separate sector in the whole economy. Then the monetary flow is constructed and the economic impact for each sector (thus each HEI) is computed. In a DEA model, the relative efficiencies of HEIs are computed either among HEIs, where each HEI is considered as a DMU, or among different periods of each HEI, where each pair of HEI and a time period is considered as a DMU.

The I-O and DEA methods are complementary, reflecting different aspects of evaluations for HEIs. There have been few attempts to bridge the gap between those two research fields (Zofío, 2007). In contrast to attempts where the authors employ the DEA method to the data in the I-O table (Charnes et al., 1978; Din \& 
Cretan, 2005; Jamasb \& Pollitt, 2001; Wolszczak-Derlacz, 2014), this chapter proposes another way. In this simple yet practical combination, the output of the I-O model is used inside the DEA model. Furthermore, in the first step of utilizing the I-O table analysis to compute the economic impact of each HEI, instead of disaggregating monetary flow for each HEI in relation with other economic sectors and then applying the I-O analysis, the author proposes a novel method. In the author's method, the economic impact of each HEI is disaggregated from the multiplier of the whole HEIs sector using linear regression. While the details of each method and the combination are given in the next sections of this chapter, this section briefly overviews general picture of the combination. Figure 2.3 presents the structure of the combination to evaluate performances of HEIs, providing intelligent insights for strategic policies. Strategic policies further adjust the data of the four steps, which are illustrated as arrows between the top box and the step in the figure. The four steps of evaluating HEIs are summarized as follows:

1. Aggregate Input-Output table. In this phase, the I-O table representing the monetary flow between economic sectors is collected. After classifying economic sectors into several groups, each group is considered as a separate economic sector. Their monetary flow is aggregated from the original table, resulting in an aggregated I-O table.

2. Economic impact of HE sector. Following the I-O model method, Leontief inverse matrix is computed and the economic impacts of sectors, including HE, is estimated.

3. Disaggregate economic impacts for individual HEIs. The computed impacts of the HE sector is used to disaggregate the impacts of individual HEIs. Two methods are proposed, using proportion of expenditures and regression.

4. Efficiencies assessment. The economic impacts, along with other collected input and output data of HEIs, are passed to the DEA model to assess the efficiencies of HEIs. As mentioned before, these efficiencies are relative and there are two views to evaluate the efficiencies: to evaluate between HEIs or to evaluate each HEI but in different periods.

It is clear from Figure 2.3 that the proposed framework forms a loop, where policy changes affect the data (the financial flow, the input and output of economic sectors), then the analysis is taken to evaluate the HEIs quantitatively. Then the analysis results again affect the policies by guiding the policy makers on the ways to improve performances of HEIs. The novelty of this framework is the combination of two quantitative measures in a unified framework, which allows the analysis to be more insightful and practical. 


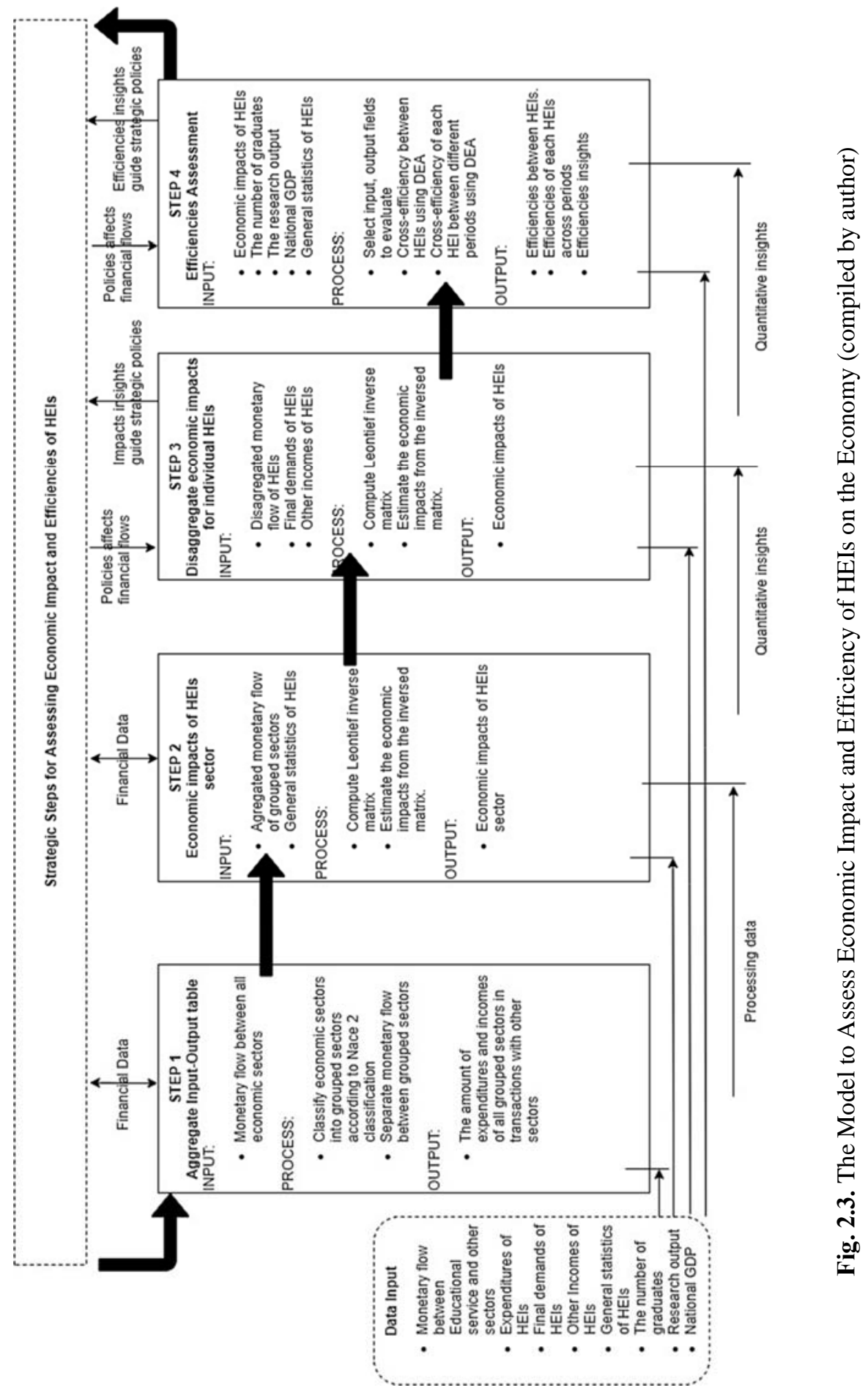


The quantitative measure is provided by the Input-Output model, in which first all the HEIs are considered as a separate sector of the economy and their overall economic impacts is evaluated. Then, disaggregation methods are employed to infer the impacts of each individual HEI. Intuitively, the economic impact of a sector estimates how much the whole economic output will change with respect to a unit change in final demand for such a sector. In another perspective, the quantitative measure provided by the DEA model suggests the amount of change to apply in the input or output of an HEI so that such a HEI can achieve the ideal performance. The novelty of this framework lies in using economic impacts computed by the Input-Output table model inside the DEA models to gain practical and insightful views of the performances of HEIs. The framework contributes a new attempt to connect two complementary areas of research in performance analysis.

\subsection{Incorporating Results in the Higher Education Institutions Assessment Framework}

While the I-O model provides an estimate for the impact of each HEI on the national economy, the DEA model provides guidance for improving efficiency to each HEI. Thus, a simple yet practical combination of these two complementary fields of research was introduced. This combination bridges the gap by including the advantages provided by each model, resulting in more practical guidance for HEIs to improve their efficiency and/or economic impacts.

The output multiplier of the I-O model can be an output of the corresponding HEI in the DEA model.

1. This comes from the following two points of view. First, the I-O model prepares a more practical output than the DEA model, as the multipliers reflect the economic impacts on the national economy.

2. Second, the DEA analysis gives feedback to each HEI on its economic impact, so that they make strategic adjustments in order to be more efficient.

First, the data input (resource flows between economic sectors) are processed so that the Input-Output table is created, in which the HEIs are considered as a separate sector in the economy (the idea of combination is illustrated in Figure 2.4). The second step involves quantitative analysis, where the economic impact of the whole HEIs sector is computed. Such an impact is then disaggregated into the impacts of individual HEIs with metrics for ranking the economic impact of each HEI. 


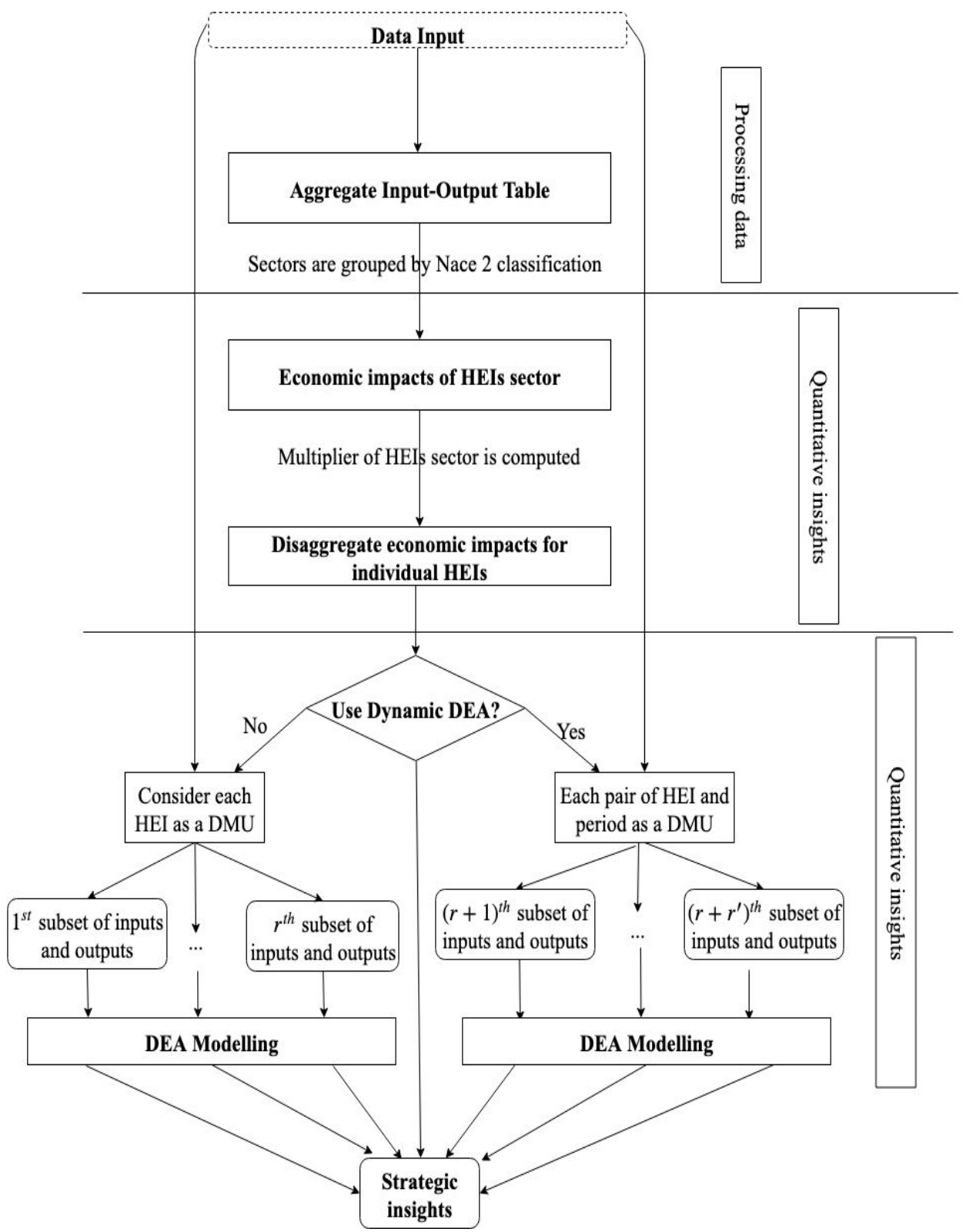

Fig. 2.4. Algorithm of Economic Impact and Efficiency Assessment of Higher Education Institutions (compiled by the author) 
Thirdly, two DEA methods non-dynamic and dynamic, are employed to assess the efficiencies of HEIs from different perspectives. The non-dynamic one compares all the HEIs to find the most efficient HEI and scores the others based on most efficient HEI. On the other hand, the dynamic scheme compares individual HEIs throughout different points of time to find the time at which the HEI is the most efficient. It also scores the other time points based on the time. By having the assessment scores, strategy makers can know by how much each HEI can increase their current output or decrease their current input in order to achieve their optimal efficiencies.

As mentioned above, the I-O model and DEA models both quantitatively evaluates HEIs. The I-O model estimates how much the whole economic output will change, with respect to a unit change in final demand for HEIs. On the other hand, depending on type (input-oriented or output-oriented), a DEA model suggests how much of a change in the input or output of a HEI should be applied, so that each HEI can achieve the ideal performance (See Table 2.4 for a more detailed explanation). The purpose of using the economic impacts inside the DEA models is that the DEA models will give feedback to HEIs on improvements to achieve the maximum economic impact. The analysis is thus very insightful and practical, providing valuable strategic insights about performances and efficiencies of HEIs.

It should be noted that, although both the I-O model and the DEA model use the terms "Input" and "Output", the meaning is different as illustrated in Table 2.9.

Table 2.9. Difference in Input, Output Terms Used in the I-O and DEA models (Zhu, 2015)

\begin{tabular}{|l|l|l|}
\hline Model & Input & Output \\
\hline I-O Model & $\begin{array}{l}\text { Expenditures such as compen- } \\
\text { sation of employees, product } \\
\text { taxes less subsidies, etc. }\end{array}$ & $\begin{array}{l}\text { Income such as the amount of } \\
\text { funds received, tuition fees, etc. }\end{array}$ \\
\hline DEA Model & $\begin{array}{l}\text { Income such as the amount of } \\
\text { funds received, tuition fees etc.. }\end{array}$ & $\begin{array}{l}\text { Outcome such as the number of } \\
\text { graduates, the number of pub- } \\
\text { lished papers, etc. }\end{array}$ \\
\hline
\end{tabular}

While the output of the I-O model is considered as the input in the case of the DEA model, the input of the I-O model is represented by expenditures and the output of the DEA model is represented by the outcomes of the HEIs.

The I-O model provides multipliers as one more informative measure (output) for evaluating efficiencies of HEIs. While the normal output types, such as the number of graduates or the weighted points for scientific work, essentially reflect the quality of an HEI, the economic impact (multiplier) on the national 
economy adds a stronger practical output, resulting in a more detailed and insightful evaluation of HEIs' efficiencies.

As analysed in the previous sections, the DEA model provides guidance to each HEI for optimizing its performance by either reducing the input (and keeping the current level of output) or increasing the output (and keeping the current level of input) in order to achieve an efficient point. By considering the multiplier from the I-O model as an output in the DEA model, the DEA analysis answers the following two practical questions.

- How much of the income (such as received funds) can a HEI reduce while still being able to keep the current level of economic impact (I-O multiplier)? This question is answered by the input-oriented DEA model.

- How much can an HEI increase its economic impact while keeping the same level of income? This question is answered by the output-oriented DEA model.

Figure 2.5 illustrates that the DEA would give feedback that $H_{1}$ should have the economic impact of $\mathrm{M}_{1 \mathrm{O}}$ in order to achieve the efficiency.

In conclusion, considering the multipliers that result from the I-O model as one of the outputs in the DEA model provides a more practical, detailed, and insightful analysis into the efficiency of the HEIs. The result of the analysis further provides a guidance for strategic policy for HEIs so that they can improve general efficiencies, as well as their impact on the national economy.

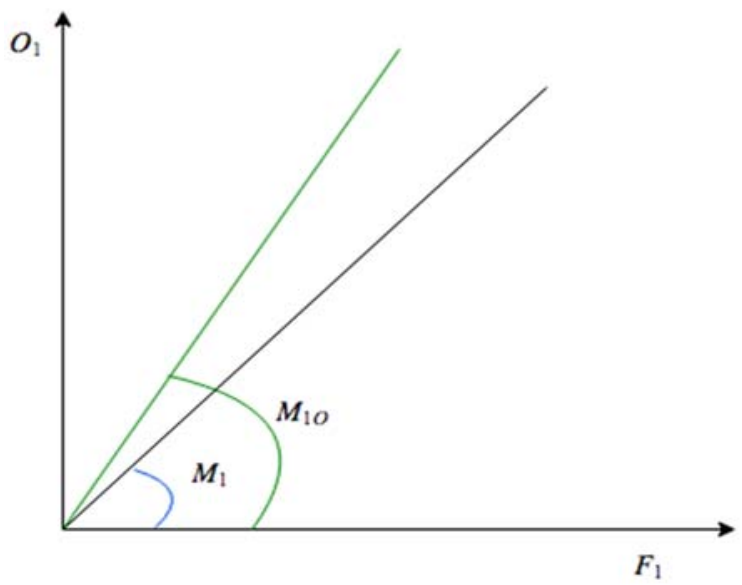

Fig. 2.5. The Data Envelopment Analysis model gives feedback to $H_{1}$ (Zhu,2015)

To summarize, then, different methods of economic impact assessment have different strengths and weaknesses, and no single method achieves all aims. The 
two major approaches to economic efficiency evaluation that have been analysed - Data Enveloped Analysis and Stochastic Frontier Analysis - each have major strengths, making them suitable for use alongside certain methodological techniques and strategies. DEA is useful for larger datasets with few errors, while Stochastic Frontier Analysis is best suited where the researcher is evaluating a single input and wishes to model the influence of different variables upon the efficiency of HEIs. The next section draws overall conclusions based upon these observations and formulates the further steps of the dissertation.

\subsection{Conclusions of Chapter 2}

In order to create a more practical analysis of the economic effects of HEIs the further methodological steps were defined:

1. From the I-O table of the national economy, the sectors are classified following the standard of Nace 2 classification. The Input-Output table for the new groups is aggregated from the original table. After that, the standard I-O analysis helps to find the multiplier for HEIs sector which is interpreted as the economic impact of that sector. Given the economic impact of the HEIs sector, the impacts of individual HEIs is estimated based on their expenditures and their incomes.

2. From the given incomes and the outcomes of HEIs over several periods, the DEA model is employed to evaluate their efficiencies in two perspectives: efficiencies between HEIs and efficiencies of each HEI between different periods. It should be noted that these efficiencies are relative where we considered a set of DMUs and try to figure out which ones are efficient and compute the efficiency scores of others based on those efficient ones.

3. The economic impact of HEIs is further considered to be an output in the DEA model. While the output of the I-O model makes the DEA analysis more detailed, insightful, and practical; the results of the DEA method further gives feedback to HEIs to improve their economic impacts. The created model introduces a unique implementation of the two complementary methods (I-O and DEA) within an integrated model for analyzing economic effects of HEIs. Below the study moves to showing the use of the model in the context of the Lithuanian Higher Education sector (particularly - public universities). 


\section{Assessing Economic Impact and Efficiency of Higher Education Institutions}

In this chapter, the impact of public universities (that collects the biggest part of public funds) on Lithuanian economy and its dynamic efficiency level over a temporal and spatial scale are tested. In the context of this empirical study public universities are considered as HEIs and vice versa.

The Lithuanian educational climate is undergoing massive change in many areas in recent years. Currently, the Lithuanian HE system is undergoing drastic structural and strategic changes, resulting in the merging of the 14 existing public universities into nine larger universities. The methodology carried out in this study can help to replicate findings to suggest the output multiplier effect or modelling to predict the outcomes associated with the consolidated public universities. This would allow analysis of their effect on the economy in order to determine whether the new composition of the public universities will contribute further improvements to the economy, or potentially even negatively impact the economy. The study's methodology is important since this kind of restructuring is inevitable in order to meet the contemporary demands and requirements of the education sector.

These changes could be exacerbated by the exceptionally diverse realm of HE system. Each year, the number of students entering the Lithuanian HE system 
is shrinking. An institutional framework is being considered to reform the HEI system. These proposed reforms provide enough reason to investigate the impacts of all Lithuanian public universities within a single consolidated framework making use of the advantages of the DEA portion of the model.

Based on the latest data from OECD (2017) on tertiary education, the main issues faced by HEIs in Lithuania are:

- Despite having one of the highest participation levels in tertiary education in the world (OECD, 2017), the education system is facing serious challenges. There are many small institutions which fail to reach the efficiency and quality required to compete internationally. This is because the funds, issued by the state, are insufficient compared to that of funds issued to larger institutions by their respective states in our immediate surrounding areas. Therefore, the situation in these countries are better than that of ours. With less outreach and a decline in public's trust over these institutions have deteriorated the reputation of these HEIs in the country.

- Lithuania's funding of both public and private tertiary institutions is close to international benchmarks and reaches the OECD average (OECD, 2017). However, the inefficient use of these resources has led a low standard of education with research efficiency. The country's universities have failed to reach a satisfactory level of performance in research and development compared to that of universities in foreign countries.

Lithuania faces challenges in the consolidation of its tertiary education. The resolution of these problems would allow HEIs to increase the efficiency of public resources used in HEIs. Education reforms would also facilitate the implementation of changes that would help them to compete well in international environment. This is desired because:

- Without migration of qualified and experienced academic personnel and students, the quality of education in these HEIs is diminishing.

- Low number of students in HEIs results in inefficiency of human resources (lecturers, workers and surrounding communities) and physical resources (financial resources and raw materials).

- Low student enrolment poses a threat to the quality of instructional programs, with less qualified academic personnel. The course offerings decrease in value and peer to peer learning which has exaggerated the situation in these HEIs. As a result, fewer students and academic personnel are attracted to the state's institutions, which further reduces the quality of education obtained. 
- The small-sized institutions have limited access to the research infrastructure, researchers, and facilities. This is one of the major hurdles of these HEIs to perform well in scientific research at an international level.

To conclude, various factors offer reason to investigate the impact of HEIs on the Lithuanian economy. These institutions are not working as per international standards and demands. Large number of students is looking up the better career and educational opportunities in the overseas. The HE system is undergoing infrastructure reforms because of increasing doubt of public over the performance of these institutions. Therefore, there is a need for a single consolidated framework is used to investigate the impacts of all Lithuanian HEIs in the education sector as per international standards. Prior to this, no one has tried to calculate the economic impact of HEIs in Lithuania independently of each other, nor as a modelled industry. There is also a lack of effort to estimate the efficiency scores of these HEIs in economic terms which is also incorporated in this research work. In the following section, this study offers an approach that accounts for both factors in the Lithuanian Higher Education sector.

The findings of Chapter 3 have been published in 2 papers (Vaiciukevičiūtè, Stankevičienè, Bračikovienè 2019; Stankevičienė, Kraujalienè, Vaiciukevičiūtė 2017).

\subsection{Model Application Guidelines}

Here, empirical research on public universities in Lithuania was conducted to better analyse the data with statistical tools and infer the results about the proposed hypothesis. The Input-Output (I-O) and Data Envelopment Analysis (DEA) models from Chapter 2 have been used, which includes the small, large classical research institutions, and highly specialized public universities to make the research outcome more rigour and comprehensive. The sample of public universities includes the majority of HE attendees, i.e. 87\% of the country's HE students.

There are various reasons for investigating the impact of public universities on the Lithuanian economy. A wide network of these public universities has developed in the economy. However, not all the time public universities are working as per international standards and demands. Large number of students are pursuing better career and educational opportunities overseas. The HE system is undergoing infrastructure reforms because of increasing doubt of public over the performance of these institutions.

Therefore, there is a need for a single consolidated framework to investigate the impacts of all Lithuanian public universities in the education sector as per international standards. Prior to this, no one has tried to calculate the economic impact of public universities in Lithuania independently of each other, nor as a 
modelled industry. There is also a lack of effort to estimate the efficiency scores of these public universities in economic terms, which is also incorporated in this research work. The model presented below is one of the key contributions of this thesis.

This section describes the application of the suggested model in Lithuania with core influential factors. This assessment could also be made using a longitudinal approach to indicate the impact of changes to the economy together with efficiency level of public universities over the period. The detailed application guidance of the model is given in Table 3.1.

Table 3.1. Model Application Guidance (compiled by author)

\begin{tabular}{|c|c|c|}
\hline Implementation & Process Sequence & \\
\hline Data Collection & $\begin{array}{l}\text { Data is collected from several rel } \\
\text { such as the Official Statistics Por } \\
\text { cial Activities Reports (OFAR), } \\
\text { ters, Lithuanian Public Procurem } \\
\text { for Lithuania 2010, Lithuanian M } \\
\text { ence, Education management info } \\
\text { Research Council of Lithuania, ar } \\
\text { tion Monitoring and Analysis Cer } \\
\text { Due to lack of reliability and data } \\
\text { private HEIs are excluded from th }\end{array}$ & $\begin{array}{l}\text { le statistical data sources, } \\
\text { Universities Official Finan- } \\
\text { te Enterprise Centre of Regis- } \\
\text { Office, Input-Output Table } \\
\text { istry of Education and Sci- } \\
\text { nation system (EMIS), The } \\
\text { Research and Higher Educa- } \\
\text { e (MOSTA). } \\
\text { mitations, the colleges and } \\
\text { sources of data. }\end{array}$ \\
\hline Research Scope & $\begin{array}{l}\text { Evaluation of the economic impa } \\
\text { national economy; moreover, the } \\
\text { versities and changes are discusse } \\
\text { ods of time. }\end{array}$ & $\begin{array}{l}\text { of public universities on the } \\
\text { ficiencies between public uni- } \\
\text { critically over different peri- }\end{array}$ \\
\hline $\begin{array}{l}\text { Stage I - Input- } \\
\text { Output Table } \\
\text { Preparation } \\
\text { (Aggregation } \\
\text { Procedure) }\end{array}$ & \multicolumn{2}{|c|}{$\begin{array}{l}\text { Classification of all the economic activities into standard groups } \\
\text { defined by the Nace } 2 \text { classification. The Input-Output table is ag- } \\
\text { gregated from the original table. }\end{array}$} \\
\hline \multirow[b]{2}{*}{$\begin{array}{l}\text { Stage II - Out- } \\
\text { put Multipliers } \\
\text { Calculation }\end{array}$} & $\begin{array}{l}\text { Compute the Leontief inverse } \\
\text { matrix. }\end{array}$ & $\begin{array}{l}\text { 1. Application of the for- } \\
\text { mula: } \\
(I-A)^{-1}\end{array}$ \\
\hline & $\begin{array}{l}\text { Economic impacts - output mul- } \\
\text { tiplier estimations. }\end{array}$ & $\begin{array}{l}\text { 2. Application of the for- } \\
\text { mula: } \\
\left((I-A)^{-1}\right)^{T}\left[\begin{array}{c}1 \\
\ldots \\
1\end{array}\right]\end{array}$ \\
\hline
\end{tabular}


Continued Table 3.1

\begin{tabular}{|c|c|c|}
\hline \multirow[t]{2}{*}{ Implementation } & \multicolumn{2}{|l|}{ Process Sequence } \\
\hline & $\begin{array}{l}\text { Estimation of disaggre- } \\
\text { gate multipliers for in- } \\
\text { dividual public univer- } \\
\text { sity. }\end{array}$ & $\begin{array}{l}\text { 3. Application of the formula: } \\
M_{H_{h}}=\frac{\widehat{e_{h}}}{\widehat{e_{1}}+\ldots+\widehat{e_{n}}} M_{1}\end{array}$ \\
\hline $\begin{array}{l}\text { Stage III - DEA } \\
\text { Inputs and Out- } \\
\text { puts Selection }\end{array}$ & \multicolumn{2}{|c|}{$\begin{array}{l}\text { Since selecting variables to evaluate (a subset of inputs and outputs) } \\
\text { is crucial for DEA analysis, this step selects different subsets of in- } \\
\text { puts and outputs for evaluation. For each subset, the DEA model is } \\
\text { applied. Furthermore, in each subset, the output multipliers com- } \\
\text { puted in stage III are taken as outputs. }\end{array}$} \\
\hline \multirow[t]{3}{*}{$\begin{array}{l}\text { Stage IV - DEA } \\
\text { Efficiency } \\
\text { Scores Calcula- } \\
\text { tion }\end{array}$} & $\begin{array}{l}\text { CRS model is used for } \\
\text { estimating efficiency } \\
\text { between public univer- } \\
\text { sities for each subset of } \\
\text { inputs and outputs } \\
\text { taken from stage IV. }\end{array}$ & $\begin{array}{l}\text { Considering each public university as a } \\
\text { DMU. } \\
\text { Computing average value for variables } \\
\text { over periods. } \\
\text { Formulating the linear programming } \\
\text { problem as: } \\
\text { max } \theta_{h} \text { s.t. } \quad-\theta_{h} y_{h}+Y \lambda_{h} \geq 0 \\
x_{h}-X \lambda_{h} \geq 0 \theta_{h} \text { free, } \lambda_{h} \geq 0 \\
\text { Computing the cross efficiency of } H_{j} \text {, } \\
\text { using the weights that is } H_{h} \text {, } \\
E_{h j}=\frac{\left(v_{h}^{\prime}\right)^{T} x_{j}}{\left(u_{h}^{\prime}\right)^{T} y_{j}} \\
\text { Computing DEA cross score for each } \\
\text { subset of variables (inputs and outputs): } \\
\overline{E_{j}}=\frac{1}{n} \sum_{h=1}^{n} E_{h j}\end{array}$ \\
\hline & $\begin{array}{l}\text { Efficiency between uni- } \\
\text { versities for each subset } \\
\text { of inputs and outputs } \\
\text { from stage IV using the } \\
\text { VRS model. }\end{array}$ & $\begin{array}{l}\text { Considering each university as a DMU. } \\
\text { Computing average value for variables } \\
\text { over periods. }\end{array}$ \\
\hline & $\begin{array}{l}\text { Formulating the linear } \\
\text { programming problem }\end{array}$ & $\begin{array}{l}\max \theta_{h} \text { s.t. } \quad-\theta_{h} y_{h}+Y \lambda_{h} \geq 0 \\
x_{h}-X \lambda_{h} \geq 0 \\
1^{T} \lambda_{h}=1 \theta_{h} \text { free, } \lambda_{h} \geq 0\end{array}$ \\
\hline
\end{tabular}


Continued Table 3.1

\begin{tabular}{|c|c|c|}
\hline Implementation & \multicolumn{2}{|l|}{ Process Sequence } \\
\hline \multirow{5}{*}{$\begin{array}{l}\text { Stage IV - DEA } \\
\text { Efficiency } \\
\text { Scores Calcula- } \\
\text { tion }\end{array}$} & $\begin{array}{l}\text { Computing the cross ef- } \\
\text { ficiency of } H_{j} \text {, using } \\
\text { the weights that is } H_{h} \text {, }\end{array}$ & $E_{h j}=\frac{\left(v_{h}^{\prime}\right)^{T} x_{j}}{\left(u_{h}^{\prime}\right)^{T} y_{j}}$ \\
\hline & $\begin{array}{l}\text { Computing DEA cross } \\
\text { score for each subset of } \\
\text { variables (inputs and } \\
\text { outputs) }\end{array}$ & $\overline{E_{j}}=\frac{1}{n} \sum_{h=1}^{n} E_{h j}$ \\
\hline & $\begin{array}{l}\text { Efficiency of each uni- } \\
\text { versity between periods } \\
\text { for each subset of in- } \\
\text { puts and outputs from } \\
\text { stage IV using the CRS } \\
\text { model. }\end{array}$ & $\begin{array}{l}\text { Considering each pair of university as } \\
\text { period of DMU. } \\
\text { Formulating the linear programming } \\
\text { problem as: } \\
\text { max } \theta_{h} \text { s.t. } \quad-\theta_{h} y_{h}+Y \lambda_{h} \geq 0 \\
x_{h}-X \lambda_{h} \geq 0, \theta_{h} \text { free, } \lambda_{h} \geq 0 \\
\text { Computing the cross efficiency of } H_{j} \\
\text { using the weights that is } H_{h}, \\
E_{h j}=\frac{\left(v_{h}^{\prime}\right)^{T} x_{j}}{\left(u_{h}^{\prime}\right)^{T} y_{j}} \\
\text { Computing DEA cross efficiency score } \\
\text { for each subset of variables (inputs and } \\
\text { outputs) as: } \\
\overline{E_{j}}=\frac{1}{n} \sum_{h=1}^{n} E_{h j}\end{array}$ \\
\hline & $\begin{array}{l}\text { Efficiency of each uni- } \\
\text { versity between periods } \\
\text { for each subset of in- } \\
\text { puts and outputs from } \\
\text { stage IV using the VRS } \\
\text { model. }\end{array}$ & $\begin{array}{l}\text { Considering each pair of university as } \\
\text { the period of DMU. } \\
\text { Formulating the linear programming } \\
\text { problem as: } \\
\max \theta_{h} \text { s.t. } \quad-\theta_{h} y_{h}+Y \lambda_{h} \geq 0 \\
x_{h}-X \lambda_{h} \geq 0\end{array}$ \\
\hline & & $\begin{array}{l}1^{T} \lambda_{h}=1 \theta_{h} \text { free, } \lambda_{h} \geq 0 \\
\text { Computing the cross efficiency of } H_{j} \\
\text { using the weights that is } H_{h},\end{array}$ \\
\hline
\end{tabular}


End of Table 3.1

\begin{tabular}{|c|c|c|}
\hline Implementation & \multicolumn{2}{|l|}{ Process Sequence } \\
\hline \multirow{2}{*}{$\begin{array}{l}\text { Stage IV - DEA } \\
\text { Efficiency } \\
\text { Scores Calcula- } \\
\text { tion }\end{array}$} & \multirow{2}{*}{$\begin{array}{l}\text { Computing DEA cross } \\
\text { score for each subset of } \\
\text { variables (inputs and } \\
\text { outputs) }\end{array}$} & $E_{h j}=\frac{\left(v_{h}^{\prime}\right)^{T} x_{j}}{\left(u_{h}^{\prime}\right)^{T} y_{j}}$ \\
\hline & & $\overline{E_{j}}=\frac{1}{n} \sum_{h=1}^{n} E_{h j}$ \\
\hline $\begin{array}{l}\text { Stage V - } \\
\text { Possible Errors } \\
\text { Checking }\end{array}$ & \multicolumn{2}{|c|}{$\begin{array}{l}\text { Comparing the results taken from Stage I, stage III, Stage IV and } \\
\text { Stage V in order to check whether they are consistent and follow } \\
\text { the general logics and methodological requirements or no. }\end{array}$} \\
\hline $\begin{array}{l}\text { Stage VI - } \\
\text { Data } \\
\text { Interpretation }\end{array}$ & \multicolumn{2}{|c|}{$\begin{array}{l}\text { Based on the underlying intuition of the created model. Interpreta- } \\
\text { tion of the data is based upon the economic impact and the possi- } \\
\text { ble efficiency improvements of public universities. }\end{array}$} \\
\hline
\end{tabular}

As explained in Table 3.1 above, the model consists of 8 steps total. The first two steps, data collection and establishing the scope of the research, are necessary preconditions for the six-stage process that follows. The six-stage process consists of: 1) Preparing Input-Output Table, 2) Calculating output multipliers, 3) Selecting the DEA inputs and outputs, 4) Calculating DEA efficiency scores, 5) Checking for errors, and 6) Interpreting the data. Economic impact assessment of Lithuanian public universities will be made in the following chapter by following these steps.

\subsection{Economic Impact of Higher Education Institutions}

There are 14 public universities in Lithuania, ranging from small institutions such as the Lithuanian Academy of Music and Theatre, to large research-based universities considered to be more traditional, such as Vilnius University. There are also highly specialized public universities, such as the Lithuanian University of Health Sciences for the healthcare industry, that devote their resources and instructional guidance towards specific areas of education.

13 out of these 14 public universities were accepted into the sample data for modelling, representing an $87 \%$ participation rate of Lithuanian HE system (EMIS, 2016). One public university rejected from the sample group was the General Jonas Žemaitis Military Academy of Lithuania. This university was rejected due to a lack of availability of data caused by its operation under the Ministry of 
National Defence. All other public universities operate under the Ministry of Education and are included in the sample group.

The sample consists of inputs and outputs of these 13 public universities of various scales operating in Lithuania from 2010 to 2016. It was not possible to include the data for 2017 since most of the data sources have a different calculation methodology, thus making the data incomparable under the proposed research framework. Therefore, the data related for 2017 was omitted from the sample period. Notation of public universities are from $\mathrm{HE}_{1}$ to $\mathrm{HE}_{13}$.

The data is collected and formulated into a unique database, according to accounting information and other reliable sources. The main idea behind this format is to distinguish each public university as an independent sector in an I-O national table, providing the ability to discern heterogeneity of income and expense sources. Therefore, an I-O method as an accounting means was adopted (look at the Annexes A, B and C).

In addition, various other forms of analysis have been undertaken to better touch on different elements of the framework. It is crucial to recognize the significance of the variety of revenues affecting public universities, because it highlights the extent to which universities are dependent on public funding and their impact on the national or regional economy. The typical inputs measured in this model includes the expenditures of the HEI (wages, taxes, and subsidies) and the outputs, which are considered the income of the HEI (funds, tuition fees, etc.).

A number of interesting results arise when we look inside the HE sector; first of all, there is a clear distinction between the economic impact of the larger and smaller public universities in the highly active and competitive education industry. Economies are spending more on building universities to better cater to the industrial and technological needs and demands by providing the most advanced education.

Figure 3.1 shows the output multipliers of selected universities separately. Three of the biggest public universities have the highest multipliers: $\mathrm{HE}_{12}$ scored $0.00214, \mathrm{HE}_{2}$ scored 0.00128 , and $\mathrm{HE}_{7}$ scored 0.00112 . In contrast, smaller institutions score far lower for multiple reasons. Shortage of funds is a major issue. As the results show, the scores of $\mathrm{HE}_{5}$ and $\mathrm{HE}_{6}$ are 0.00015 and 0.00012 , respectively.

Figure 3.1 confirms what was noted in the literature analysis. The difference in scores was identified as a result of the increased human capital or stock of knowledge associated with larger institutions. Moreover, in these institutions, more work is being done by experienced and talented academic personnel and students. These universities are more active in collaborations with international institutions and equipped with more advanced tools and channels. $\mathrm{HE}_{12}$ has a significantly higher multiplier than the other three biggest public universities combined. This fact suggests the existence of agglomeration effects. Whenever businesses and industries locate near a HEI, they can flourish and expand by utilizing 
the talent and research conducted by these public universities. In other words, the research conducted in public universities benefits industries and EIs.

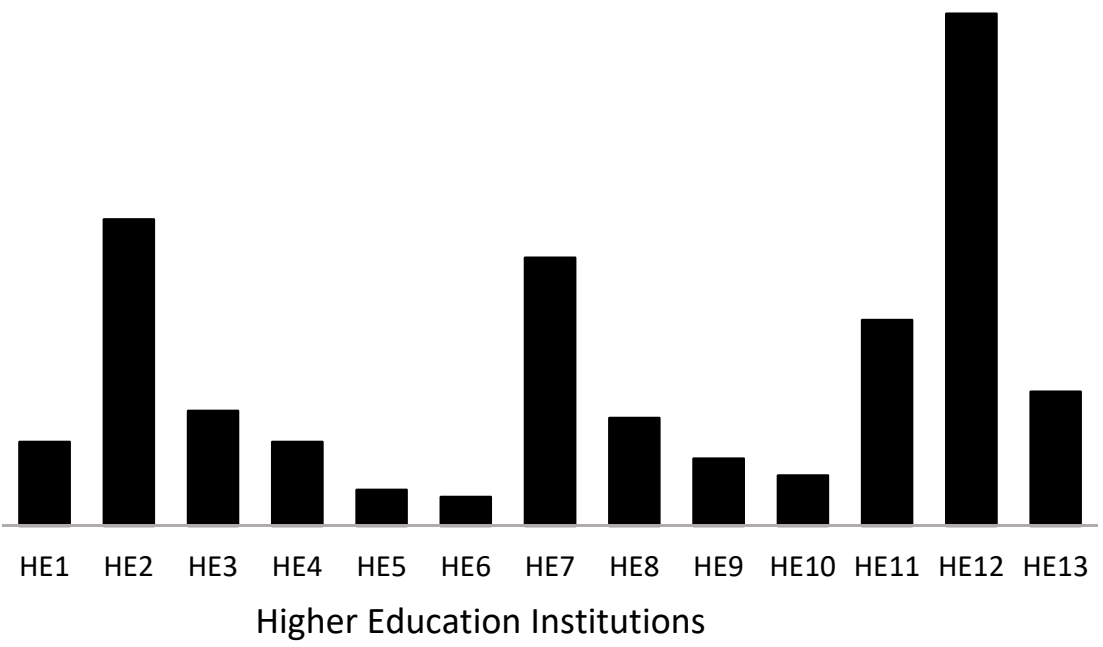

Fig. 3.1. Raw Type II Output Multipliers of Public Universities in Lithuania (compiled by author)

However, the results presented in Table 3.1 are less sharp when it comes to specialized universities. For instance, $\mathrm{HE}_{6}, \mathrm{HE}_{9}$, and $\mathrm{HE}_{4}$ have minor output multiplier effects. However, for others, such as $\mathrm{HE}_{2}$, the multiplier effect is higher. So, being a specialized HEI does not per se determine its economic impact. The type of specialization also plays a key role on its performance and impact on the economy. For example, $\mathrm{HE}_{6}$ focuses on sports studies, hence it has little connection with the local economy, whereas, $\mathrm{HE}_{2}$ is a technology-driven institution and thus has a significant impact on the local economy.

The I-O matrix was used to estimate the impact of public universities on Lithuania's economy. To this end, an I-O table of Lithuania's 11 main economic activities, according to NACE 2 classification, is used and presented (see Table 2.2.).

The aim of this research is to determine the impact of each HEI on the economy. Since the information on some of the public universities was not available in the I-O table, multiple approaches were used to analyses this data. Two forms of regression approaches were used. The first is based on income, the number of students, and the number of full-time equivalent staff members (FTE). The second is based on all other variables, like state grants and funds for studies and research work, scholarships, administration, education standards in EU and other countries, 
international organizations, industrial income, EU research grants, imports, compensation of employees and intermediate expenditures. After that, a single proportional approach was used, based on the expenses of each HEI. It was formulated in this way to test the consistency and reliability of the data in a more appealing and result-oriented way.

Three different temporal disaggregation approaches are applied in the research to calculate public universities' impact on the economy. One of these approaches is related to a proportional approach and the other two are from regression approaches. Details of these are given below:

1. Proportional Approach:

This method involves the analysis of data observed by using a high-frequency indicator with the expenditure of each HEI. This process forces the condition that the sum of the series must be equal to the initial value of all results pertaining to $\mathrm{HE}$ in an I-O table. The expenditure is selected as an indicator because the gross value added to the education system of Lithuania is calculated according to the proportional approach.

\section{Regression Approach:}

The regression model relates the disaggregated series with a known set of high frequency indicators. Two different sets of indicators are used:

A - Total income, number of students, and number of FTE

B - Income from the Lithuanian government dispersed by purpose, exports income separated by purpose and other income.

The final results of each method are close to each other, with the maximum difference of no more than $5 \%$. This shows that the research outcome in the data is not due to chance, while also demonstrating the stability and reliability of the results.

This section of the chapter examines the issues surrounding the expenditure of public universities on the economy of Lithuania by employing an I-O analysis. The I-O model serves as an appropriate tool for assessing the overall impact of public universities on national economic growth, compared to a pure economic impact analysis. As such, the output multipliers for the 13 public universities has been calculated.

As shown in the below Table 3.2, the size of the multiplier of the public universities lies below the size of multiplier of the basic and secondary education sector. However, it is above the size of the multipliers of the other education sectors, namely pre-primary education, primary education, and secondary education. This The public universities in Table 3.2 showed one of the highest Type II output multipliers, when compared with other education sectors; they were only surpassed by the economic output of the basic and secondary education sectors. This 
outcome could be due to the fact that the employees in the tertiary education system form a larger share of the expenditure than any of the other sectors.

outcome could be since employees in the tertiary education system forms a lower share of the expenditure compared to the basic and secondary education sector, and a higher share compared to pre-primary education, primary education, and colleges. The fact that the economic impact of public universities ' multiplier is neither the highest nor the lowest among a set of alternative sectors is compatible with a number of findings in the related literature.

Looking within the HE sector to evaluate each institution individually, there is a clear distinction between the larger and the smaller public universities and their economic impacts. Table 3.2 clearly shows this, more specifically, the three largest public universities $\left(\mathrm{HE}_{12}, \mathrm{HE}_{2}\right.$ and $\left.\mathrm{HE}_{7}\right)$ have the highest multiplier scores, with $0.00214,0.00128$, and 0.00112 , respectively. Contrary to this, small institutions like $\mathrm{HE}_{5}$ and $\mathrm{HE}_{6}$ scores far lower which are 0.00015 and 0.00012 , respectively. The difference in the scores is because of their access to financial and human resources, which impact the performance of these institutions. Since there are resources like more academic personnel, more students, and access to academic research, the chances of excelling in the education field increase.

$\mathrm{HE}_{12}$ demonstrates significantly higher multipliers than the other three largest public universities collectively. This suggests that the existence of agglomeration effects the performance of public universities; this term describes is the phenomenon whereby businesses and industries locate themselves near an HEI, thus providing the institution the ability to flourish and expand its output through collaboration.

Each attribute of the mutual collaboration contributes to the high economic output and efficiency level of each HEI. For specialized universities such as $\mathrm{HE}_{6}$, $\mathrm{HE}_{9}$, and $\mathrm{HE}_{4}$, the output multiplier effect is minor in comparison, indicating how these specialized public universities have issues collaborating with surrounding institutions in sharing their knowledge and research work. Here, agglomeration plays an important role in explaining spatial variations in the impact of public universities over economic performance and efficiency.

The findings indicate the investment inputs into public universities, which have yielded sufficient value to justify a continuation of funding by the state. Alternatively, results of this methodology that show insufficient value can be used as a justification for discontinuing further investment or consolidating low-value public universities. Lastly, insights provided here could encourage Lithuania's leadership to create additional output streams, which would increase the value of the public universities by adding to the local economy. Such streams include enhanced specialization programs, research incentives, job creation, and/or labour income. To improve the state of HE and the associated institutions, the government must implement measures and allow ways for their public universities to develop through new avenues. 
Table 3.2. Economic Effect Multipliers of public universities (compiled by author)

\begin{tabular}{|l|c|c|c|}
\hline Activity area & $\begin{array}{l}\text { Regression } \\
\text { Approach (based on } \\
\text { Income, Number of } \\
\text { Students and FTE) }\end{array}$ & $\begin{array}{l}\text { Regression } \\
\text { Approach (based } \\
\text { on all Variables) }\end{array}$ & $\begin{array}{l}\text { Proportional } \\
\text { Approach } \\
\text { (based on Ex- } \\
\text { penses) }\end{array}$ \\
\hline P - Education & 0.04100 & 0.04100 & 0.04100 \\
\hline $\begin{array}{l}\text { Pre-Primary and } \\
\text { Primary Education }\end{array}$ & 0.00600 & 0.00600 & 0.00600 \\
\hline $\begin{array}{l}\text { Basic and Secondary } \\
\text { Education }\end{array}$ & 0.01500 & 0.01500 & 0.01500 \\
\hline Colleges & 0.00100 & 0.00100 & 0.00100 \\
\hline Higher Education & 0.00800 & 0.00800 & 0.00800 \\
\hline $\mathrm{HE}_{1}$ & 0.00035 & 0.00035 & 0.00035 \\
\hline $\mathrm{HE}_{2}$ & 0.00128 & 0.00130 & 0.00131 \\
\hline $\mathrm{HE}_{3}$ & 0.00048 & 0.00047 & 0.00047 \\
\hline $\mathrm{HE}_{4}$ & 0.00035 & 0.00034 & 0.00034 \\
\hline $\mathrm{HE}_{5}$ & 0.00015 & 0.00015 & 0.00015 \\
\hline $\mathrm{HE}_{6}$ & 0.00012 & 0.00013 & 0.00013 \\
\hline $\mathrm{HE}_{7}$ & 0.00112 & 0.00111 & 0.00111 \\
\hline $\mathrm{HE}_{8}$ & 0.00045 & 0.00046 & 0.00046 \\
\hline $\mathrm{HE}_{9}$ & 0.00028 & 0.00029 & 0.00028 \\
\hline $\mathrm{HE}_{10}$ & 0.00021 & 0.00021 & 0.00021 \\
\hline $\mathrm{HE}_{11}$ & 0.00086 & 0.00086 & 0.00086 \\
\hline $\mathrm{HE}_{12}$ & 0.00214 & 0.00214 & 0.00214 \\
\hline $\mathrm{HE}_{13}$ & 0.00056 & 0.00053 & 0.00053 \\
\hline $\begin{array}{l}\mathrm{R} \& \mathrm{D} \text { in the field of } \\
\text { education }\end{array}$ & 0.01000 & 0.01000 & 0.01000 \\
\hline
\end{tabular}

To conclude, this analysis offers valuable insights for stakeholders about the value of HE by revealing public universities' high-value contributions to the Lithuanian economy. Overall, the findings reveal that increased output value to the local economy is highly correlated to increased HEI activity. This analysis has the potential to contribute to the current policy debates about HE in Lithuania. There should be extra consideration regarding the substandard performance of small and specialized public universities. This report has the potential to enable a discussion about the effects of increasing or decreasing funding to these public universities 
in the immediate future. Yet, it does not provide a statement on the effects of that change towards wider industrial and business policies.

The findings of this research have important policy implications. First, the results act as a reminder to policymakers in Lithuania that HE plays a significant role in the regional and national economies, despite the recent problems associated with the operation of public universities. Furthermore, in the upcoming reformulation of HE in the country, care should be taken when dealing with each HEI separately. There is a great heterogeneity among the universities in terms of their impact on the economy. In fact, universities are linked with each other and have a very complex relationship, which influence the performance of the economy. The plan is to reduce the number of public universities from 14 to nine to consolidate the expenses and quality of each institution. Agglomeration effects should also be given due consideration when choosing which universities to support with public funds.

An issue for future studies would be to consider the return-on-investment in education and the quality of HE in the Lithuania, which are not discussed in this study. Despite a considerable degree of certainty regarding the inputs and outputs of each individual HEI, it would be of interest to obtain more in-depth information regarding the expenditure on purchased goods and services.

\subsection{Efficiency of Higher Education Institutions}

The cross-efficiency version of the DEA in the STATA package within R was used to analyses the data. With the agreement between the results based on Constant Returns to Scale (CRS) and Variable Returns to Scale (VRS), there are some assumptions included in the statistical analysis. The data was prepared on the eight input and three output variables, defined in Table 3.3 for the 13 selected public universities.

Cross-efficiency Estimates Based on Aggregated Data Between 2010 -2016. The eight input variables in Table 3.3 account for the multiple forms of income received by Lithuanian public universities, including state funding and research grants. The three output variables in Table 3.3 encompass the impact of the public universities on the economy.

The first set of DEA cross-efficiency models, as shown in Tables 3.4 and 3.5, was built using data from 2010-2016, which provides information on the overall efficiency of each HEI in this period. The mean CRS and VRS estimates are correlated significantly (Spearman and Pearson correlations are 0.945 and 0.965 , respectively) (Hauke, Kossowski, 2011).

Table 3.4 shows the CRS cross-efficiency estimates for all 13 public universities in Lithuania included in this study. Each university is accounted for on a yearly basis. Table 3.5 shows the VRS cross-efficiency estimates. Each university is accounted for on a yearly basis in the table. 
Table 3.3. Variable Definitions and Model Specifications (compiled by author)

\begin{tabular}{|c|c|c|c|c|c|c|c|c|c|c|c|c|}
\hline \multirow[t]{2}{*}{$\frac{0}{\frac{0}{0}}$} & \multirow[t]{2}{*}{ 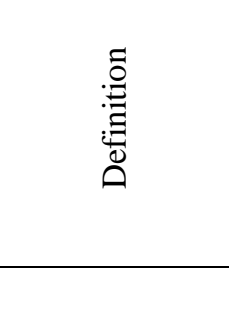 } & \multicolumn{3}{|c|}{ 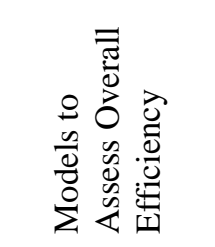 } & \multicolumn{2}{|c|}{ 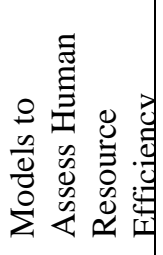 } & \multicolumn{3}{|c|}{ 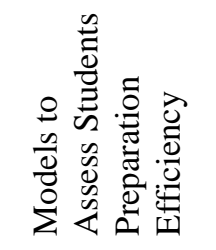 } & \multicolumn{3}{|c|}{ 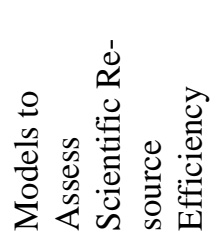 } \\
\hline & & $1 \mathrm{a}$ & $1 b$ & 1c & $2 \mathrm{a}$ & $2 b$ & 3a & $3 b$ & $3 c$ & $4 a$ & $4 \mathrm{~b}$ & $4 c$ \\
\hline 1 & 2 & 3 & 4 & 5 & 6 & 7 & 8 & 9 & 10 & 11 & 12 & 13 \\
\hline I1 & $\begin{array}{l}\text { State funds for } \\
\text { studies }\end{array}$ & + & + & & & & + & + & + & & & \\
\hline $\mathrm{I} 2$ & $\begin{array}{l}\text { Free income } \\
\text { (scholarships) }\end{array}$ & + & + & & & & + & + & + & & & \\
\hline I3 & $\begin{array}{l}\text { State research } \\
\text { grants }\end{array}$ & + & + & & & & & & & + & + & + \\
\hline $\mathrm{I} 4$ & Administration & + & + & & & & & & + & & & + \\
\hline I5 & Other income & + & + & & & & & & + & & & + \\
\hline I6 & Total income & & & + & + & + & & & & & & \\
\hline I7 & Academic staff & & & & + & + & & & + & + & + & + \\
\hline I8 & $\begin{array}{l}\text { Administrative } \\
\text { staff }\end{array}$ & & & & + & + & & & + & & & + \\
\hline $\mathrm{O} 1$ & $\begin{array}{l}\text { GDP* by mul- } \\
\text { tiplier coeffi- } \\
\text { cient }\end{array}$ & + & + & + & + & + & & + & & & + & \\
\hline $\mathrm{O} 2$ & $\begin{array}{l}\text { Number of } \\
\text { graduates }\end{array}$ & & + & + & & & + & & + & & & \\
\hline $\mathrm{O} 3$ & $\begin{array}{l}\text { The weighted } \\
\text { sum of points } \\
\text { for the level } 11 \\
\text { scientific (ar- } \\
\text { tistic) work }\end{array}$ & & + & + & + & & & & & + & & + \\
\hline
\end{tabular}


Table 3.4. Constant Returns to Scale Cross-Efficiency Estimates of 13 Public

Universities in Lithuania Using Aggregated Data from 2010-2016 (compiled by author)

\begin{tabular}{|l|l|l|l|l|l|l|l|l|l|l|l|l|}
\hline \multirow{2}{*}{$\mathrm{HEI}$} & \multicolumn{1}{|l}{ Model (CRS) } \\
\cline { 2 - 13 } & $1 a$ & $1 b$ & $1 c$ & $2 a$ & $2 b$ & $3 a$ & $3 b$ & $3 c$ & $4 a$ & $4 b$ & $4 c$ & \\
\hline $\mathrm{HE}_{1}$ & 0.80 & 0.67 & 0.85 & 0.78 & 0.90 & 0.39 & 0.84 & 0.53 & 0.21 & 0.89 & 0.16 & 0.64 \\
\hline $\mathrm{HE}_{2}$ & 0.89 & 0.73 & 0.87 & 0.85 & 0.97 & 0.27 & 0.55 & 0.50 & 0.28 & 0.86 & 0.32 & 0.65 \\
\hline $\mathrm{HE}_{3}$ & 0.93 & 0.86 & 0.79 & 0.79 & 0.84 & 0.68 & 0.94 & 0.64 & 0.57 & 0.84 & 0.58 & 0.77 \\
\hline $\mathrm{HE}_{4}$ & 0.91 & 0.89 & 0.90 & 0.87 & 0.90 & 0.61 & 0.69 & 0.77 & 0.76 & 0.85 & 0.76 & 0.81 \\
\hline $\mathrm{HE}_{5}$ & 0.94 & 0.97 & 0.81 & 0.77 & 0.72 & 0.28 & 0.57 & 0.61 & 0.91 & 0.53 & 0.96 & 0.73 \\
\hline $\mathrm{HE}_{6}$ & 0.86 & 0.74 & 0.90 & 0.83 & 0.93 & 0.40 & 0.52 & 0.83 & 0.37 & 0.96 & 0.35 & 0.70 \\
\hline $\mathrm{HE}_{7}$ & 0.81 & 0.62 & 0.80 & 0.80 & 0.93 & 0.08 & 0.31 & 0.33 & 0.16 & 0.98 & 0.17 & 0.54 \\
\hline $\mathrm{HE}_{8}$ & 0.97 & 0.99 & 0.97 & 0.84 & 0.86 & 1.00 & 0.85 & 1.00 & 0.94 & 0.79 & 1.00 & 0.93 \\
\hline $\mathrm{HE}_{9}$ & 0.96 & 0.87 & 0.98 & 0.85 & 0.96 & 0.76 & 0.78 & 0.91 & 0.41 & 0.91 & 0.40 & 0.80 \\
\hline $\mathrm{HE}_{10}$ & 0.91 & 0.91 & 0.85 & 0.95 & 0.92 & 0.37 & 0.66 & 0.54 & 0.97 & 0.76 & 0.97 & 0.80 \\
\hline $\mathrm{HE}_{11}$ & 0.92 & 0.81 & 0.87 & 0.80 & 0.91 & 0.36 & 0.50 & 0.68 & 0.28 & 0.90 & 0.30 & 0.67 \\
\hline $\mathrm{HE}_{12}$ & 0.84 & 0.72 & 0.81 & 0.85 & 0.90 & 0.17 & 0.37 & 0.54 & 0.52 & 0.82 & 0.61 & 0.65 \\
\hline $\mathrm{HE}_{13}$ & 0.85 & 0.79 & 0.83 & 0.85 & 0.87 & 0.44 & 0.53 & 0.79 & 0.75 & 0.88 & 0.77 & 0.76 \\
\hline
\end{tabular}

Table 3.5. Variable Returns to Scale Cross-Efficiency Estimates of 13 Public

Universities in Lithuania Using Aggregated Data from 2010-2016 (compiled by author)

\begin{tabular}{|l|l|l|l|l|l|l|l|l|l|l|l|l|}
\hline \multirow{2}{*}{ HEI } & \multicolumn{1}{|l}{ Model (VRS) } & \multicolumn{10}{|l|}{ Mean } \\
\cline { 2 - 13 } & $1 a$ & $1 b$ & $1 c$ & $2 a$ & $2 b$ & $3 a$ & $3 b$ & $3 c$ & $4 a$ & $4 b$ & $4 c$ & \\
\hline $\mathrm{HE}_{1}$ & 1.04 & 1.08 & 0.91 & 0.82 & 0.95 & 1.93 & 1.52 & 1.57 & 0.32 & 0.98 & 0.35 & 1.04 \\
\hline $\mathrm{HE}_{2}$ & 0.93 & 0.90 & 0.93 & 0.91 & 1.01 & 1.37 & 1.05 & 1.26 & 0.46 & 0.89 & 0.52 & 0.93 \\
\hline $\mathrm{HE}_{3}$ & 1.06 & 1.11 & 0.85 & 0.92 & 0.88 & 3.62 & 1.89 & 2.81 & 0.86 & 0.94 & 0.93 & 1.44 \\
\hline $\mathrm{HE}_{4}$ & 1.06 & 1.18 & 0.97 & 1.07 & 0.96 & 3.29 & 1.45 & 2.73 & 1.15 & 0.95 & 1.27 & 1.46 \\
\hline $\mathrm{HE}_{5}$ & 1.19 & 2.15 & 0.86 & 1.17 & 0.80 & 1.56 & 1.32 & 1.47 & 1.40 & 0.58 & 2.64 & 1.38 \\
\hline $\mathrm{HE}_{6}$ & 1.00 & 1.03 & 0.97 & 0.90 & 0.98 & 1.95 & 0.91 & 1.79 & 0.57 & 1.09 & 0.60 & 1.07 \\
\hline $\mathrm{HE}_{7}$ & 0.85 & 0.79 & 0.86 & 0.79 & 0.96 & 0.33 & 0.45 & 0.41 & 0.24 & 1.08 & 0.26 & 0.64 \\
\hline $\mathrm{HE}_{8}$ & 1.15 & 1.30 & 1.06 & 1.16 & 0.94 & 4.89 & 1.50 & 3.68 & 1.44 & 0.99 & 1.58 & 1.79 \\
\hline $\mathrm{HE}_{9}$ & 1.13 & 1.16 & 1.06 & 0.96 & 1.02 & 4.04 & 1.61 & 3.31 & 0.62 & 1.02 & 0.67 & 1.51 \\
\hline $\mathrm{HE}_{10}$ & 1.06 & 1.38 & 0.91 & 1.29 & 0.98 & 2.06 & 1.49 & 1.79 & 1.51 & 0.81 & 1.95 & 1.38 \\
\hline $\mathrm{HE}_{11}$ & 1.06 & 1.02 & 0.94 & 0.86 & 0.96 & 1.93 & 1.05 & 1.78 & 0.43 & 1.00 & 0.49 & 1.05 \\
\hline $\mathrm{HE}_{12}$ & 0.83 & 0.89 & 0.87 & 0.97 & 0.94 & 0.79 & 0.59 & 0.86 & 0.83 & 0.86 & 0.95 & 0.85 \\
\hline $\mathrm{HE}_{13}$ & 0.95 & 1.06 & 0.89 & 1.01 & 0.91 & 2.23 & 0.99 & 2.00 & 1.14 & 0.97 & 1.22 & 1.22 \\
\hline
\end{tabular}


A second set of efficiency estimates were obtained in Table 3.5 by considering each HEI year as a separate decision-making unit. This allowed for year to year intertemporal comparisons and an estimation of efficiency across and within the universities. The average CRS and VRS scores are highly correlated with Pearson correlation at 0.83 and Spearman correlation at 0.84 .

The top five ranked public universities having high technical efficiency are $\mathrm{HE}_{8}, \mathrm{HE}_{4}, \mathrm{HE}_{9}, \mathrm{HE}_{10}$, and $\mathrm{HE}_{3}$, in respective order. The least efficient public universities, ranked 11 to 13 , are $\mathrm{HE}_{2}, \mathrm{HE}_{12}$ and $\mathrm{HE}_{7}$ respectively. See Table 3.6 below for the rankings.

For computational reasons, the VRS assumptions were not met in some of the estimated models, as efficiency scores resulted in infinite values. Under CRS assumptions, the default returns to scale assumption for this procedure in the corresponding $\mathrm{R}$ package All 11 specifications resulted in valid cross-efficiency scores, and the same were used for analysis.

Table 3.6. Ranking of Efficiency (based on aggregated data of 2010-2016) (compiled by author)

\begin{tabular}{|c|c|c|c|}
\hline HEI & CRS Rank & VRS Rank & Average Rank \\
\hline $\mathrm{HE}_{8}$ & 1 & 1 & 1 \\
\hline $\mathrm{HE}_{4}$ & 2 & 3 & 2.5 \\
\hline $\mathrm{HE}_{9}$ & 4 & 2 & 3 \\
\hline $\mathrm{HE}_{10}$ & 3 & 5 & 4 \\
\hline $\mathrm{HE}_{3}$ & 5 & 4 & 4.5 \\
\hline $\mathrm{HE}_{5}$ & 7 & 6 & 6.5 \\
\hline $\mathrm{HE}_{13}$ & 6 & 7 & 6.5 \\
\hline $\mathrm{HE}_{6}$ & 8 & 8 & 8 \\
\hline $\mathrm{HE}_{11}$ & 9 & 9 & 9 \\
\hline $\mathrm{HE}_{1}$ & 12 & 10 & 11 \\
\hline $\mathrm{HE}_{2}$ & 11 & 11 & 11 \\
\hline $\mathrm{HE}_{12}$ & 10 & 12 & 11 \\
\hline $\mathrm{HE}_{7}$ & 13 & 13 & 13 \\
\hline & & & \\
\hline
\end{tabular}

Over the six-year period studied, $\mathrm{HE}_{8}$ maintained its rank at number 1 , while $\mathrm{HE}_{7}$ stayed at number 13 . $\mathrm{HE}_{6}, \mathrm{HE}_{11}$, and $\mathrm{HE}_{2}$ also maintained their ranking between 2010 and 2016. The other HEs moved by no more than one full rank from their place between 2010 and 2016.

Yearly changes were hard to identify for most public universities, but the overall change in efficiency was clear to see in the data presented in Figures 3.2 and 3.3 below. 
Figure 3.2 shows the changes in $\mathrm{HE}_{1}$ to $\mathrm{HE}_{6}$. Among these HEs, it is noteworthy was $\mathrm{HE}_{3}$ experienced a steady growth in efficiency starting in 2012. However, it is still in an overall decline of 7.1\% in efficiency between 2010 and 2016.
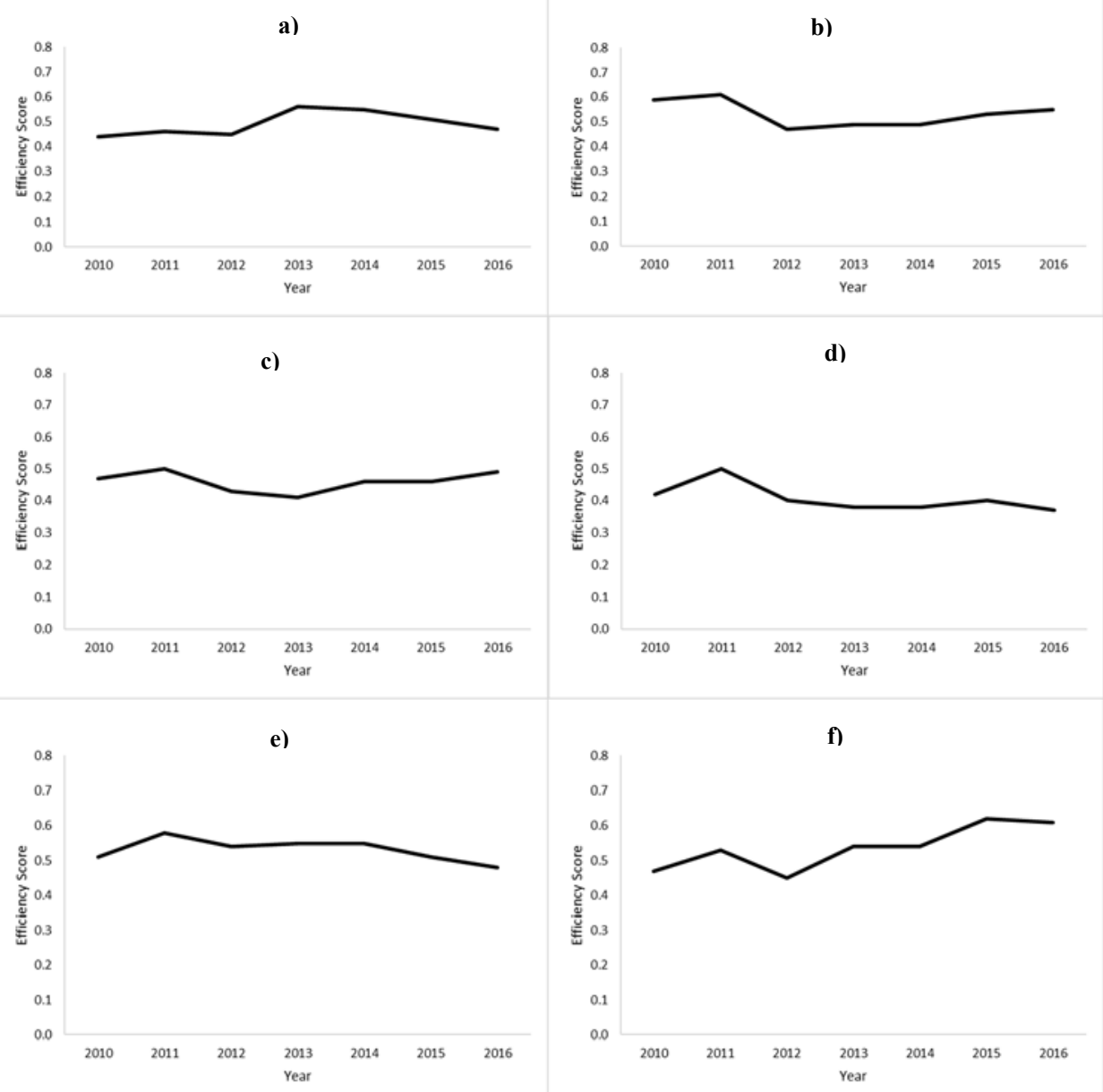

Fig. 3.2. Mean Efficiency Scores for a) $\mathrm{HE}_{1}$, b) $\mathrm{HE}_{3}$, c) $\mathrm{HE}_{2}$, d) $\mathrm{HE}_{5}$, e) $\mathrm{HE}_{6}$ and f) $\mathrm{HE}_{4}$ for the years 2010 to 2016 (compiled by author)

Figure 3.3 below shows the mean efficiency scores of $\mathrm{HE}_{9}$ to $\mathrm{HE}_{13}$. $\mathrm{HE}_{9}$ had the most positive change, with an efficiency increase up to $37.1 \%$, whereas $\mathrm{HE}_{12}$ had the largest decline in efficiency at is $33.9 \%$. This decline was due to a sharp decline the institution experienced in 2012; since then they stabilized. 
g)

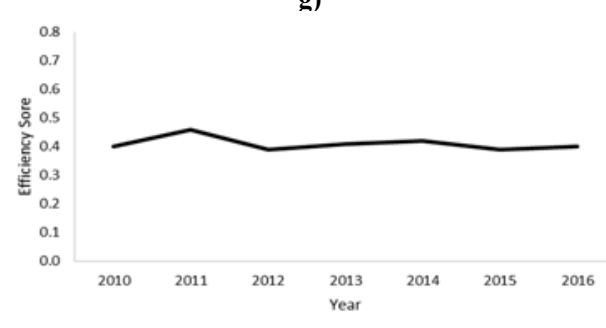

i)

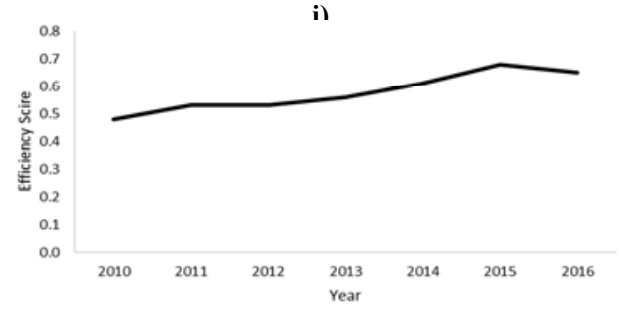

i)

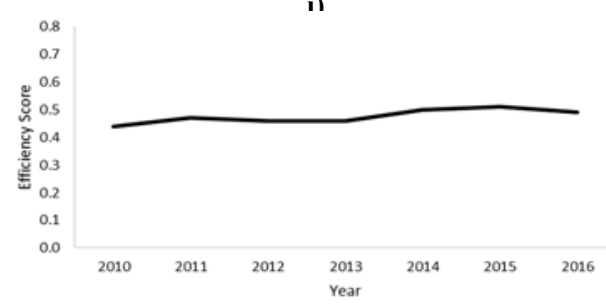

h)

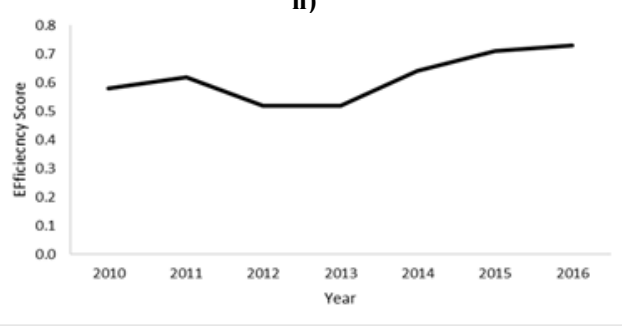

v)

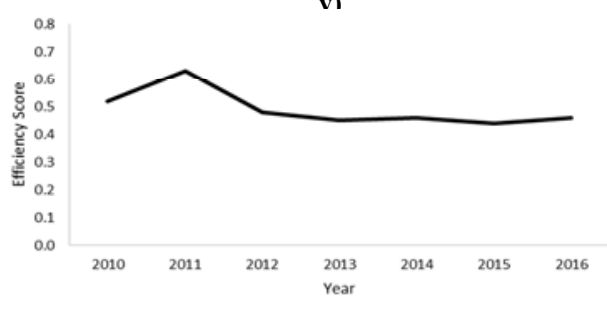

k)

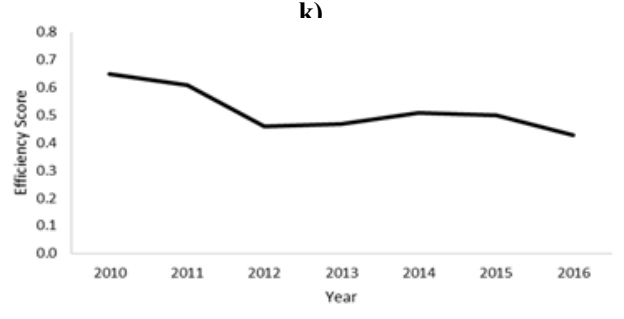

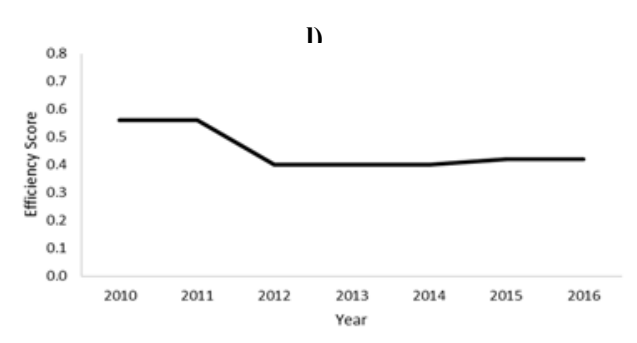

Fig. 3.3. Mean efficiency scores for: g) $\mathrm{HE}_{7}$, h) $\mathrm{HE}_{8}$, i) $\mathrm{HE}_{9}$, y) $\mathrm{HE}_{10}$, j) $\mathrm{HE}_{11}$, k) $\mathrm{HE}_{13}$ and l) $\mathrm{HE}_{12}$ for the years 2010 to 2016 (compiled by author)

Figure 3.4 below summarizes the data presented in Figures 3.2 and 3.3. $\mathrm{HE}_{13}$ decreased in efficiency by $33.9 \%$, and $\mathrm{HE}_{9}$ increased in efficiency by $37.1 \%$ over a six-year period. Most public universities fluctuated in increasing or decreasing 
efficiencies by over $10 \%$ with only $\mathrm{HE}_{1}, \mathrm{HE}_{2}, \mathrm{HE}_{7}, \mathrm{HE}_{3}$ and $\mathrm{HE}_{6}$ remaining relatively constant under this threshold. This is where it can also be seen that $\mathrm{HE}_{13}$ went from being the most efficient in 2010 to the least efficient in 2016.

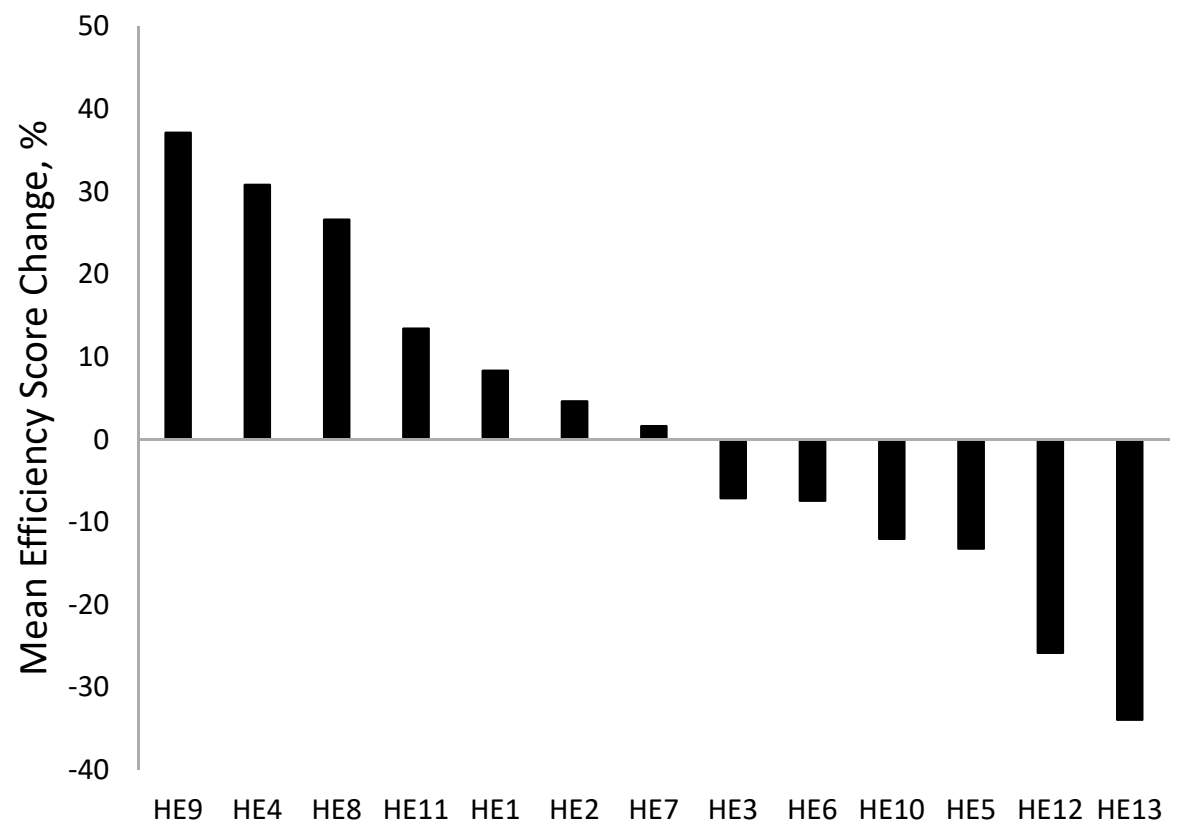

Fig. 3.4. Changes in Mean Efficiency Score as Increased or Decreased Percentage for each Higher Education Institution from 2010 to 2016 (compiled by author)

Decomposing Efficiency into HEI and Time-Specific Effects. Having obtained measures of efficiency for each year for each HEI, a fixed-effects panel data regression model was applied to the data. In this regression analysis, efficiency was explained by incorporating two sets of dummy variables: one for universities and the other for years (see Table 3.7 below).

The null hypothesis used to test these proposed models were: "Some years did not have an abnormally low or high efficiency due to external factors." None of the period-specific effects were significant, as none of them exceed the $95 \%$ confidence interval level, indicating the stability of efficiency over the time. In other words, the null hypothesis could not be rejected.

The university specific effects, however, were significant ( $p=<0.05)$, indicating that there is a substantial issue of heterogeneity across public universities, including in their efficiency. Compared to $\mathrm{HE}_{1}, \mathrm{HE}_{4}$ and $\mathrm{HE}_{7}$, there were, on av- 
erage, significantly less efficiency as inferred by the negative regression coefficients having significant value of $\mathrm{p}$ at $5 \%$ level of significance or $\mathrm{p}<0.05$. $\mathrm{HE}_{13}$ and $\mathrm{HE}_{8}$, on the other hand, were comparatively more efficient as the value of $\mathrm{p}$ is significant at $5 \%$ level of significance. For example, $\mathrm{HE}_{5}$ systematically had, on average, an efficiency rate of 0.08 points lower than $\mathrm{HE}_{1}(\mathrm{p}<0.01)$. The variable 'Year' was added in the linear equation without converting it to a dummy indicator, and the results remained the same (See Table 3.8 in Specification 2).

Table 3.7. The Efficiency Scores for the 13 Public Universities from 2010-2016 with the \% in Change Ranked from Most Positive Efficient Change to Most Negative. (compiled by author)

\begin{tabular}{|l|c|c|c|c|c|c|c|l|}
\hline Universities & 2010 & 2011 & 2012 & 2013 & 2014 & 2015 & 2016 & $\begin{array}{l}\text { Effi- } \\
\text { ciency } \\
\text { Change } \\
2010- \\
2016, \\
\%\end{array}$ \\
\hline $\mathrm{HE}_{9}$ & 0.5 & 0.5 & 0.5 & 0.6 & 0.6 & 0.7 & 0.7 & 37.1 \\
\hline $\mathrm{HE}_{4}$ & 0.5 & 0.5 & 0.5 & 0.5 & 0.5 & 0.6 & 0.6 & 30.8 \\
\hline $\mathrm{HE}_{8}$ & 0.6 & 0.6 & 0.5 & 0.5 & 0.6 & 0.7 & 0.7 & 26.6 \\
\hline $\mathrm{HE}_{11}$ & 0.4 & 0.5 & 0.5 & 0.5 & 0.5 & 0.5 & 0.5 & 13.4 \\
\hline $\mathrm{HE}_{1}$ & 0.4 & 0.5 & 0.5 & 0.6 & 0.6 & 0.5 & 0.5 & 8.3 \\
\hline $\mathrm{HE}_{2}$ & 0.5 & 0.5 & 0.4 & 0.4 & 0.5 & 0.5 & 0.5 & 4.6 \\
\hline $\mathrm{HE}_{7}$ & 0.4 & 0.5 & 0.4 & 0.4 & 0.4 & 0.4 & 0.4 & 1.6 \\
\hline $\mathrm{HE}_{3}$ & 0.6 & 0.6 & 0.5 & 0.5 & 0.5 & 0.5 & 0.6 & -7.1 \\
\hline $\mathrm{HE}_{6}$ & 0.5 & 0.6 & 0.5 & 0.6 & 0.6 & 0.5 & 0.5 & -7.4 \\
\hline $\mathrm{HE}_{10}$ & 0.5 & 0.6 & 0.5 & 0.5 & 0.5 & 0.4 & 0.5 & -12.0 \\
\hline $\mathrm{HE}_{5}$ & 0.4 & 0.5 & 0.4 & 0.4 & 0.4 & 0.4 & 0.4 & -13.2 \\
\hline $\mathrm{HE}_{12}$ & 0.6 & 0.6 & 0.4 & 0.4 & 0.4 & 0.4 & 0.4 & -25.8 \\
\hline $\mathrm{HE}_{13}$ & 0.7 & 0.6 & 0.5 & 0.5 & 0.5 & 0.5 & 0.4 & -33.9 \\
\hline
\end{tabular}

Both models were equal in estimation as per model fitness relative to the number of estimated parameters. According to AIC (Akaike Information Criterion), the longer model and BIC (Bayesian Information Criterion), for shorter model were suitable. 
Table 3.8. Regression Parameter Estimates (Dependent Variable: Cross-Efficiency Score, Explanatory Variables: Year and HEI, Heteroscedasticity-Robust Standard Errors) (compiled by author)

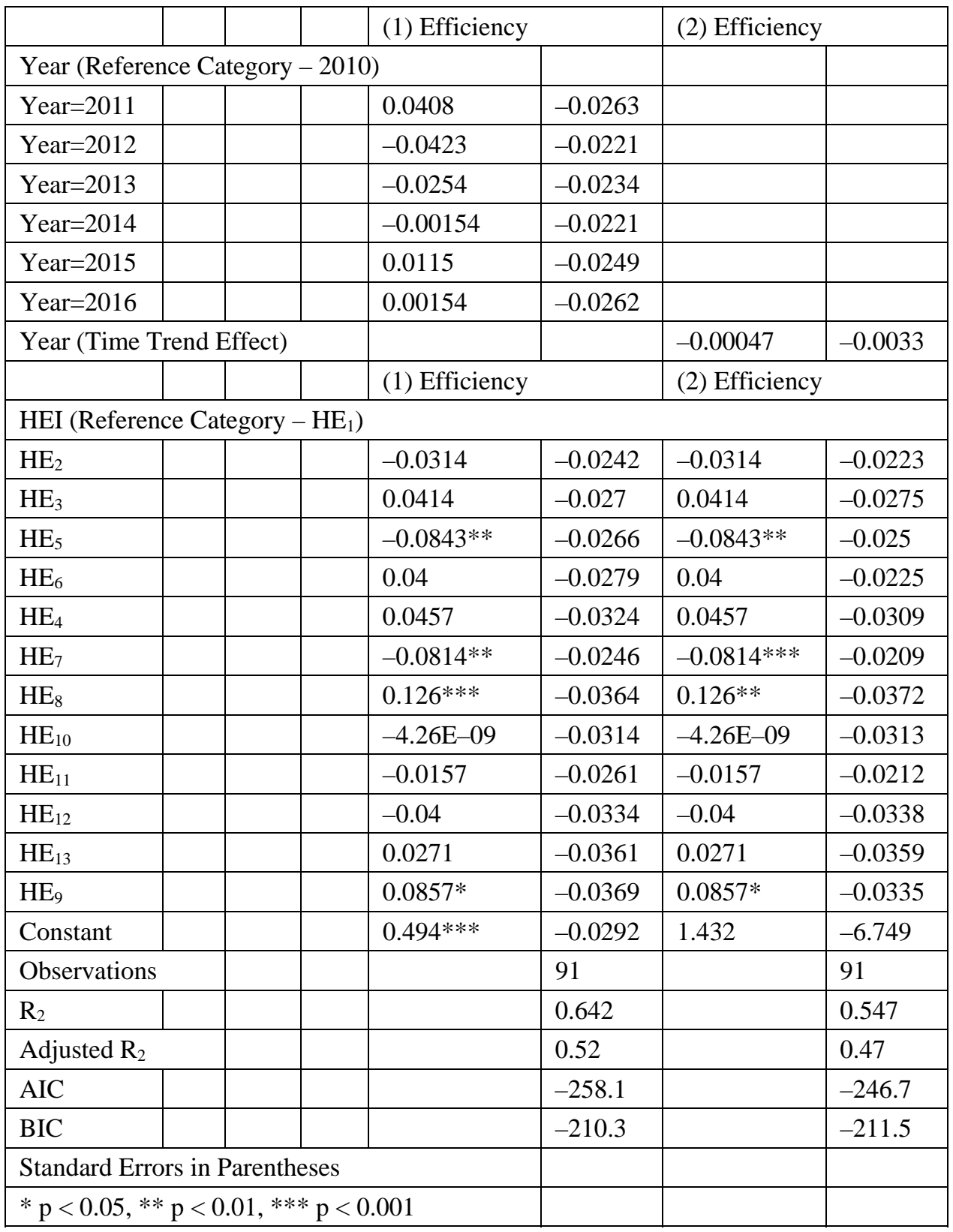


From an empirical point of view, this dissertation creates new knowledge for assessing the economic impact and efficiency of HEIs. By applying the new model developed in this dissertation in the context of Lithuania, this research offers important insights on their contribution to the economy.

There are various concerns regarding the HE sector which inevitably need to be resolved in order to strengthen the structure of state-funded HEIs in Lithuania. The country's limited educational funds have raised the public's doubts about the quality of the education provided in these institutions. There are high rates of emigration by professors and researchers from Lithuania; this is due to the low salary packages issued by the state, which make their compensation insufficient to support themselves and their families (MacDonald, 2010; Yudkevich, Altbach, \& Rumbley, 2017). In addition to casing them to leave the country, the state also loses the valuable work they will produce elsewhere. This situation minimises some of the output variables considered in many models.

Attrition from the system has been worsened by the students following their lecturers, as they are also leaving Lithuania in favour of foreign HEIs (Daniunas, et al., 2013; Herndon, 2008). All these things lead to the pursuit of career growth, opportunities, and monetary benefits in foreign countries. The loss of talent, with respect to both academic personnel and students, is further enhanced by issues with quality control in upholding state provided education (Legcevic \& Hecimovic, 2016). The Centre for Quality Assurance in HE (CQAHE), a state agency, was made in 2007 year to monitor the level and quality of education in HEIs, and to provide the enough resources to effectively carry out all such functions. Some citizens question the value of credentials received from these public institutions, which incentivises them to look elsewhere (Thomas, 2001).

This research posits that, given Lithuania's current brain drain and diminished participation in national HEIs, this is an urgent matter that, if left unresolved, leaves Lithuania's future economic development in question. The model presented in this dissertation is applicable and relevant to other Higher Education systems throughout the world, many of which are currently facing economic pressures.

\subsection{Conclusions of Chapter 3}

1. Public universities showed one of the highest type II output multipliers compared to other educational sectors, revealing HE sector is an important asset within Lithuanian economy. The only sector to surpass it was the basic and secondary educational system. This result is because employees in the tertiary education system demand a much larger share of expenditures than any other sectors in the country. 
2. Public universities' type II output multipliers are neither the highest nor the lowest among the education sectors. HEI is surpassed by the basic and secondary educational systems while it surpasses pre-primary and primary education and colleges.

3. Biggest universities (according to the number of students, academic personnel and budget fund received) are scoring high in Type II output multipliers compared to that of small $\mathrm{HE}$ public universities. $\mathrm{HE}_{12}$ scores 0.00214 , nearly more than the other top two public universities combined. This can be attributed to the size of the $\mathrm{HE}_{12}$ at nearly 20,000 enrolled students, whereas $\mathrm{HE}_{2}$, the second highest HEI, scoring 0.00128, has just over 16,000 students. Thus, the amount of human capital here is lower in terms of both students and academic personnel.

4. $\mathrm{HE}_{6}$ scored the lowest multiplier of 0.00012 in the selected public universities. Here only 2,000 students are enrolled, as it is a specialized HEI. This has two implications: first, a smaller student count correlates with a reduced number of academic personnel and, thus, reduced human capital; second, being a specialized HEI limits the amount of knowledge that can spill-over into the surrounding region and country. Some businesses can thrive from sports education, for example, but the majority will benefit from it. $\mathrm{HE}_{2}$ is also a specialized HEI; however, its score is the second highest input and so reveals that there is no consistency with HEI type I and Type II output.

5. The top five most efficient public universities are $\mathrm{HE}_{8}, \mathrm{HE}_{4}, \mathrm{HE}_{9}, \mathrm{HE}_{10}$, and $\mathrm{HE}_{3}$ respectively. However, the least efficient public universities are $\mathrm{HE}_{2}, \mathrm{HE}_{12}$, and $\mathrm{HE}_{7}$ respectively. This is interesting because all the top five public universities are large (some also being specialized) except $\mathrm{HE}_{10}$, a specialized HEI with only 2,000 enrolled students. Therefore, the assumptions stated in the start of this thesis, that smaller and more specialist public universities are inefficient in providing outputs compared to their inputs, is not valid in all cases. In the least three efficient public universities, two of these are specialized public universities yet $\mathrm{HE}_{12}$ is the largest public and non-specialized HEI in Lithuania, again showing these assumptions to be incorrect.

6. A panel data regression estimation of cross efficiency allowed for intertemporal comparisons, which was a vital step in assessing the dynamics of efficiency changes within the public universities. $\mathrm{HE}_{13}$ decreased in efficiency by $33.9 \%$, and $\mathrm{HE}_{9}$ increased in efficiency by $37.1 \%$ over a sixyear period. Most public universities fluctuated in increasing or decreas- 
ing efficiencies by over $10 \%$ with only $\mathrm{HE}_{1}, \mathrm{HE}_{2}, \mathrm{HE}_{7}, \mathrm{HE}_{3}$ and $\mathrm{HE}_{6}$ remaining relatively constant under this threshold. This is where it can also be seen that $\mathrm{HE}_{13}$ went from being the most efficient in 2010 to the least efficient in 2016. Therefore, this would be an area of interest to investigate, to see why this is the case for their largest public universities.

7. Assessing efficiency into time-specific effects allows the testing of the null hypothesis, which is "Some years did not have an abnormally low or high efficiency due to external factors." Looking year to year, none of the temporal effects produced a significant result from the model; none of these exceeded the 95\% confidence level, and so the hypothesis cannot be rejected. This shows the stability of the efficiencies over this period.

8. The specific effects of the public universities are significant, showing that there is heterogeneity between the efficiency levels of each HEI. HE ${ }_{1}$ is significantly more efficient than that of $\mathrm{HE}_{5}, \mathrm{HE}_{4}$, and $\mathrm{HE}_{7}$; however, these are significantly less efficient than $\mathrm{HE}_{13}$ and $\mathrm{HE}_{8}$. $\mathrm{HE}_{5}, \mathrm{HE}_{4}$ and $\mathrm{HE}_{7}$ are all specialized public universities. Nevertheless, the research findings suggest that at this institutional level, there is a difference in the types of public universities, which could have been overshadowed in the preliminary findings

\subsection{Future Research Directions}

The work answers the results of Chapter 3 call for some potentially interesting extensions. The chapter concludes by summarizing four such future directions for research.

1. First, given that some public universities in the sample are ranked high according to the size of their multiplier but low according to their efficiency level (and the opposite), a composite evaluation index could be constructed that would consider both criteria (size of multiplier and efficiency level). This new index could then be used to rank the universities in a consistent way.

2. Second, it would be interesting to repeat the study outlined in Chapter 3 for the case of the other Baltic states. Potential similarities and, especially, differences on the results obtained could then shed light on some of the questions facing public universities in Lithuania.

3. A third extension that would be particularly interesting given the upcoming restructuring of HE in Lithuania would be to examine the economic impact of HE in countries before and after similar reformulations. Did 
these reformulations improve or deteriorate the impact of HE? Examples of such mergers are provided by Finland, Norway, Sweden, Netherlands, Belgium, Germany, Great Britain, and South Africa. Examining the outcome of this strategy in different countries could help the authorities in Lithuania in their own attempts to reduce the number of universities in the country.

4. Finally, in order to comprehend the relative impact of public universities on the economy, it would be interesting to compare the output multipliers of the current study with those of the other sectors of the economy (namely, the non-education sectors). The literature has shown that the public universities ' multipliers usually lie above the median multipliers of an economy (but below the maximum ones). Verifying (or rejecting) a similar result for the case of Lithuania will again provide a better comprehension of public universities relative importance for the regional and national economy. 



\section{General Conclusions}

1. The existing theoretical concepts have been systematized in order to assess HEIs' economic impact and efficiency. This process has shown the need to consider HEIs as a significant element of a nation's economic development. Effective strategic decision-making on economic activities should be based on analysing past performance and making forecasts for the future. Maintaining HE's impact on the economy can be enforced through effective usage of financial resources and intellectual capital in HEIs. This interaction is the departure point for analysing economic impact and efficiency of HEIs in a country's economic development.

2. Furthermore, this study offered a new methodology to assess economic impact and efficiency of HEIs within one system. The integrated methodology is convenient for generating new knowledge on the effective usage of resources in the HE sector. The methodology can be a valuable instrument to assess the nexus between HEIs and other key sectors of the economy. This methodology represents a scientific contribution that can be applied in the context of HEIs throughout the world.

3. This study developed a new model for assessing the economic impact and efficiency of HEIs in the context of the local and national economy. Economic impact and efficiency can be measured by recognizing HEIs, not 
only as knowledge producers but as long-term enhancers of local economies. The research combined and adapted the I-O and DEA methods in a novel way. The study brought much-needed granularity to the evaluation of the economic impact and the efficiency of HEIs. In concert, the I-O and DEA methods injected a stronger degree of practicality into the impact analysis of these institutions. Namely, this analytical framework disaggregated the HEI sector into individual institutions, allowing its output multiplier to be computed via the standard I-O approach. In essence, this multiplier is a more exact estimate of the economic impact of each individual HEI. Theoretically, the DEA component benefits from modifications to the I-O analysis by allowing for greater detail in analysis. This, in turn, can provide more sensitive feedback for informing HEI economic efficiency in practice. The major findings bear out the benefits of deploying this framework.

4. This study conducted empirical research on Lithuania's public universities, a key cog in Lithuania's economy, and helped to test the proposed model. Since the government is planning a massive structural reform to merge the 14 public universities into 9, these findings provide useful information to stakeholders about the economic value of the country's publicly funded tertiary education system. The investigated public universities had one of the largest type II output multipliers compared to other educational sectors. Surprisingly, they were surpassed only by the basic and secondary educational system. Intertemporal comparisons of public universities' efficiency provide new insights into the degraded or increased efficiency at an institutional level. One of the most important findings of this paper is debunking the previous assumption that small public universities are inefficient compared to their larger counterparts. One of the smallest public university is ranked in the top five most efficient, and the largest public university is ranked $12^{\text {th }}$ out of 13 as the least efficient public university in the country. 


\section{References}

Abbott, M., \& Doucouliagos, C. (2009). Competition and efficiency: overseas students and technical efficiency in Australian and New Zealand universities. Education Economics, 17(1), 31-57. doi: 10.1080/09645290701773433

Adelle, C., \& Weiland, S. (2012). Policy assessment: The state of the art. Impact assessment and project appraisal, 30(1), 25-33.

Agasisti, T., \& Haelermans, C. (2015). Comparing Efficiency of Public Universities among European Countries: Different Incentives Lead to Different Performances. Higher Education Quarterly, 70(1), 81-104. doi: 10.1111/hequ.12066

Agasisti, T., \& Johnes, G. (2009). Beyond frontiers: Comparing the efficiency of higher education decision-making units across more than one country. Education Economics, 17(1), 59-79.

Agasisti, T., \& Johnes, G. (2015). Efficiency, costs, rankings and heterogeneity: The case of US higher education. Studies in Higher Education, 40(1), 60-82.

Airy, S., \& Brown, G. (2018). Community Education in New Zealand. Global Adaptations of Community College Infrastructure, 135-154. doi: 10.4018/978-1-5225-5861-3.ch010

Alexander, F. K. (2000). The changing face of accountability: Monitoring and assessing institutional performance in higher education. The Journal of Higher Education, 71(4), 411-431. 
Alves, J., Carvalho, L., Carvalho, R., Correia, F., Cunha, J., Farinha, L., \& Nicolau, A. (2015). The impact of polytechnic institutions on the local economy. Tertiary Education and Management, 21(2), 81-98.

Alzadjali, A. (2018). Policies and Initiatives for the Internationalization of Higher Education in Oman. Policies and Initiatives for The Internationalization of Higher Education, 12-31. doi: 10.4018/978-1-5225-5231-4.ch002

Anselin, L., Varga, A., \& Acs, Z. (1997). Local geographic spill overs between university research and high technology innovations. Journal of Urban Economics, 42(3), 422-448.

Anselin, L., Varga, A., \& Acs, Z. (2000). Geographical spill overs and university research: A spatial econometric perspective. Growth and Change, 31(4), 501-515.

Armstrong, H., Darral, J. and Grove-White, R., (1997). Maximizing the Local Economic, Environmental and Social Benefits of a University: Lancaster University.

Arrow, K. J. (1962). The economic implications of learning by doing. The Review of Economic Studies, 29(3), 155-173.

Athanassopoulos, A. D., \& Shale, E. (1997). Assessing the comparative efficiency of higher education institutions in the UK by the means of data envelopment analysis. Education Economics, 5(2), 117-134.

Aziz, S., Mahmood, M., \& Bano, S. (2018). Total quality management: A framework for Higher Education Institutions. Journal of Research in Social Sciences, 6(1), 121-141.

Barra, C., \& Zotti, R. (2017). Investigating the human capital development-growth nexus: Does the efficiency of universities matter? International Regional Science Review, 40(6), 638-678.

Barrio-Castro, T. D., \& García-Quevedo, J. (2005). Effects of university research on the geography of innovation. Regional Studies, 39(9), 1217-1229.

Beck, R., Elliott, D., Meisel, J., \& Wagner, M. (1995). Economic impact studies of regional public colleges and universities. Growth and Change, 26(2), 245-260.

Beise, M., \& Stahl, H. (1999). Public research and industrial innovations in Germany. Research Policy, 28(4), 397-422.

Bernaoui, R., Issolah, R., \& Hassoun, M. (2015). Strategic issues of a value-added information system for higher education in Algeria. Perspectives of Innovations, Economics and Business, 15(1), 57-66. doi: 10.15208/pieb.2015.05

Blackwell, M., Cobb, S., \& Weinberg, D. (2002). The Economic Impact of Educational Institutions: Issues and Methodology. Economic Development Quarterly, 16(1), 88-95. doi: $10.1177 / 0891242402016001009$

Blundell, R., L. Deardren, and B. Sianesi. (2005). Measuring the Returns to Education. In S. Machin \& A. Vignoles (Eds.), What's the Good of Education: The Economics of Education in the UK (pp. 117-146). Princeton, NJ: Princeton University Press. 
Bonwell, C. C., \& Eison, J. A. (1991). Active Learning: Creating Excitement in the Classroom. 1991 ASHE-ERIC Higher Education Reports. ERIC Clearinghouse on Higher Education, The George Washington University, One Dupont Circle, Suite 630, Washington, DC 20036-1183.

Booth, G. G., \& Jarrett, J. E. (1976). The identification and estimation of a university's economic impacts. The Journal of Higher Education, 47(5), 565-576.

Borralho, C., Feria, I., \& Lopes, S. (2015). The impact of Higher Education on socioeconomic and development dynamics: Lessons from six study cases. Investigaciones de Economía de la Educación, 10, 887-905.

Boughey, C. (2003). From Equity to Efficiency: Access to higher education in South Africa. Arts and Humanities in Higher Education, 2(1), 65-71. doi: 10.1177/1474022203002001006

Bowen, H. (2018). Investment in learning: The individual and social value of American higher education. Routledge.

Bowen, H., Caffrey, J., \& Isaacs, H. (1971). Estimating the Impact of a College or University on the Local Economy. The Journal of Higher Education, 43(1), 82. doi: $10.2307 / 1980786$

Bowen, W. M., \& Qian, H. (2017). State spending for higher education: Does it improve economic performance? Regional Science Policy \& Practice, 9(1), 7-23. doi:10.1111/rsp3.12086

Bowlin, W. F. (1998). Measuring performance: An introduction to Data Envelopment Analysis (DEA). The Journal of Cost Analysis, 3-27.

Bramwell, A., \& Wolfe, D. A. (2008). Universities and regional economic development: The entrepreneurial University of Waterloo. Research Policy, 37(8), 1175-1187.

Brennan, J., Cochrane, A., Lebeau, Y., \& Williams, R. (2018). Introduction: On Universities and Their 'Places'. In the University in its Place (pp. 3-12). Springer: Dordrecht.

Bridge, M. (2011). Higher Education Economic Impact Studies: Accurate Measures of Economic Impact? Journal of College Teaching \& Learning (TLC), 2(2). doi: 10.19030/tlc. v2i2.1777

Brown, K. H., \& Heaney, M. T. (1997). A note on measuring the economic impact of institutions of higher education. Research in Higher Education, 38(2), 229-240.

Caffrey, J., \& Isaacs, H. H. (1971). Estimating the Impact of a College or University on the Local Economy.

Cano, E., \& Ion, G. (2014). Curriculum Development through Competency-Based Approach in Higher Education. Handbook of Research on Transnational Higher Education, 79-95. doi: 10.4018/978-1-4666-4458-8.ch005 
Carlsson, B., \& Fridh, A. C. (2003). Technology transfer in United States universities. In J. Metcalfe \& U. Cantner (Eds.), Change, Transformation and Development (pp. 379412). Physica: Heidelberg.

Carroll, M. C., \& Smith, B. W. (2006). Estimating the economic impact of universities: The case of Bowling Green State University. The Industrial Geographer, 3(2), 1-12.

Charles, D. (2011). The role of universities in building knowledge cities in Australia. Built Environment, 37(3), 281-298.

Cheah, S., \& Yu, C. (2016). Assessing economic impact of research and innovation originating from public research institutions and universities - case of Singapore PRIs. Triple Helix, 3(1), 6.

Ciccone, A., \& Peri, G. (2006). Identifying human-capital externalities: Theory with applications. The Review of Economic Studies, 73(2), 381-412.

Clemmons, K., Nolen, A., \& Hayn, J. (2014). Constructing Community in Higher Education Regardless of Proximity. Handbook of Research on Transnational Higher Education, 713-729. doi: 10.4018/978-1-4666-4458-8.ch036

Cowan, J. (1985). Effectiveness and efficiency in higher education. Higher Education, 14(3), 235-239. doi: 10.1007/bf00136107

Cox, S., \& Taylor, J. (2006). The impact of a business school on regional economic development: A case study. Local Economy, 21(2), 117-135.

Crompton, J. L. (1995). Economic impact analysis of sports facilities and events: Eleven sources of misapplication. Journal of Sport Management, 9, 14-35.

Crompton, J. L., Lee, S., \& Shuster, T. J. (2001). A guide for undertaking economic impact studies: The Springest example. Journal of Travel Research, 40, 79-87.

Daniunas, A., Kliukas, R., Prentkovskis, O., \& Ulinskaite, D. (2013). The impact of Lithuanian science and study reform on university activities (admission): A case of Vilnius Gediminas Technical University. Procedia - Social and Behavioral Sciences, 93, 565573.

Dixit, A. (2002). Incentives and Organizations in the Public Sector: An Interpretative Review. The Journal of Human Resources, 37(4), 696. doi: 10.2307/3069614

Drucker, J. (2015). Reconsidering the regional economic development impacts of higher education institutions in the United States. Regional Studies, 50(7), 1185-1202. doi:10.1080/00343404.2014.986083

Drucker, J. (2016). Reconsidering the regional economic development impacts of higher education institutions in the United States. Regional Studies, 50(7), 1185-1202.

Drucker, J., \& Goldstein, H. (2007). Assessing the regional economic development impacts of universities: A review of current approaches. International Regional Science review, 30(1), 20-46. 
Dyson, R., Allen, R., Camanho, A., Podinovski, V., Sarrico, C., \& Shale, E. (2001). Pitfalls and protocols in DEA. European Journal of Operational Research, 245-259.

Eesley, C. E., \& Miller, W. F. (2018). Impact: Stanford University’s Economic Impact via Innovation and Entrepreneurship. Foundations and Trends in Entrepreneurship, 14(2), 130-278.

Elliott, D., Levin, S., \& Meisel, J. (1988). Measuring the economic impact of institutions of higher education. Research in Higher Education, 28(1), 17-33. doi: 10.1007/bf00976857

Eurostat (2008) "NACE Rev. 2 Statistical classification of economic activities in the European Community," European Communities, Luxembourg.

Felsenstein, D. (1996). The university in the metropolitan arena: Impacts and public policy implications. Urban Studies, 33(9), 1565-1580.

Florax, R., \& Folmer, H. (1992). Knowledge impacts of universities on industry an aggregate simultaneous investment model. Journal of Regional Science, 32(4), 437-466.

Forrant, R. (2001). Pulling together in Lowell: The university and the regional development process. European Planning Studies, 9(5), 613-628.

Furková, A. (2013). Alternative Approaches to Efficiency Evaluation of Higher Education Institutions. Journal on Efficiency and Responsibility in Education and Science, 6(3), 167-178. doi: 10.7160/eriesj.2013.060304

Gaffikin, F., \& Morrissey, M. (2008). A new synergy for universities: Redefining academy as an 'engaged institution'. Education, Citizenship and Social Justice, 3(1), 97-116.

Garrido-Yserte, R., \& Gallo-Rivera, M. T. (2010). The impact of the university upon local economy: Three methods to estimate demand-side effects. The Annals of Regional Science, 44(1), 39.

Ghisellini, P., Cialani, C., \& Ulgiati, S. (2016). A review on circular economy: The expected transition to a balanced interplay of environmental and economic systems. Journal of Cleaner production, 114, 11-32.

Glasson, J. (2003). The Widening Local and Regional Development Impacts of the Modern Universities - A Tale of Two Cities (and North-South Perspectives). Local Economy 18(1), 21-37.

Goddard, J., \& Vallance, P. (2013). The University and the City. New York: Routledge.

Golany, B., \& Roll, Y. (1989). An application procedure for DEA. Omega, 237-250.

Goldstein, H., \& Renault, C. (2004). Contributions of universities to regional economic development: A quasi-experimental approach. Regional Studies, 38(7), 733-746.

Golooba, M., \& Ahlan, A. R. (2013). Service value co-creation in research \& innovation practices in higher education institutions. Procedia Technology, 11, 342-347. 
Granzow, H. (1979). Efficiency in Higher Education. Western European Education, 11(34), 53-63. doi: 10.2753/eue1056-493411030453

Greenwood, J., Sanchez, J., \& Wang, C. (2013). Quantifying the impact of financial development on economic development. Review of Economic Dynamics, 16(1), 194-215. doi: 10.1016/j.red.2012.07.003

Guerrero, M., Cunningham, J. A., \& Urbano, D. (2015). Economic impact of entrepreneurial universities' activities: An exploratory study of the United Kingdom. Research Policy, 44(3), 748-764.

Guerrero, M., Urbano, D., \& Cunningham, J. (2016). The economic impact of public universities in the United Kingdom. In Phan, P. H. (Ed.) Academic entrepreneurship: Translating discoveries to the marketplace. Edward Elgar Publishing.

Hackett, P., Lemoine, P., \& Richardson, M. (2017). Impact of Technology Ambiguity on Leadership in Global Higher Education. Encyclopedia of Strategic Leadership and Management, 270-281. doi: 10.4018/978-1-5225-1049-9.ch020

Harris, R. I. (1997). The impact of the University of Portsmouth on the local economy. Urban Studies, 34(4), 605-626.

Hatakenaka, S. (2015). The Role of Higher Education Institutions in Innovation and Economic Development. International Higher Education, 47. doi: 10.6017/ihe.2007.47.7961

Hauke, J., \& Kossowski, T. (2011). Comparison of values of Pearson's and Spearman's correlation coefficients on the same sets of data. Quaestiones geographicae, 30(2), 87-93

Hayter, C. S. (2016). A trajectory of early-stage spinoff success: The role of knowledge intermediaries within an entrepreneurial university ecosystem. Small Business Economics, 47(3), 633-656.

Hermannsson, K., \& Swales, K. (2010). Capturing the overall economic impacts of HEIs. Commissioned report.

Hermannsson, K., Lisenkova, K., McGregor, P. G., \& Swales, J. K. (2013). The Expenditure Impacts of Individual Higher Education Institutions and Their Students on the Scottish Economy under a Regional Government Budget Constraint: Homogeneity or Heterogeneity? Environment and Planning A: Economy and Space, 45(3), 710-727. https://doi.org/10.1068/a45233

Hermannsson, K., Lisenkova, K., McGregor, P. G., \& Swales. J. K. (2015). The expenditure impacts of London's higher education institutions: the role of diverse income sources. Studies in Higher Education, 40(9), 1641-1659.

Hermannsson, K., Lisenkova, K., McGregor, P., \& Swales, J. (2010). The expenditure impacts of individual higher education institutions (HEIS) and their students on the Scottish economy under devolution: homogeneity or heterogeneity? Discussion Papers in Economics, 10(16), 1-45.

Hermannsson, K., Lisenkova, K., McGregor, P., \& Swales, J. (2010). An HEI-disaggregated input-output table for Wales. 
Herndon, M. C. (2008). The public benefits of higher education: examining the relationship between state spending on higher education and the formation of human capital (Doctoral dissertation, Virginia Tech).

Hoenack, S. (1982). Pricing and Efficiency in Higher Education. The Journal of Higher Education, 53(4), 403. doi: 10.2307/1981606

Hudson, B. (1974). Regional economic effects of higher education institutions. SocioEconomic Planning Sciences, 8(4), 181-194. doi: 10.1016/0038-0121(74)90042-1

Huggins, R., \& Cooke, P. (1997). The economic impact of Cardiff University: Innovation, learning and job generation. GeoJournal, 41(4), 325-337.

Huggins, R., \& Johnston, A. (2009). The economic and innovation contribution of universities: a regional perspective. Environment and Planning C: Government and Policy, 27(6), 1088-1106.

Huggins, R., Johnston, A., \& Thompson, P. (2012). Network capital, social capital and knowledge flow: How the nature of inter-organizational networks impacts on innovation. Industry and Innovation, 19(3), 203-232.

Jaeger, A., \& Kopper, J. (2014). Third mission potential in higher education: Measuring the regional focus of different types of HEIs. Review of Regional Research, 34(2), 95118.

Jalil, A., \& Idrees, M. (2013). Modelling the impact of education on the economic growth: Evidence from aggregated and disaggregated time series data of Pakistan. Economic Modelling, 31, 383-388. doi: 10.1016/j.econmod.2012.11.035

Johansen, T., \& Arano, K. (2016). The Long-Run Economic Impact of an Institution of Higher Education. Economic Development Quarterly, 30(3), 203-214. doi: 10.1177/0891242416655204

Kaiser, F., Vossensteyn, H., \& Koelman, J. (2001). Public funding of higher education. A comparative study of funding mechanisms in ten countries. Enter for Higher Education Policy Studies, 1-127.

Kalkbrenner, E. (2015). The Japanese Tertiary Education System and Its Impact on Economic Conditions from 2000 to 2010. Handbook of Research on Advancing Critical Thinking in Higher Education, 443-471. doi: 10.4018/978-1-4666-8411-9.ch018

Keller, K. R. I. (2006). Investment in primary, secondary, and higher education and the effects on economic growth. Contemporary Economic Policy, 24(1), 18-34

Kelly, U., McNicoll, I., \& McLellan, D. (2004). The Impact of the University of Strathclyde on the Economy of Scotland and the City of Glasgow.

Kimenyi, M. S. (2011). Contribution of Higher Education to Economic Development: A Survey of International Evidence. Journal of African Economies, 20(Supplement 3), iii14iii49. doi:10.1093/jae/ejr018 
Kotsz, B., Gaunard-Anderson, M. F., \& Lukovics, M. (2018). The local economic impact of universities: An international comparative analysis (France and Hungary). In Entrepreneurship in post-communist countries (pp. 115-131). Springer: Cham.

Langford, C. H. (2002). Measuring the impact of university research on innovation. Knowledge clusters and regional innovation: Economic development in Canada, Montreal. McGill-Queen's University Press

Lee, J. (2018). The Local Economic Impact of A Large Research University: Evidence From Uc Merced. Economic Inquiry, 57(1), 316-332. doi: 10.1111/ecin.12734

Legcevic, J., \& Hecimovic, V. (2016). Internal quality assurance at a higher education institution. Business Excellence, 10(2), 75-87.

Leigh, N. G., \& Blakely, E. J. (2016). Planning local economic development: Theory and practice. SAGE publications.

Lepori, B., Benninghoff, M., Jonbloed, B., Salerno, C., \& Slipersaeter, S. (2007). Changing models and patterns of higher education funding: Some empirical evidence. In A. Bonaccorsi, \& C. Daraio (Eds.), Universities and strategic knowledge creation (pp. 85111). Cheltenham: Edward Elgar.

Leslie, L. L., \& Brinkman, P. T. (1988). The Economic Value of Higher Education. American Council on Education/Macmillan Series on Higher Education. New York, NY: Macmillan Publishing.

Levin, H. (2018). Privatizing Education: Can the school marketplace deliver freedom of choice, efficiency, equity, and social cohesion? Routledge.

Lilles, A., \& Rõigas, K. (2017). How do higher education institutions contribute to the growth in regions of Europe? Studies in Higher Education, 42(1), 65-78.

Lin, T. C., Kung, S. F., \& Wang, H. C. (2015). Effects of firm size and geographical proximity on different models of interaction between university and firm: A case study. Asia Pacific Management Review, 20(2), 90-99.

Lithuanian Public Procurement Office (2018), Data on Universities Public Procurement Procedures from the period (2010-2016), retrieved from: http://vpt.Irv.lt/en/

Lowe Boyd, W. (2004). Are education and efficiency antithetical? Journal of Educational Administration, 42(2), 160-173. doi: 10.1108/09578230410525586

Lu, M., Miller, M., \& Newman, R. (2014). The Global Scholar. Handbook of Research on Transnational Higher Education, 612-622. doi: 10.4018/978-1-4666-4458-8.ch030

MacDonald, J. L. (2010). Lithuanian migration in crisis? A look into the effects of the current economic crisis on migration. Master Thesis: Lund University.

Marginson, S. (1991). Productivity and Efficiency in Education. Australian Journal of Education, 35(2), 201-214. doi: 10.1177/000494419103500207

Mason, G. (2014). Part-time Higher Education: Employer Engagement Under Threat? Higher Education Quarterly, 68(3), 305-327. doi: 10.1111/hequ.12053 
Mayer, H. (2007). What is the role of the university in creating a high-technology region? Journal of Urban Technology, 14(3), 33-58.

McGregor, P., K. Swales, \& D. McLellan. (2006). The Overall Impact of Higher Education Institutions on Regions: A Critical Review.” In Network on the Overall Impact of HEIs on Regional Economies: Final Report, Centre for Public Policy for the Regions, 835. Glasgow: Centre for Public Policy for Regions.

Mikušová, P. (2017). Measuring the Efficiency of The Czech Public Higher Education Institutions: An Application Of DEA. Journal on Efficiency and Responsibility in Education And Science, 10(2), 58-63. doi: 10.7160/eriesj.2017.100204

Miller, R. E., \& Blair, P. D. (2009). Input-Output Analysis (2 ${ }^{\text {nd }}$ ed.). Cambridge, MA: Cambridge University Press.

Monjon, S., \& Waelbroeck, P. (2003). Assessing spill overs from universities to firms: evidence from French firm-level data. International Journal of Industrial Organization, 21(9), 1255-1270.

Moretti, E. (2004). Estimating the social return to higher education: Evidence from longitudinal and repeated cross-sectional data. Journal of Econometrics, 121(1-2), 175-212.

Moretti, E. (2004). Workers' education, spillovers, and productivity: evidence from plantlevel production functions. American Economic Review, 94(3), 656-690.

Motohashi, K. (2005). University-industry collaborations in Japan: The role of new technology-based firms in transforming the National Innovation System. Research Policy, 34(5), 583-594.

Nair, S., \& Sáiz Álvarez, J. (2018). Handbook of research on ethics, entrepreneurship, and governance in higher education.

Nicholl, P., Graham, D., Redpath, J., Kearney, P., Wallace, J., \& Mulvenna, M. et al. (2014). Identifying the Barriers and Enablers for Supporting Learners with Special Needs in Higher Education. Handbook of Research on Transnational Higher Education, 467485. doi: 10.4018/978-1-4666-4458-8.ch024

Official Reports of Financial Activities (2010-2016) year period (2018), Aleksandras Stulginskis University. Retrieved from: http://asu.lt/universitetas-2/pagrindiniai-veiklosdokumentai/

Official Reports of Financial Activities (2010-2016) year period (2018), Kaunas University of Technology. Retrieved from: https://ktu.edu/dokumentai/ataskaitos/\#finansai

Official Reports of Financial Activities (2010-2016) year period (2018), Klaipeda University. Retrieved from: https://www.ku.lt/apie-universiteta/veiklos-dokumentai

Official Reports of Financial Activities (2010-2016) year period (2018), Lithuanian University of Educational Sciences.

Official Reports of Financial Activities (2010-2016) year period (2018), Lithuanian Academy of Music and Theatre. Retrieved from: https://Imta.lt/lt/finansines-ataskaitos/ 
Official Reports of Financial Activities (2010-2016) year period (2018), Lithuanian Sports University. Retrieved from: https://www.lsu.lt/documents/ataskaitos/

Official Reports of Financial Activities (2010-2016) year period (2018), Lithuanian University of Health Sciences. Retrieved from: http://www.Ismuni.lt/lt/apie-universiteta/svarbus-dokumentai/

Official Reports of Financial Activities (2010-2016) year period (2018), Mykolas Romeris University Retrieved from: https://www.mruni.eu/lt/universitetas/asm_spec_poreikiais/ataskaitos/

Official Reports of Financial Activities (2010-2016) year period (2018), Šiauliai University. Retrieved from:http://www.su.lt/index.php?option=com_content\&view=article\&Itemid=175\&id=12159:finansini-ataskait-rinkiniai\&catid=47\&lang=lt

Official Reports of Financial Activities (2010-2016) year period (2018), Vilnius Academy of Arts. Retrieved from: https://www.vda.lt/lt/dokumentai/finansines-ataskaitos

Official Reports of Financial Activities (2010-2016) year period (2018), Vilnius Gediminas Technical University. Retrieved from:https://www.vgtu.lt/universitetas/strategija/planai-ir-ataskaitos/59?lang=1

Official Reports of Financial Activities (2010-2016) year period (2018), Vilnius University. Retrieved from: https://www.vu.lt/apiemus/dokumentai\#finansines-ataskaitos

Official Reports of Financial Activities (2010-2016) year period (2018), Vytautas Magnus University. Retrieved from: https://www.vdu.lt/lt/apie-vdu-kaune/svarbiausi-vdu-dokumentai/

Official Statistics Portal of Lithuania (2018). Classification of Economic Activities (EVRK) [12/09/2017]. Retrieved from https://osp.stat.gov.lt/600

Official Statistics Portal (2018). National Accounts. 2010 Input and output tables (XLSX). Retrieved from: https://osp.stat.gov.lt/nacionalines-saskaitos

Olivares, M., \& Wetzel, H. (2014). Competing in the Higher Education Market: Empirical Evidence for Economies of Scale and Scope in German Higher Education Institutions. CESifo Economic Studies, 60(4), 653--680. doi:10.1093/cesifo/ifu001

Owen, J. (1981). Strategic Planning in Tertiary Education. Journal of Tertiary Education Administration, 3(2), 125-131. doi: 10.1080/0157603810030203

Palmer, S., \& Torgerson, D. J. (1999). Economics notes: Definitions of efficiency. BMJ: British Medical Journal, 318(7191), 1136.

Pastor, J. M., Pérez, F., \& De Guevara, J. F. (2013). Measuring the local economic impact of universities: An approach that considers uncertainty. Higher Education, 65(5), 539564.

Penfield, T., Baker, M. J., Scoble, R., \& Wykes, M. C. (2014). Assessment, evaluations, and definitions of research impact: A review. Research Evaluation, 23(1), 21-32. 
Powell, B., Gilleland, D., \& Pearson, L. (2012). Expenditures, Efficiency, and Effectiveness in U.S. Undergraduate Higher Education: A National Benchmark Model. The Journal of Higher Education, 83(1), 102-127. doi: 10.1353/jhe.2012.0005

Power, D., \& Malmberg, A. (2008). The contribution of universities to innovation and economic development: In what sense a regional problem? Cambridge Journal of Regions, Economy and Society, 1(2), 233-245.

Prieto, A. M., \& L. Zofío, J. (2007). Network DEA efficiency in input-output models: With an application to OECD countries. European Journal of Operational Research, 178(1), 292-304.

Proctor, D. (2009). Accessibility of Technology in Higher Education. Encyclopedia of Distance Learning, Second Edition, 16-28. doi: 10.4018/978-1-60566-198-8.ch003

Psacharopoulos, G \& Patrinos, H (2002) Returns to investment in education: A further update. World Bank Policy Research Working Paper 2881, Washington, DC: The World Bank.

Quah, E., \& Haldane, J. B. S. (2007). Cost-benefit analysis. Routledge.

Rabovsky, T.M. (2012). Accountability in Higher Education: Exploring Impacts on State Budgets and Institutional Spending Patterns. Journal of Public Administration Research and Theory, 675-700.

Rapple, B. (1992). A Victorian experiment in economic efficiency in education. Economics of Education Review, 11(4), 301-316. doi: 10.1016/0272-7757(92)90039-6

Research and Higher Education Monitoring and Analysis Centre (2016). Review of Science and Studies in Lithuania, Research and Higher Education Monitoring and Analysis Centre.

Republic of Lithuania. (2011). Law on Higher Education and Research. Retrieved from https://www.mruni.eu/mru_lt_dokumentai/direkcijos/studiju_direkcija/teises_aktai/Lietuvos\%20teises\%20aktai/Law_on_Higher_Education_and_Research.pdf

Roberts, E. B., \& Eesley, C. E. (2011). Entrepreneurial impact: The role of MIT. Foundations and Trends in Entrepreneurship, 7(1-2), 1-149.

Saiz-Alvarez, J. (2014). Some Keys for Success in Higher Education. Handbook of Research on Higher Education in The MENA Region, 298-321. doi: 10.4018/978-1-46666198-1.ch013

Schartinger, D., Schibany, A., \& Gassler, H. (2001). Interactive relations between universities and firms: Empirical evidence for Austria. The Journal of Technology Transfer, 26(3), 255-268.

Schubert, T., \& Kroll, H. (2016). Universities' effects on regional GDP and unemployment: The case of Germany. Papers in Regional Science, 95(3), 467-489.

Schwab, K. (2010, September). The global competitiveness report 2010-2011. Geneva: World Economic Forum. 
Sen, A. (1975). The concept of efficiency. Contemporary Issues in Economics, 196-210. Sevinc, H. (2014). The role of universities in local economic development: A case of TRA2 region in Turkey. Research Journal of Business and Management, 1(4), 448-459.

Shah, S. K., \& Pahnke, E. C. (2014). Parting the ivory curtain: understanding how universities support a diverse set of startups. The Journal of Technology Transfer, 39(5), 780792.

Siegfried, J. J., Sanderson, A. R., \& McHenry, P. (2007). The economic impact of colleges and universities. Economics of Education Review, 26(5), 546-558.

Smilor, R., \& Matthews, J. (2004). University venturing: Technology transfer and commercialisation in higher education. International Journal of Technology Transfer and Commercialisation, 3(1), 111-128.

Solow, R. M. (1957). Technical change and the aggregate production function. The Review of Economics and Statistics, 39(3), 312-320.

Steinacker, A. (2005). The economic effect of urban colleges on their surrounding communities. Urban Studies, 42(7), 1161-1175.

Stokes, K., \& Coomes, P. (1998). The local economic impact of higher education: An overview of methods and practice. AIR Professional File, 67(6), 1-14.

Syvertud, G., \& Williams, C. (2016). Higher education's impact on the New England economy: Investing in people. New England Board of Higher Education. 1-34.

Tavoletti, E. (2007). Assessing the Regional Economic Impact of Higher Education Institutions: An Application to the University of Cardiff. Transition Studies Review, 14(3), 507-522. doi: 10.1007/s11300-007-0157-9

Taylor, B., \& Harris, G. (2004). Relative efficiency among South African universities: A data envelopment analysis. Higher Education, 47(1), 73-89. doi: 10.1023/b: high.0000009805.98400.4d

Taylor, C. (2007). Developing relationships between higher education, enterprise and innovation in the creative industries. Entrepreneurship in The Creative Industries: An International Perspective, 178-196.

Thanki, R. (1999). How do we know the value of higher education to regional development? Regional Studies, 33(1), 84-94.

The Research Council of Lithuania (2018), Mokslo (meno) veiklos rezultatų vertinimas. Retrieved from: https://www.lmt.lt/lt/mokslo-kokybe/mokslo-meno-veiklos-rezultatu-vertinimas/182

Thomas, H. G. (2001). Towards a new higher education law in Lithuania: reflections on the process of policy formulation. Higher Education Policy, 14, 213-223.

Tilak, J. (2003). Higher education and development. International Seminar, University XXI, Brasilia, November 
Tilak, J. B. (2018). The Kothari commission and financing of education. In Education and Development in India (pp. 255-282). Palgrave Macmillan, Singapore.

Tornquist, K. M., \& Hoenack, S. A. (1996). Firm utilization of university scientific research. Research in Higher Education, 37(5), 509-534.

Tsukhlo, S. (2018). Import Substitution: Russian Industry's Investment Preferences. SSRN Electronic Journal. doi: 10.2139/ssrn.3191851

Turner, D. A. (1997). The economic impact of a university on its environment. European Education, 29(3), 88-95.

Uyarra, E. (2010). Conceptualizing the regional roles of universities, implications and contradictions. European Planning Studies, 18(8), 1227-1246.

Varga, A. (2001). Universities and regional economic development: Does agglomeration matter? In Johansson, B. Karlsson, C, Stough, R. Theories of endogenous regional growth (pp. 345-367). Berlin: Springer Heidelberg.

Vengris, S. (1997). External evaluation of studies at Vilnius University, 1994-95. Quality in Higher Education, 3(1), 81-85.

Viaene, J. M., \& Zilcha, I. (2013). Public funding of higher education. Journal of Public Economics, 108, 78-89.

Vidal, M., Vidal-García, J., \& Barros, R. (2017). Big Data in Higher Education. Handbook of Research on Emerging Business Models and Managerial Strategies In The Nonprofit Sector, 1-16. doi: 10.4018/978-1-5225-2537-0.ch001

Waldo, S. (2007). On the use of student data in efficiency analysis-Technical efficiency in Swedish upper secondary school. Economics of Education Review, 26(2), 173-185. doi: 10.1016/j.econedurev.2005.06.005

Wang, S. B., \& Tian, Y. Z. (2008). Research on core capacity of higher education institutions based on value creation. 2008 International Conference on Management Science and Engineering: $15^{\text {th }}$ Annual Conference Proceedings.

Weisbrod, B and G. Weisbrod (1997): Measuring economic impacts of projects and programs. Economic Development Research Group.

Weisbrod, G., \& Weisbrod, B. (1997). Assessing the economic impact of transportation projects: How to choose the appropriate technique for your project. Transportation Research Circular, (477).

Yen, S. H., Ong, W. L., \& Ooi, K. P. (2015). Income and employment multiplier effects of the Malaysian higher education sector. The Journal of Applied Economic Research, 9(1), 61-91.

Yudkevich, M., Altbach, P. G., \& Rumbley, L. E. (2017). International faculty in higher education: Comparative perspectives on recruitment, integration, and impact. New York, NY: Routledge. 
Yusuf, S. (2007) University-industry links: Policy dimensions. In S. Yusuf \& K. Nabeshima (Eds.), How universities promote economic growth. Washington, DC: World Bank.

Zhang, Q., Larkin, C., \& Lucey, B. (2015). The economic impact of higher education institutions in Ireland: Evidence from disaggregated input-output tables. Studies in Higher Education, 42(9), 1601-1623. doi: 10.1080/03075079.2015.1111324

Zofío, J. L., \& Prieto, A. M. (2007). Measuring productive efficiency in input-output models by means of data envelopment analysis. International Review of Applied Economics, 519-537. 


\section{List of Publications by the Author on the Topic of the Dissertation}

\section{Papers in the Reviewed Scientific Journals}

Vaiciukevičiūtė, A.; Stankevičienė, J.; Bratčikovienė, N. Higher education institutions’ impact on the economy // Journal of business economics and management. Vilnius: VGTU Press. ISSN 1611-1699. eISSN 2029-4433. 2019, vol. 20, iss. 3, p. 507-525. DOI: 10.3846/jbem.2019.10156. [Scopus; Social Sciences Citation Index (Web of Science); [Citav. rod.: 1,503 (2017, InCites JCR SSCI)]

Stankevičienè, J.; Kraujalienè, L.; Vaiciukevičiūtė, A. Assessment of technology transfer office performance for value creation in higher education institutions // Journal of business economics and management. Vilnius; London: Technika; Taylor \& Francis. ISSN 1611-1699. eISSN 2029-4433. 2017, Vol. 18, iss. 6, p. 1063-1081. DOI: 10.3846/16111699.2017.1405841. [Scopus; Business Source Complete; Science Citation Index Expanded (Web of Science)

Stankevičienè, J.; Vaiciukevičiūtè, A. Value creation for stakeholders in higher education management // E\&M Economics and Management = E\&M Ekonomie a management. Liberec: Technická Univerzita v Liberci. ISSN 1212-3609. 2016, Vol. 19, iss. 1, p. 17-32. DOI: 10.15240/tul/001/2016-1-002. [EconLit; Scopus; Social Sciences Citation Index (Web of Science)]; [Citav. rod.: 1,163 (2016, InCites JCR SSCI)] 


\section{Papers in Other Journals}

Stankevičienè, J.; Vaiciukevičiūtè, A. Conceptual strategy map implementation for higher education institution // The 8th international scientific conference "Business and Management 2014”: selected papers. May 15-16, 2014. Vilnius: Technika, 2014. ISBN 9786094576522. p. 709-716. DOI: 10.3846/bm.2014.086. [Conference Proceedings Citation Index - Social Science \& Humanities (Web of Science)] 


\section{Summary in Lithuanian}

\section{lvadas}

\section{Problemos formulavimas}

Aukštojo mokslo indèlis - visos šalies konkurencingumo didinimo ir ilgalaikio ekonomikos užtikrinimo prasme - esminis. Valstybę ir visuomenę ypač domina tiek trumpalaikè, tiek ilgalaikẻ ekonominė aukštojo mokslo pridètinè vertė. Atlikti teoriniai tyrimai atskleide, jog siekiant priimti ekonomiškai pagrịstus AMI valdymo sprendimus reikia AMI vertinti integruotai poveikio ekonomikai ir efektyvaus resursų panaudojimo požiūriu. Siekiant spręsti šią fundamentalią ekonomikos problemą, kylančią iš poreikio efektyviau naudoti ribotus išteklius, AMI poveikio ekonomikai vertinimas tampa ypatingai aktualus globalios ekonomikos sąlygomis. Empiriniu požiūriu šis mokslinis darbas sukuria naujų žinių, kaip ịvertinti kiekvienos AMI poveikị šalies ekonomikai atskirai, tačiau vienoje integralioje sistemoje, siekiant priimti ekonomiškai pagrịstus valdymo sprendimus ateityje. Atlikus kritinę literatūros šaltinių analizę išskiriamos šios ekonomikos mokslui svarbios problemos:

1. Ekonominio poveikio ir efektyvumo vertimo metodai, dažniausiai naudojami versle, prastai atspindi AMI poveikị šalies ekonomikai. Nepakanka sistemingų metodikų, kaip ịvertinti AMI poveikị ir efektyvumą, todèl tokie vertinimai nèra atliekami arba vykdomi ne sisteminiu būdu. Kadangi nèra išsamios vertinimo sistemos, neįmanoma palyginti tame pačiame regione ar šalyje veikiančių AMI veiklos efektyvumo ir poveikio ekonomikai požiūriu. 
2. Nepakanka AMI poveikio ekonomikai ir efektyvumo vertinimo stebėsenos metodų, kurie sudarytų sąlygas ne tik ịvertinti konkrečios institucijos poveikị ar veiklos efektyvumą, bet leistų ir lyginti institucijas tarpusavyje.

3. AMI poveikio ekonomikai ir efektyvumo vertinimo metodų trūkumas neleidžia AMI, valstybei ir kitoms suinteresuotosioms grupèms įvertinti, ar investicijos ị aukštojo mokslo sektorių sukuria pakankamą ekonominį efektą.

4. Kiekybiniai AMI efektyvumo ir poveikio ekonomikai vertinimo metodai yra sudètingi ir sunkiai pritaikomi, todèl retai naudojami sprendžiant šiuolaikines ekonomikos problemas.

\section{Darbo aktualumas}

Ši disertacija papildo mokslinius tyrimus pasiūlytu modeliu, kuris susieja AMI ekonominio poveikio ir efektyvumo vertinimo metodus integralioje sistemoje. AMI ekonominį poveikị galima suprasti kaip ịvairius būdus, kuriais šios institucijos daro poveikị visai ekonomikai. Šis veiksnys įvertina AMI išorinį poveikị arba jų ekonominį poveikị, daromą už institucijų ribų. Šis poveikis yra juntamas tiek mikro (vietos ekonomikos), tiek makro (valstybinès, regiono) lygmeniu. Mokslininkai išskiria tiesioginį, netiesioginị ir dirbtinị ekonominius poveikius. Netiesioginis ir dirbtinis poveikiai kartais bendrai yra vadinami antriniu poveikiu.

Efektyvumas reiškia geriausią įmanomą būdą, kaip institucija gali panaudoti jai skirtus išteklius. Bendriausia prasme, didelis efektyvumas rodo institucijos gebejjimą sukurti didžiausią našumą esant santykinai mažoms sąnaudoms. Tai reiškia, jog šis veiksnys yra susijęs su institucijos vidinio ūkio veikla. Pavyzdžiui, jei institucija gali sumažinti infrastruktūros priežiūrai skirtas išlaidas ir tuo pačiu metu sukurti daugiau pajamų, tai reiškia efektyvų išteklių panaudojimą. Taigi efektyvumas yra svarbus vidinis rodiklis, kurị pasitelkus institucijos ekonominę veiklą galima vertinti daug išsamiau.

Nė vienas rodiklis pats savaime nėra pakankamas pagrindas, kuriuo remdamasi valstybė galètų priimti sprendimą dèl santykinių išlaidų, kurias ji numatytų individualiai AMI arba aukštojo mokslo sektoriui bendrai. Atsižvelgiant ị tai, kad valdžios atstovai yra atskaitingi mokesčių moketojams už veiksmingą valstybès ekonominès veiklos valdymą, jie turi ịvertinti tiek AMI daromą poveikị ekonomikai, tiek ir tai, kaip AMI efektyviai panaudoja valstybės lěšas. Ekonominis poveikis, kaip išorinis šio modelio veiksnys, daro poveikị tiek trumpalaikiam, tiek ilgalaikiam ekonomikos augimui. Stiprus ekonominis poveikis didesniam žmonių kiekiui užtikrina didesni užimtumą bei didesnį atlyginimą. Nepaisant to, plačiajai visuomenei AMI efektyvumo rodikliai nèra tokie akivaizdūs, todèl valstybinès institucijos turètų stebėti šị rodiklį, kad efektyviai investuojant ị AMI būtų maksimaliai padidintas ekonominis poveikis. Kartu šie du elementai gali suformuoti perspektyvų modelį, kurị valstybė gali panaudoti siekdama prasmingai investuoti ị aukštojo mokslo sektorių.

\section{Tyrimo objektas}

Tyrimo objektas - aukštojo mokslo institucijų ekonominis poveikis ir efektyvumas. 


\section{Darbo tikslas}

Sukurti ir empiriškai patikrinti aukštojo mokslo institucijų ekonominio poveikio ir efektyvumo vertinimo modelị, kurio taikymas leistų priimti racionalius ekonominius sprendimus.

\section{Darbo uždaviniai}

Darbo tikslui pasiekti iškelti šie uždaviniai:

1. Atlikti ekonominio poveikio ir efektyvumo sampratų ir vertinimo metodų literatūros šaltinių analizę siekiant išnagrinèti AMI poveikio ekonomikai ir efektyvumo vertinimo problematiką bei apibrěžti disertacijos teorini pagrindą.

2. Teoriškai pagrịsti aukštojo mokslo institucijų ekonominio poveikio ir efektyvumo vertinimo metodų bei metodikos pasirinkimą.

3. Pasiūlyti AMI ekonominio poveikio ir efektyvumo vertinimo modelį, leisiantị atskirai ịvertinti kiekvienos AMI poveiki šalies ekonomikai.

4. Atlikti Lietuvos valstybinių universitetų ekonominio poveikio ir efektyvumo vertinimo tyrimą ir patikrinti siūlomo modelio veiksmingumą.

\section{Tyrimų metodika}

Aukštojo mokslo institucijų poveikio ekonomikai ir efektyvumo vertinimo problemoms atskleisti naudota sisteminè ir mokslinès literatūros analizè, interpretavimo ir konceptualizavimo metodai. AMI poveikio ekonomikai ir efektyvumo vertinimo šaltinių kritinei analizei naudoti mokslinès literatūros, modelių lyginamosios analizės metodai. Integruoto AMI ekonominio poveikio ir efektyvumo vertinimo modelio I etape, skirtame apskaičiuoti kiekvienos AMI poveikio ekonomikai našumo koeficientus, buvo naudoti skaidymo metodai (agregavimo ir išagregavimo), sąnaudų-rezultatų analizės modeliavimo, normalizavimo (pagal NACE klasifikatorių) bei statistinès analizès metodai. Rezultatų patikimumui užtikrinti skaičiavimai atlikti dviem skirtingais regresinės analizès būdais: proporciniu bei linijiniu. II etape pirmojo etapo metu gauti duomenys panaudoti AMI efektyvumo rangams skaičiuoti. Šiame etape sukurti keturi modeliai: bendram AMI efektyvumui, AMI žmogiškųjų išteklių panaudojimo efektyvumui, studentų veiklos efektyvumui bei mokslinių išteklių panaudojimo efektyvumui vertinti. AMI efektyvumui vertinti panaudoti duomenų apgaubimo modeliavimo metodai remiantis pastovaus pelningumo (PPV) ir kintamojo pelningumo vertinimu (KPV) techniniam efektyvumui apskaičiuoti. Atskirai atliktas kryžminio (siekiant AMI efektyvumą palyginti viena kitos atžvilgiu) ir dinaminio (siekiant palyginti AMI efektyvumą laiko eilutėje) duomenų apgaubimo analizè. Skaičiavimams atlikti naudota STATA bei *R statistikos programinė ịranga, rezultatams interpretuoti taikytas grafinès analizès ir loginès abstrakcijos metodai. 


\section{Darbo mokslinis naujumas}

Pasiekti šie ekonomikos mokslui svarbūs rezultatai:

1. Pasiūlyti kriterijai, skirti ịvertinti AMI ekonomini poveikị ir veiklos efektyvumą.

2. Sukurta kiekybinè sąnaudų-rezultatų modeliavimo analizè, leidžianti įvertinti kiekvienos AMI poveikị ekonomikai, panaudojant linijinę ir proporcinę regresinę analizę.

3. Sukurtas integralus modelis, sąnaudų-rezultatų modeliavimo analizès ir duomenų apgaubimo metodų pritaikymo būdas, leidžiantis bendrai vertinti AMI poveikị šalies ekonomikai.

4. Sukurtas AMI ekonominio poveikio ir efektyvumo vertinimo rezultatų algoritmas.

\section{Darbo rezultatụ praktinè reikšmè}

Integruotas AMI ekonominio poveikio ir efektyvumo vertinimo modelis yra reikšmingas dèl šių priežasčių:

1. Modelis yra universalus ir gali būti taikomas ịvairioms AMI - tiek dideliems tiek ir mažiems universitetams. Modelis gali būti naudojamas ir pritaikomas institucijų, kurios savo veiklą grindžia ekonomiškai pagrịstais valdymo būdais, poreikiams.

2. Modelis yra sudarytas taip, kad ịvertintų ne tik kiekvienos AMI poveikị šalies ekonomikai, bet ir leistų palyginti AMI veiklos efektyvumo požiu.

3. Sukurto modelio rezultatai tinka valstybès institucijoms, AMI vadovams informuoti, nes atspindi AMI padètị tiriamos problemos požiūriu ir duomenis pateikia agreguota forma.

4. Sudarytas AMI poveikio šalies ekonomikai ir efektyvumo vertinimo modelis galètų būti taip pat naudojamas praktikoje atliekant AMI stebėseną, tai sukurtų prielaidas ekonomiškai pagrịstos ir valstybès interesus atitinkančios strategijos sukūrimui.

\section{Ginamieji teiginiai}

1. AMI poveikis ir efektyvumas šalies ekonomikai turètų būti analizuojami bendroje sistemoje - tai leistų daug išsamiau įvertinti kiekvienos AMI daromą įtaką šalies ekonomikai, bei palyginti AMI ekonominius ir efektyvumo rodiklius tarpusavyje.

2. Nustatytas AMI poveikio ekonomikai vertinimo ịrankių trūkumas - dominuojantys taikomi modeliai sudètingi ir sunkiai pritaikomi.

3. AMI ekonominio poveikio ir efektyvumo vertinimo problema gali būti sprendžiama taikant sukurtą vertinimo modelị, ị kurị integruojamas AMI poveikio ekonomikai ir efektyvumo vertinimas. 
4. Naudojamas modelis leidžia nustatyti kiekvienos AMI poveikio ekonomikai našumo koeficientą, o efektyvumo metodai leidžia identifikuoti AMI padètį kitų AMI atžvilgiu.

5. Modelio rezultatai gali būti naudojami formuojant Lietuvos AMI poveikio ekonomikai bei efektyvumo vertinimo strategiją.

\section{Disertacijos struktūra}

Disertaciją sudaro įvadas, 3 skyriai, bendrosios išvados, literatūros sąrašas, autoriaus publikacijų sąrašas, santrauka lietuvių kalba ir 7 priedai. Visa disertacijos apimtis yra 154 puslapiai, išskyrus priedus, taip pat disertaciją sudaro 8 grafikai, 25 lentelès, 29 sunumeruotos formulès, disertacijoje panaudoti 192 moksliniai šaltiniai.

\section{Aukštojo mokslo institucijụ poveikio ekonomikai tyrimai šiuolaikinès ekonomikos kontekste}

AMI poveikio ekonomikai tyrimai kaip atskiro mokslo dalyko tyrimai plačiai pradèti vystyti Jungtinès Amerikos Valstijose ir Didžiojoje Britanijoje. Dèl didejjančios konkurencijos tarp AMI jaučiamas vis didesnis poreikis tokių tyrimų tolimesniam vystymui. Dauguma AMI poveikio ekonomikai tyrimu yra fragmentiški ir dažnai apima tik pavienių organizacijų poveikio analizę kaštu valdymo metodu. Tačiau verta pripažinti, jog AMI poveikio šalies ekonomikai vertinimai yra retesni, bet ne mažiau svarbūs. Didelis dèmesys skiriamas susisteminti skirtingas AMI poveikio šalies ekonomikai teorines nuostatas, auga poreikis vystyti AMI poveikio ekonomikai vertinimo principus ir remiantis jais atlikti empirinius tyrimus. Tarp mokslininkų vis dar nėra bendro sutarimo kokią ekonominę naudą turètų kurti AMI. Literatūroje pagrindinis dèmesys skiriamas trims veiksnių grupėms: trumpalaikiam išlaidų poveikiui, žiniomis ir žmogiškuoju kapitalu pagristam poveikiui, (ilgalaikiam) vertės kūrimo poveikiui ir žinių perdavimo poveikiui (žr. S1.1 lentelę, kurioje pateikiama skirtingų požiūrių įvairovè).

Vienas dažniausių būdų vertinti AMI poveikị ekonomikai yra tiesioginis (pirminis) poveikis, kuris priskiriamas tiesioginès AMI veiklos vertinimui (Kotosz, Gaunard-Anderson, ir Lukovics, 2018). Šie pokyčiai, susiję su tiesioginiu išlaidų AMI pasikeitimo poveikiu. Kitaip tariant, tai yra pasikeitimai ekonominèje veikloje per pirmą išlaidų ciklą. AMI ženkliai prisideda prie vietinès rinkos darbo vietų kūrimo vykdydami savo tiesioginę veiklą, nes dažnu atveju yra vieni didžiausių darbdavių regione. Netiesioginis poveikis (antrinis) yra ekonominės veiklos pokyčiai, atsirandantys per įvairius tolesnius išlaidų ciklus, kai AMI savo išlaidomis veikia kitas ūkio šakas taip ne tiesiogiai skatindami darbo vietų kūrimą ir kituose ekonominiuose sektoriuose (Ciccone ir Peri, 2006). Svarbu paminèti, kad AMI veiklos antrinius poveikius vertinti sudètinga. Tikimasi, kad šie pirminiai (trumpalaikiai) poveikiai paskatins antrosios eilès (ilgalaikius), šalutinius pasiūlos poveikius.

AMI, ypač universitetai, turi tris pagrindines savo veikimą iprasminančias funkcijas. Be švietimo, AMI atlieka mokslinius tyrimus ir prisideda prie visuomenės vystymosi (Alzadjali, 2018). Švietimas ugdo žmogiškuosius išteklius, kurie panaudojami moksliniams tyrimams atlikti, o moksliniai tyrimai užtikrina aukštesnį išsilavinimo lygị (Mason, 2014). 
Pastaruoju metu iš AMI reikalaujama vis labiau prisideti prie visuomenès gerovès (Cano ir Ion, 2014). Tai reiškia, kad aukštojo mokslo institucijos negali tapti „sau pakankamos“ (Nicholl ir kt., 2014), jos turi užtikrinti savo sukauptų žinių perdavimą visuomenei. Apskritai, neskaitant keleto nepritariančių nuomonių (pvz., Goldstein ir Renault, 2004), pripažịstama, kad AMI poveikis ekonominei aplinkai yra teigiamas. AMI buvimas, ịskaitant jų veiklą ir personalą, ekonomikoms yra naudingas. Tačiau nėra bendros nuomonès dèl to, kaip būtų galima išmatuoto kokị poveiki AMI kuria savo miesto, šalies ar regiono ekonomikai.

Eknominio poveikio AMII kontekste samprata: Bridge, 2011, Elliott; Levin \& Meisel, 1988; Nair \& Sáiz Álvarez, 2018; Lee, 2018; Hudson, 1974; Tavoletti, 2007; Greenwood, Sanchez \& Wang, 2013; ir kiti.

Ekonominio poveikio AMI kontekste koceptualizavimas: Borralho, Feria \& Lopes, 2015; Ciccone \& Peri, 2006; Harris, 1997; Kotosz; Elliot, Levin \& Mesisel, 1988; Forrant, 2001; Gaunard-Anderson \& Lukovics, 2018; Goddard \& Vallance, 2013; Huggins \& Cooke, 1997; Sieg-fried, Sanderson \& McHenry, 2007; Thanki, 1999; Barra \& Zotti, 2017; Borralho et al., 2015; Florax, 1992; Garrido-Yserte \& Gallo-Rivera, 2010; Huggins \& Cooke, 1997; Huggins \& Johnston, 2009; Huggins et al., 2012; Johansen \& Arano, 2016; Psacharopoulos \& Patrinos, 2002; Goldstein \& Re-nault, 2004; Siegfried et al., 2007 ir kt.

Ekonominès priežastys vertinti AM: Caffrey \& Isaacs,1971; Booth \& Jarrett 1976; Leslie \& Brinkman 1988; Elliott et.al., 1988; Brown et.al.,1997; Armstrong \& Grove-White, 1997; Glasson, 2003; Kelly et al., 2004; Blundellet al., 2005; McGregor et. al., 2006; Keller, 2006; Drucker \& Goldstein, 2007; Huggins, \& Johnston, 2009; Kimenyi, 2011; Rabovsky, 2012; Jalil, \& Idrees, 2013; Olivares \& Wetzel 2014; Drucker, 2015; Humphreys, 2016; Bowen \& Qian, 2017 ir kiti.

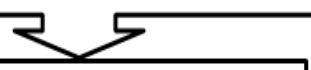

AMI ekonominio poveikio ir efektyvumo vertinimas: Felsentein, 1996, 1999; Glasson, 2003; Steinacker, 2005; Thanki, 1999; Alves, Carvalho, Car-valho, Correia, Cunha, Farinha \& Nicolau, 2015; Carlsson \& Fridh, 2003; Guerrero, Cunningham \& Urbano, 2015; Guerrero, Urbano \& Cunningham, 2016; Motohashi, 2005; Schartinger, Schibany \& Gassler, 2001; Anselin, Varga \& Acs, 1997; 2000; Barrio-Castro \& Garcia-Quevedo, 2005; Fischer \& Varga 2003; Florax, 1992; Florax \& Folmer, 1992; Baryla \& Dotterweich, 2001; Tornquist \& Hoenack, 1996; Fogarty, 1993; Goldstein \& Renault, 2004 ir kiti.
Kiekybiniai ir kokybiniai vertinimo metodai: Jamasb \& Pollitt, 2001; Din \& Cretan, 2005; Wolszczak-Derlacz, 2014; Goldberger, 1964; Hayashi, 2000; Aigner, Lovell \& Schmidt, 1977; Meeusen \& Van den Broeck, 1977; E. K. Zavadskas et al (2010), E. K. Zavadskas et al (2012), E. K. Zavadskas et al (2013), Tzeng, G-H.; Huang, J-J. (2011), Z. Turskis (2009), Podvezko, V., Podviezko, A. (2010), T. Yusuf (2012), R. Ginevičius R., V. Podvezko (2008) ir kiti.

AMI efektyvumo samprata: Abbott \& Doucou-liagos, 2009; Lowe Boyd, 2004; Waldo, 2007; Agasisti \& Haelermans, 2015; Furková, 2013; Mikušová, 2017; Granzow, 1979; Rapple, 1992; Marginson, 1991; Hoenack, 1982; Cowan, 1985; Powell, Gilleland \& Pearson, 2012; Boughey, 2003 ir kiti.

Efektyvumo AMI kontekste konceptualizavimas: Charles, 2011; Glasson, 2003; Hermannsson, Lisenkova, McGregor \& Swales, 2013; Langford, 2002; Mayer, 2007; Zhang, Larkin \& Lucey, 2017; Stokes \& Coornes, 1998; Cox \& Taylor, 2006; Yusuf, 2007; Goldstein \& Renault, 2004; Guer-rero et al., 2015; Jaeger and Kop-per, 2014; Jaeger and Kopper, 2014; Uyarra, 2010 ir kt.

S1.1 pav. Aukštojo mokslo institucijų poveikio ekonomikai ir efektyvumo vertinimo problematikos požiūrių ịvairovè (sudaryta autoriaus)

Pastaraisiais metais švietimo efektyvumo svarba susilaukè didesnio valdžios institucijų ir tarpvyriausybinių ịstaigų dėmesio (Stiglitz ir Rosengard, 2015). Pavyzdžiui, 2013 m. paskelbtoje Ekonominio bendradarbiavimo ir plètros organizacijos (EBPO) ataskaitoje pabrėžiama: jei (šalių) ūkiai nori išgyventi ir klestèti, šalims yra vis svarbiau atidžiai apsvarstyti „kaip paskirstyti išlaidas (švietimui) ir kokią politiką reikia sukurti norint pagerinti AMI teikiamo švietimo efektyvumą ir aktualumą“ (EBPO, 2013, p. 15). Valstybiniai universitetai labai priklauso nuo valstybės valdžios jiems skiriamo finansavimo. Tikètina, kad 
ateinančiais dešimtmečiais jie tikriausiai ir toliau bus pagrindinė valstybinio sektoriaus investicijų sritis, todèl yra būtina stebèti ir įvertinti, koks yra šių AMI efektyvumas.

Siekiant tirti AMI veiklos efektyvumą, svarbu ịvertinti kriterijus, kuriais remiantis būtų galima teigti, jog švietimo sistema efektyvi. Pagrindinị teorinị darbą šioje srityje atliko Bessent, Bessent ir kolegos (Bessent ir Bessent, 1980; Bessent, Bessent, Kennington ir Reagan, 1982). Autorių darbai atskleidè, kad plačiąja prasme švietimo efektyvumas pasireiškia tada, kai institucijos, atsakingos už švietimo teikimą ir igyvendinimą, išnaudoja visus savo turimus išteklius kuo geriau. Kitaip tariant, neveiksminga sistema yra tokia, kurioje yra galimybių pagerinti rezultatus nekeičiant dabartinių sąnaudų arba kai yra galimybių sumažinti sąnaudas išlaikant tokius pačius rezultatus (Gralka, 2018).

Lyginant su kitais sektoriais, švietimo sektoriaus vertinimui tenkantis kontekstas sukelia problemų (Johnes, 2014). Šio sektoriaus institucijos patiria įvairių sąnaudų, kurios nèra įkainotos. Be to, kaip sektorius, švietimas sukuria daugybę rezultatų, kurių negalima lengvai išskirti trumpuoju ir ilguoju laikotarpiais. Galiausiai, kadangi švietimas dažnai yra ne pelno veikla, neįmanoma nustatyti, kaip sąnaudos panaudojamos iš esmès nematerialiems rezultatams gauti. Vertinant AMI ekonominị poveikį ir efektyvumą, galima išskirti keturias pagrindines problemas:

1. Pirmoji, nèra galimybės stebèti efektyvaus finansinių išteklių panaudojimo ir ivvertinti jo poveiki rezultatams.

2. Antroji, nèra priemonių ir būdų, skirtų vertinti AMI ekonominiam poveikiui ir efektyvumui.

3. Trečioji, nėra metodų, skirtǔ gauti duomenis apie AMI panaudojamų žmogiškųjų išteklių rezultatus. Šioje literatūros šaltinių grupejje sutinkama, kad AMI stipriai prisideda prie vietinès ir regionų ekonomikos, tačiau nuomonès apie tai, kaip ši poveiki išmatuoti, išsiskiria.

4. Ketvirtoji, atlikus analizę paaiškèjo, kad pastangos, dedamos efektyvumo analizès integravimui ị ekonominio poveikio vertinimą, yra nepakankamos, todèl siekiant spręsti šiuos, ekonomikos mokslui svarbius klausimus, pasiūlytas integralus modelis, leidžiantis vienu metu vertinti AMI ekonomini poveiki ir efektyvumą.

\section{Aukštojo mokslo institucijų ekonominio poveikio ir efektyvumo vertinimo metodologija}

AMI ekonominio poveikio ir efektyvumo vertinimo modeliui formuoti pasirinkti Leontjevo bei DAA modeliai.

Pagrindinė Leontjevo analizès dalis apima sąnaudų-rezultatų lenteles. Kiekvienoje lentelèje pateikiami konkretūs su sektoriumi susiję duomenys, surūšiuoti stulpeliuose ir eilutėse. Peržiūrint lenteles arba tarpšakinę matricą, kuri yra pagrindinè Leontjevo modelio priemonè, matomi keli stulpeliai, rodantys skirtingus ekonominius parametrus. Pavyzdžiui, stulpelyje „irašai“ paprastai nurodomos sąnaudos konkrečiam pramonès sektoriui, o eilutės yra skirtos nurodytam sektoriui. Šis formatas aiškiai rodo skirtingų sektorių tarpusavio priklausomybę ir leidžia aiškiau analizuoti ir ịvertinti duomenis. Be to, kiekvienos eilutès ir stulpelio antraštėse yra išvardinti arba nurodyti konkretūs ūkio sektoriai. 
AMI efektyvumui įvertinti naudojami keli metodai. Šiame tyrime naudojamas DAA modelis, kuris gali būti skirtas sąnaudų arba rezultatų ir / arba pastovaus pelningumo vertinimui (PPV), arba kintamo pelningumo vertinimui (KPV). Tyrime siūlomas naujas modelis, skirtas AMI ekonominio poveikio ir efektyvumo vertinimui.

Leontjevo ir DAA metodai papildo vienas kitą ir atspindi skirtingus AMI vertinimo aspektus. Seniau yra buvę keli mėginimai panaikinti atotrūkį tarp šių dviejų mokslinių tyrimų sričiu (Zofío, 2007). Šis paprastas, tačiau praktiškas derinys Leontjevo modelio rezultatus panaudoja DAA modelyje. Be to, pirmajame Leontjevo lentelių analizės panaudojimo etape, siekiant apskaičiuoti kiekvienos AMI ekonominị poveikị, siūloma neskirti atskirti kiekvieną AMI pinigų srautą kitu ekonomikos sektorių atžvilgiu ir tada taikyti Leontjevo analizę, ji siūlo naują būdą. Autorès siūlomame metode kiekvienos AMI ekonominis poveikis yra atskirtas nuo bendro viso AMI sektoriaus koeficiento, panaudojant tiesinę regresiją.

Šioje darbo dalyje trumpai nagrinejjami bendrieji integruoto modelio etapai:

1. Suvestinè sąnaudų-rezultatų lentelè. Šiame etape sudaroma sąnaudų-rezultatų lentelè, kuri atspindi pinigų srautus tarp ekonomikos sektorių. Suklasifikavus ūkio sektorius ị kelias grupes, kiekviena grupẻ laikoma atskiru ūkio sektoriumi. Grupių pinigų srautas yra apibendrinamas iš pradinès lentelès, taip suformuojama suvestinè sąnaudų-rezultatų lentelè.

2. AM sektoriaus ekonominis poveikis. Vadovaujantis Leontjevo modelio metodu, apskaičiuojama atvirkštinè Leontjevo matrica bei sektorių, įskaitant AM, ekonominis poveikis.

3. Ekonominių poveikių atskyrimas atskiroms AMI. Apskaičiuotas AM sektoriaus poveikis naudojamas atskirų AMI poveikiui išskirti. Siūlomi du metodai: naudojant išlaidų proporciją ir regresiją.

4. Efektyvumo vertinimas. Siekiant ịvertinti AMI efektyvumą, ekonominis poveikis kartu su kitais surinktais AMI sąnaudų ir rezultatų duomenimis integruojamas ị DAA modelị. Kaip jau minèta, šie efektyvumo rodikliai yra santykiniai ir yra du požiūriai, kuriais remiantis galima įvertinti efektyvumą: vertinti efektyvumą tarp kelių AMI arba vertinti kiekvienos AMI efektyvumą skirtingais laikotarpiais. S2.1 paveiksle pateikiamas grafinis ekonominio poveikio ir efektyvumo vertinimo modelis.

Nors Leontjevo modelis pateikia kiekvienos AMI poveikio nacionalinei ekonomikai ịvertinimą, DAA modelis pateikia gaires, kuriomis naudojantis galima būtų pagerinti kiekvienos AMI efektyvumą. Tokiu būdu buvo pristatytas paprastas, tačiau praktiškas šių dviejų viena kitą papildančių mokslinių tyrimų sričių integruotas modelis. Šis modelis pašalina atotrūkị, ịtraukdamas kiekvieno metodo teikiamus privalumus, todèl AMI suteikiamos praktiškesnès gairès, kuriomis vadovaudamasi AMI gali pagerinti savo efektyvumą ir (arba) ekonomini poveikį. Integruotas modelis mėgina sujungti dvi komplementarias tyrimų sritis našumo analizėje. S2.2 paveiksle pateikiamas AMI poveikio ekonomikai ir efektyvumo vertinimo algoritmas. 


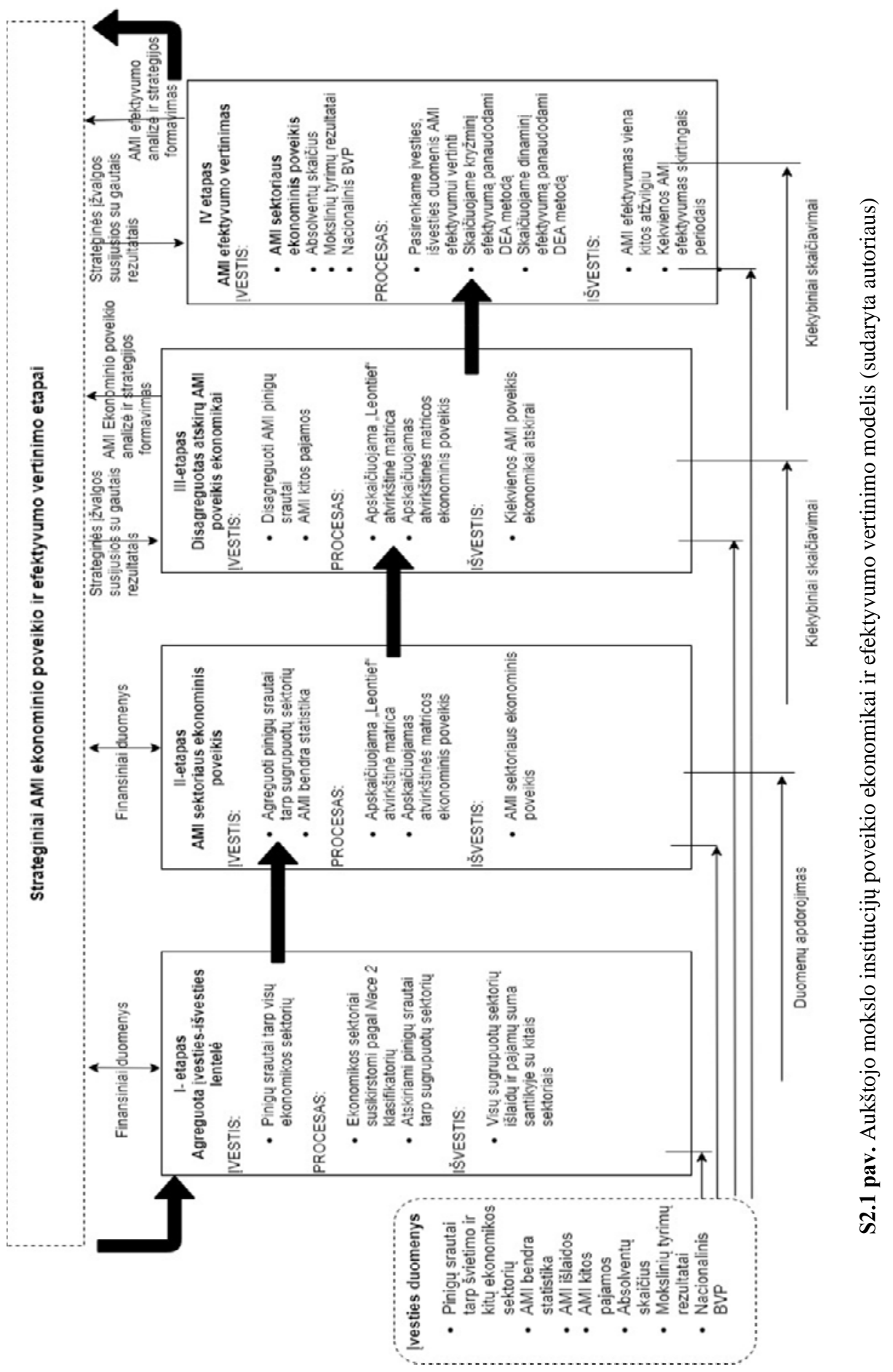




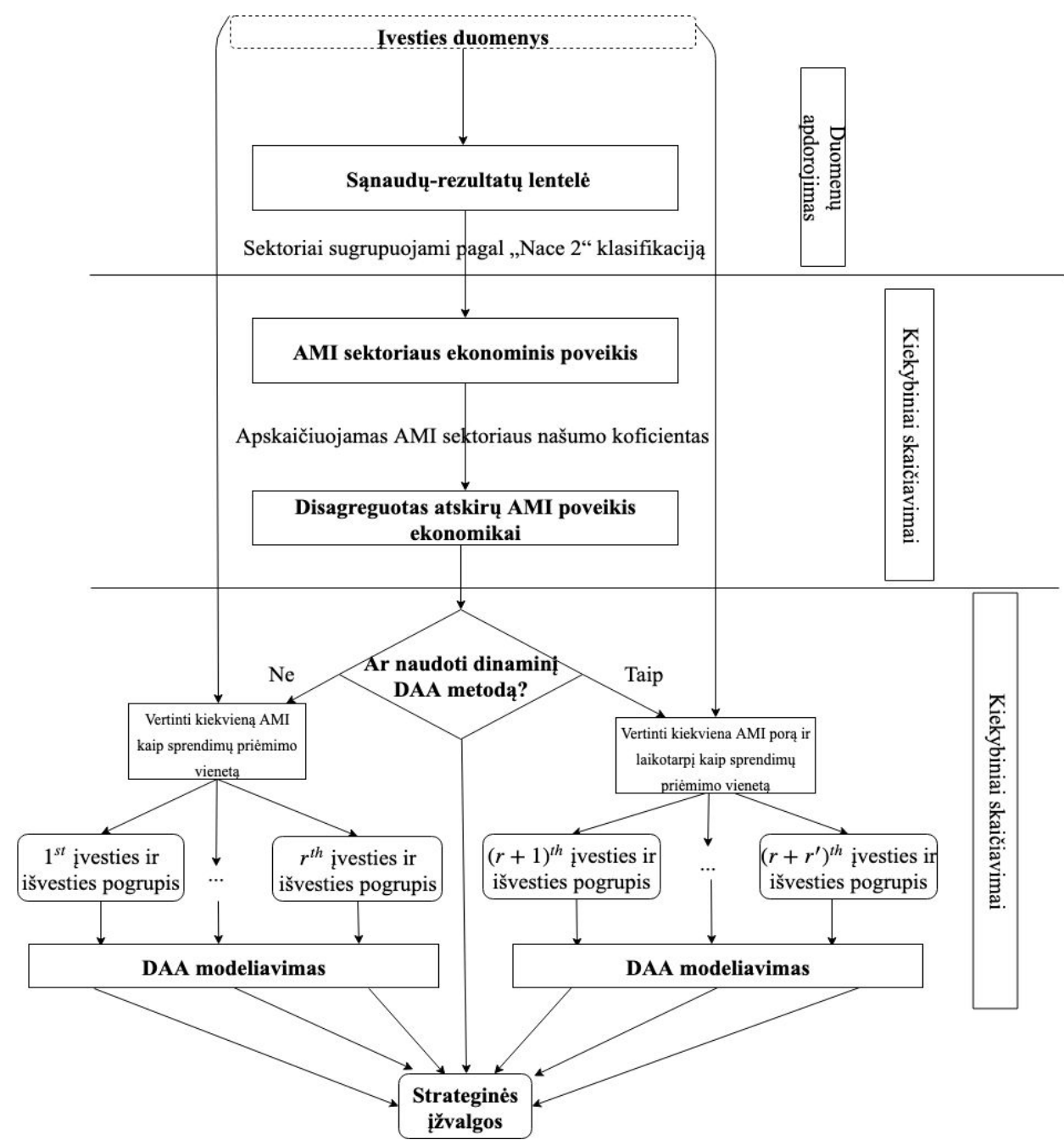

S2.2 pav. Aukštojo mokslo institucijų poveikio ekonomikai ir efektyvumo vertinimo algoritmas (sudaryta autoriaus)

Vertinant iš Leontjevo modelio gaunamus koeficientus kaip vieną iš DAA modelio rezultatų, galima atlikti praktiškesnę, detalesnę ir daugiau įžvalgų suteikiančią AMI efektyvumo analizę. DAA buvo pasirinkta, nes ji yra naudinga dirbant su didesnèmis duomenų aibėmis bei pasižymi mažesniu klaidų kiekiu. Analizės rezultatas taip pat nustato AMI skirtos strateginės politikos gaires, kad AMI galètų pagerinti bendrą efektyvumą ir savo poveiki šalies ekonomikai.

Šios disertacijos naujumas - ekonominių poveikių, apskaičiuotų pagal Leontjevo lentelès modelị, panaudojimas DAA modeliuose, siekiant suformuoti praktinị, ịžvalgas 
formuojantį algoritmą, skirtą AMI ekonominiam efektui vertinti. Sukurtas integralus modelis prisideda prie naujo bandymo sujungti dvi komplementarias tyrimų sritis ekonominio poveikio analizėje.

\section{Aukštojo mokslo institucijụ ekonominio poveikio ir efektyvumo vertinimas}

Pastaraisiais metais Lietuvos švietimo sistemoje vyksta struktūriniai pokyčiai lemiantys 14 valstybinių universitetų sujungimą ị devynis didesnius universitetus. Šiame tyrime pasitelkta metodika leidžia išanalizuoti AMI poveikị ekonomikai, siekiant nustatyti, kaip efektyviai universitetai gali prisidèti prie tolesnio ekonomikos augimo.

Toks restruktūrizavimas yra neišvengiamas siekiant patenkinti šiuolaikinius švietimo sektoriaus poreikius ir reikalavimus. Kiekvienais metais ị Lietuvos AM sistemą stojančių studentų skaičius mažejja. Nepaisant to, kad studijuojančių AMI lygis yra vienas iš didžiausių pasaulyje (EBPO, 2017), švietimo sistema susiduria su rimtais iššūkiais. Dèl to yra reikalinga bendra konsoliduota sistema, skirta visų Lietuvos švietimo sektoriaus AMI poveikiui tirti. Šiame skyriuje yra pateikiamas modelis, leidžiantis ịvertinti Lietuvos aukštojo mokslo sektoriaus ekonominị poveikị ir efektyvumą.

Modelio taikymo etapai. Empiriniai Lietuvos valstybinių universitetu tyrimai buvo atlikti siekiant geriau išanalizuoti duomenis statistinėmis priemonèmis ir padaryti išvadas apie siūlomą hipotezę. 2 skyriuje pateikti sąnaudų-rezultatų (Leontjevo) ir duomenų apgaubimo analizès (DAA) modeliai, apimantys smulkias bei dideles klasikines mokslinių tyrimų institucijas bei labai specializuotus valstybinius universitetus, buvo panaudoti tam, kad mokslinių tyrimų rezultatai būtų tikslesni ir visapusiškesni. Valstybinių universitetų imtyje yra dauguma AM dalyvių, t. y. 87 \% šalies aukštujų mokyklų studentų. Toliau S3.1 lentelëje pateikti modelio taikymo etapai.

Lietuvoje yra 14 valstybinių universitetų nuo mažų institucijų, tokių kaip Lietuvos muzikos ir teatro akademija (LMTA), iki stambių mokslinius tyrimus atliekančių universitetų, laikomų tradiciškesniais, pavyzdžiui, Vilniaus universitetas (VU). Vienas valstybinis universitetas, Generolo Jono Žemaičio Lietuvos karo akademija (LKA), buvo pašalintas iš imties. Šis universitetas buvo atmestas dèl duomenų trūkumo, kurị lèmė tai, kad ši AMI pavaldi Krašto apsaugos ministerijai. Visi kiti valstybiniai universitetai įtraukti ị empirinị tyrimą. Imtị sudaro 13 ịvairaus dydžio valstybinių universitetų, vykdančių veiklą Lietuvoje nuo 2010 iki 2016 m., veiklos sąnaudos ir rezultatai. Valstybinių universitetų žymèjimas yra nuo $\mathrm{AM}_{1}$ iki $\mathrm{AM}_{13}$.

AMI ekonominis poveikis. Lietuvoje yra 14 valstybinių universitetų, kurie skiriasi nuo mažų institucijų, tokių kaip Lietuvos muzikos ir teatro akademija (LMTA), iki stambių mokslinius tyrimus atliekančių universitetų, laikomų tradiciškesniais, pavyzdžiui, Vilniaus universitetas (VU). Vienas valstybinis universitetas, Generolo Jono Žemaičio Lietuvos karo akademija (LKA), nebuvo ịtrauktas ị tyrimo imtị dèl nepakankamų duomenų. Visi kiti valstybiniai universitetai veiklą vykdo prie Švietimo ministerijos ir yra ịtraukti ị imtị. Taigi imtị sudaro 13 ịvairaus dydžio valstybinių universitetų, vykdančių veiklą Lietuvoje nuo 2010 iki $2016 \mathrm{~m}$. Valstybinių universitetų žymejjimas yra nuo $\mathrm{AM}_{1}$ iki $\mathrm{AM}_{13}$. 
S3.1 lentelè. Pasiūlyto modelio taikymo etapai (sudaryta autoriaus)

\begin{tabular}{|c|c|c|}
\hline Etapai & \multicolumn{2}{|l|}{ Proceso seka } \\
\hline $\begin{array}{l}\text { Duomenų rinki- } \\
\text { mas }\end{array}$ & \multicolumn{2}{|c|}{$\begin{array}{l}\text { Lietuvos oficialios statistikos portalas, visų valstybinių universitetų finansi- } \\
\text { nių ataskaitų rinkiniai 2010-2016 m. laikotarpiu, Registrų centro duome- } \\
\text { nys, Lietuvos viešujų pirkimų tarnyba, sąnaudų-rezultatų lentelè (2010), } \\
\text { Švietimo ministerijos duomenys, Švietimo valdymo informacinės sistemos } \\
\text { duomenys (ŠVIS), Lietuvos mokslo taryba, Mokslo ir studijų stebėsenos ir } \\
\text { analizės centro duomenys (MOSTA). }\end{array}$} \\
\hline Tyrimo apimtis & \multicolumn{2}{|c|}{$\begin{array}{l}\text { Valstybinių universitetų poveikio šalies ekonomikai vertinimas; valstybinių } \\
\text { universitetų efektyvumas ir pokyčiai skirtingais laikotarpiais. }\end{array}$} \\
\hline $\begin{array}{l}\text { I etapas - } \\
\text { Sąnaudų-rezultatų } \\
\text { lentelès paruoši- } \\
\text { mas (užpildymo } \\
\text { procedūra) }\end{array}$ & \multicolumn{2}{|c|}{$\begin{array}{l}\text { Visos ekonominės veiklos rūšys klasifikuojamos pagal „Nace 2“. Sąnaudų- } \\
\text { rezultatų lentelès duomenys agreguojami iš pradinės lentelės. }\end{array}$} \\
\hline \multirow{3}{*}{$\begin{array}{l}\text { II etapas - na- } \\
\text { šumo koeficientų } \\
\text { skaičiavimas }\end{array}$} & $\begin{array}{l}\text { Apskaičiuojama Leontief atvirkštinė } \\
\text { matrica. }\end{array}$ & $\begin{array}{l}\text { 1. Taikoma formulè: } \\
(I-A)^{-1}\end{array}$ \\
\hline & $\begin{array}{l}\text { Ekonominiai poveikiai - našumo ko- } \\
\text { eficientai }\end{array}$ & $\begin{array}{l}\text { 2. Taikoma formulè: } \\
\left((I-A)^{-1}\right)^{T}\left[\begin{array}{c}1 \\
\ldots \\
1\end{array}\right]\end{array}$ \\
\hline & $\begin{array}{l}\text { Išskirstytų koeficientų vertė pagal in- } \\
\text { dividualius valstybinius universitetus }\end{array}$ & $\begin{array}{l}\text { 3. Taikoma formulè: } \\
M_{H_{h}}=\frac{\widehat{e_{h}}}{\widehat{e_{1}}+\ldots+\widehat{e_{n}}} M_{1}\end{array}$ \\
\hline $\begin{array}{l}\text { III etapas - DAA } \\
\text { sąnaudų-rezultatų } \\
\text { lentelès kintamujų } \\
\text { atranka }\end{array}$ & \multicolumn{2}{|c|}{$\begin{array}{l}\text { Kadangi DAA analizei labai svarbu parinkti vertinimo kintamuosius } \\
\text { (sąnaudų-rezultatų lentelès pogrupis), šiame etape vertinimui atrenkami } \\
\text { skirtingi sąnaudų-rezultatų lentelės kintamieji. Kiekvienam pogrupiui tai- } \\
\text { komas DAA metodas. Be to, III etape apskaičiuojami kiekvieno pogrupio } \\
\text { našumo koeficientai. }\end{array}$} \\
\hline
\end{tabular}


S3.1 lentelès tęsinys

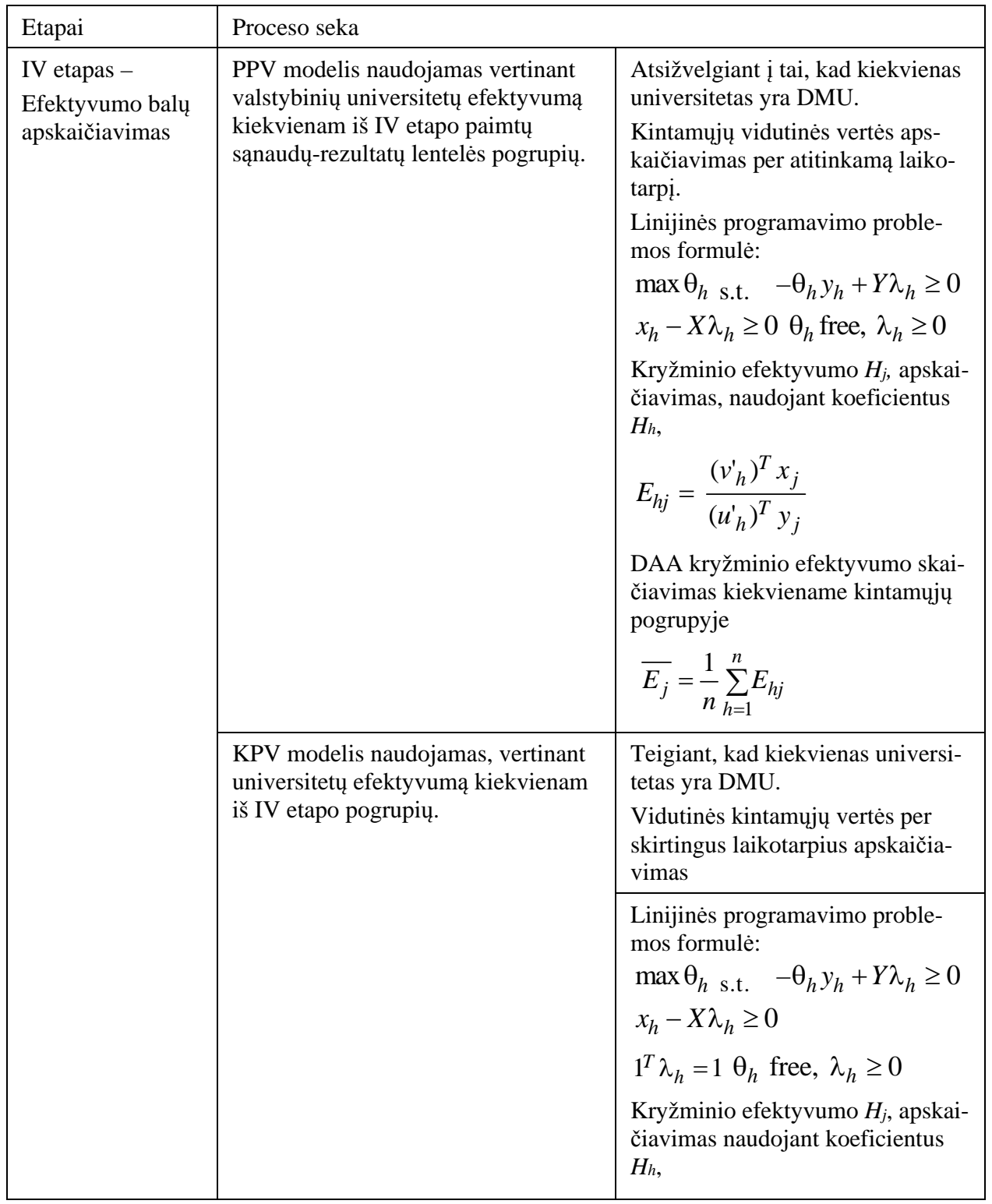


S3.1 lentelès tęsinys

\begin{tabular}{|c|c|c|}
\hline Etapai & \multicolumn{2}{|l|}{ Proceso seka } \\
\hline \multirow{3}{*}{$\begin{array}{l}\text { IV etapas - } \\
\text { Efektyvumo balų } \\
\text { apskaičiavimas }\end{array}$} & & $\begin{array}{l}E_{h j}=\frac{\left(v_{h}^{\prime}\right)^{T} x_{j}}{\left(u_{h}^{\prime}\right)^{T} y_{j}} \\
\text { DAA kryžminio efektyvumo skai- } \\
\text { čiavimas kiekviename kintamujuc } \\
\text { pogrupyje: } \\
\overline{E_{j}}=\frac{1}{n} \sum_{h=1}^{n} E_{h j}\end{array}$ \\
\hline & $\begin{array}{l}\text { PPV modelis naudojamas vertinant } \\
\text { valstybinių universitetų efektyvumą } \\
\text { kiekvienam iš IV etapo paimtų pog- } \\
\text { rupių. }\end{array}$ & 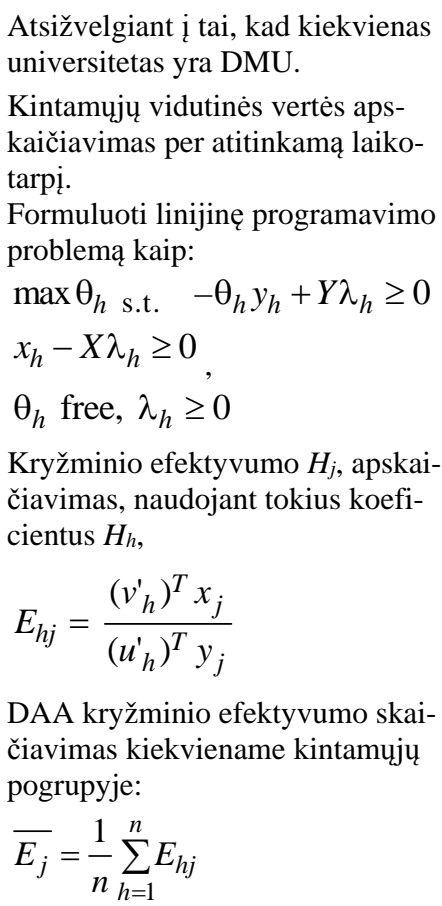 \\
\hline & $\begin{array}{l}\text { PPV modelis naudojamas vertinant } \\
\text { valstybinių universitetų efektyvumą } \\
\text { kiekvienam iš IV etapo paimtų pog- } \\
\text { rupių. }\end{array}$ & $\begin{array}{l}\text { Teigiant, kad kiekviena universi- } \\
\text { tetų pora yra DMU. } \\
\text { Linijinės programavimo proble- } \\
\text { mos formulè: } \\
\text { max } \theta_{h} \text { s.t. } \quad-\theta_{h} y_{h}+Y \lambda_{h} \geq 0 \\
x_{h}-X \lambda_{h} \geq 0\end{array}$ \\
\hline
\end{tabular}


S3.1 lentelès pabaiga

\begin{tabular}{|c|c|}
\hline Etapai & Proceso seka \\
\hline & 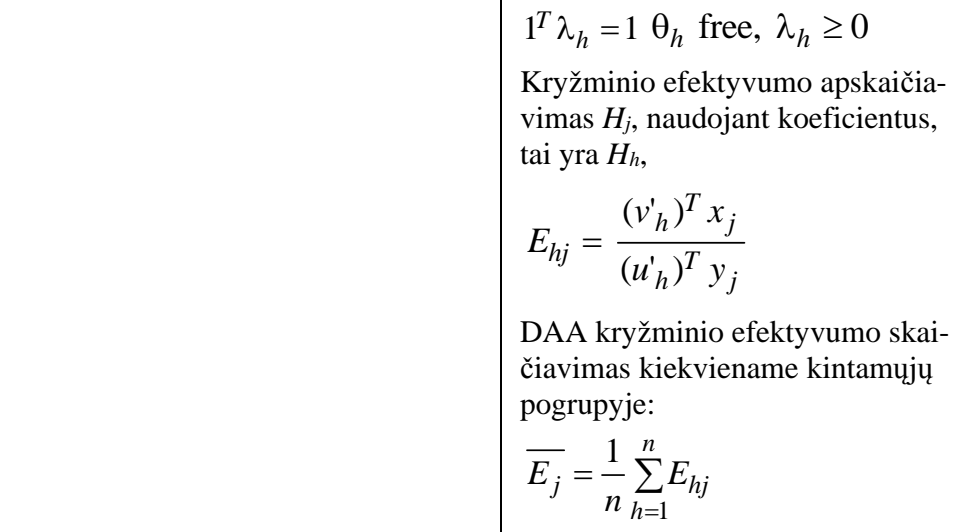 \\
\hline $\begin{array}{l}\text { V etapas - } \\
\text { Galimų klaidų pa- } \\
\text { tikrinimas }\end{array}$ & $\begin{array}{l}\text { I, III, IV ir V etapų rezultatų vertinimas, siekiant patikrinti, ar rezultatai yra } \\
\text { nuoseklūs ir atitinka (ar neatitinka) bendruosius loginius ir metodinius rei- } \\
\text { kalavimus. }\end{array}$ \\
\hline $\begin{array}{l}\text { VI etapas - } \\
\text { Duomenų interp- } \\
\text { retavimas }\end{array}$ & $\begin{array}{l}\text { Duomenų interpretavimas pagal pasiūlytą modelì. Duomenų interpretavi- } \\
\text { mas grindžiamas universitetų ekonominiu poveikiu ir galimo universitetų } \\
\text { efektyvumo padidejjimu. }\end{array}$ \\
\hline
\end{tabular}

Gauti rezultatai parodè, jog universitetas $\mathrm{HE}_{12}$ turi daug didesnị našumo koeficientą nei kiti trys didžiausi valstybiniai universitetai, ir taip yra dèl aglomeracijos poveikio. Dažnu atveju, kai įmonės ir pramonės šakos pradeda veikti šalia AMI, jos klesti ir plečiasi, naudodamos šių valstybinių universitetų turimą infrastruktūrą bei mokslinių tyrimų rezultatus. Kitaip tariant, valstybiniuose universitetuose atliekami tyrimai naudingi pramonès šakoms. Tačiau S3.1 lentelèje pateikti rezultatai yra ne tokie ryškūs, kai kalbama apie specializuotus universitetus. Pavyzdžiui, $\mathrm{HE}_{6}, \mathrm{HE}_{9}$ ir $\mathrm{HE}_{4}$ būdingas mažesnis našumo koeficiento efektyvumas. Tačiau kitų, pvz., $\mathrm{HE}_{2}$, efektyvumo koeficientai yra didesnis. Peršasi išvada, kad, jeigu AMI yra specializuota, ji savaime nenustato savo ekonominio poveikio. Specializacijos tipas taip pat daro įtaką pagrindinei mokslo institucijos veiklai ir daro poveiki ekonomikai. Pavyzdžiui, $\mathrm{HE}_{6}$ dèmesys sutelkiamas ị sporto studijas, todèl praktiškai niekaip neveikia vietos ekonomikos, o $\mathrm{HE}_{2}$ - technologijomis užsiimanti institucija, todèl daro didelę įtaką vietos ekonomikai.

Kaip parodyta lentelëje S3.2, lyginant su kitais švietimo sektoriais, valstybinių universitetų II tipo našumo koeficientai buvo vieni iš didžiausių. Tai rodo, kad valstybiniai universitetai yra svarbi Lietuvos ūkio sistemos dalis. Tačiau pažymėtina, jog lyginant su kitomis švietimo sektoriaus sistemos dalimis, valstybinių universitetų II tipo našumo koeficientai yra vidutiniški. AMI nusileidžia pagrindinio ir vidurinio išsilavinimo sistemoms, tačiau lenkia ikimokyklinio ir pradinio ugdymo bei kolegijų sistemas. Taip gali būti todèl, kad, AMI sektoriui reikalingos išlaidos yra kur kas didesnès už išlaidas, tenkančias kitoms Švietimo sektoriaus dalims. 


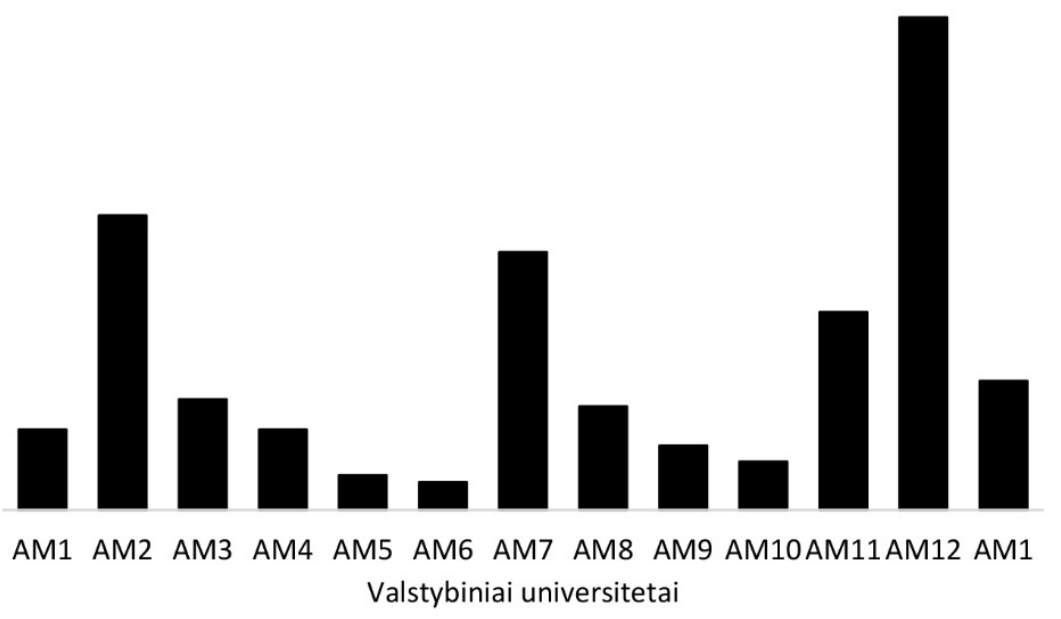

S3.1 pav. Neapdoroti II tipo Lietuvos valstybinių universitetų našumo koeficientai (sudaryta autoriaus)

Gauti rezultatai rodo, kad dideli valstybiniai universitetai pasižymi aukštais II tipo našumo koeficientais. $\mathrm{HE}_{12}$ surinko 0,00214 , beveik du kartus daugiau nei kiti du geriausi valstybiniai universitetai kartu sudèjus. Tai gali būti siejama su AM dydžiu, kurioje mokosi beveik 20000 studentų, o $\mathrm{AM}_{2}$, antroje pagal dydi AMI, surinkusioje 0,00128, yra vos daugiau nei 16000 studentų. Taigi žmogiškojo kapitalo kiekis studentų ir akademinio personalo prasme šioje institucijoje yra nedidelis. $\mathrm{AM}_{12}$ atveju akademinio personalo kiekis, reikalingas šio didesnio studentų skaičiaus mokymui, lemia didesnị tyrimų ir išteklių pritraukimą, taip sukuriant didesnio žinių kiekio perdavimą regionams ir šaliai. Tai turės didelị poveikị ekonominiams rezultatams ir efektyvumui.

Iš tyrime vertintų valstybinių universitetų $\mathrm{HE}_{6}$ gautas našumo koeficientas 0,00012 - buvo mažiausias. Šiame universitete mokosi apie 2000 studentų, tai yra specializuota AMI. Tai lemia du dalykus: pirma, mažesnis studentų skaičius lemia mažesnį akademinių darbuotojų skaičių ir taip sumažina žmogiškojo kapitalo dydį; antra, kadangi AMI yra specializuota institucija, tai apriboja žinių, kurios gali būti perduotos aplinkiniam regionui ir šaliai, kiekị. $\mathrm{AM}_{2}$ taip pat yra specializuota $\mathrm{AMI}$, tačiau jos sąnaudų rezultatas yra antras pagal dydį, tai reiškia, kad nuoseklumo tarp AMI I tipo ir AMI II tipo našumo nèra.

AMI efektyvumas. Duomenų analizei buvo panaudota R esančio STATA paketo duomenų apgaubimo analizès (DAA) kryžminio efektyvumo versija. Atsižvelgiant ị pastovaus pelningumo vertinimo (PPV) ir kintamo pelningumo vertinimo (KPV) rezultatu atitikimą, statistinèje analizèje yra padarytos kelios prielaidos. Duomenys buvo parengti pagal 13 atrinktų valstybinių universitetų aštuonis sąnaudų ir tris rezultatų kintamuosius, apibrezžtus S3.3 lentelèje. 
S3.2 lentelè. Valstybinių universitetų ekonominio poveikio našumo koficientai gauti trimis skirtingais metodais (sudaryta autoriaus)

\begin{tabular}{|c|c|c|c|}
\hline Veiklos sritis & $\begin{array}{l}\text { Regresija (remiantis } \\
\text { pajamomis, studentų } \\
\text { skaičiumi ir FTE) }\end{array}$ & $\begin{array}{l}\text { Regresija } \\
\text { (remiantis visais } \\
\text { kintamaisiais) }\end{array}$ & $\begin{array}{l}\text { Proporcingumas } \\
\text { (remiantis } \\
\text { išlaidomis) }\end{array}$ \\
\hline $\mathrm{P}$ - Švietimas & 0,04100 & 0,04100 & 0,04100 \\
\hline $\begin{array}{l}\text { Ikimokyklinis ir pradi- } \\
\text { nis ugdymas }\end{array}$ & 0,00600 & 0,00600 & 0,00600 \\
\hline $\begin{array}{l}\text { Pagrindinis ir vidurinis } \\
\text { ugdymas }\end{array}$ & 0,01500 & 0,01500 & 0,01500 \\
\hline Kolegijos & 0,00100 & 0,00100 & 0,00100 \\
\hline Aukštasis mokslas & 0,00800 & 0,00800 & 0,00800 \\
\hline $\mathrm{AM}_{1}$ & 0,00035 & 0,00035 & 0,00035 \\
\hline $\mathrm{AM}_{2}$ & 0,00128 & 0,00130 & 0,00131 \\
\hline $\mathrm{AM}_{3}$ & 0,00048 & 0,00047 & 0,00047 \\
\hline $\mathrm{AM}_{4}$ & 0,00035 & 0,00034 & 0,00034 \\
\hline $\mathrm{AM}_{5}$ & 0,00015 & 0,00015 & 0,00015 \\
\hline $\mathrm{AM}_{6}$ & 0,00012 & 0,00013 & 0,00013 \\
\hline $\mathrm{AM}_{7}$ & 0,00112 & 0,00111 & 0,00111 \\
\hline $\mathrm{AM}_{8}$ & 0,00045 & 0,00046 & 0,00046 \\
\hline $\mathrm{AM}_{9}$ & 0,00028 & 0,00029 & 0,00028 \\
\hline $\mathrm{AM}_{10}$ & 0,00021 & 0,00021 & 0,00021 \\
\hline $\mathrm{AM}_{11}$ & 0,00086 & 0,00086 & 0,00086 \\
\hline $\mathrm{AM}_{12}$ & 0,00214 & 0,00214 & 0,00214 \\
\hline $\mathrm{AM}_{13}$ & 0,00056 & 0,00053 & 0,00053 \\
\hline R\&D švietimo srityje & 0,01000 & 0,01000 & 0,01000 \\
\hline
\end{tabular}

S3.3 lentelëje pateikti aštuoni sąnaudų kintamieji apima įvairias Lietuvos valstybinių universitetų gaunamas pajamas, ịskaitant valstybės skiriamą finansavimą ir mokslinių tyrimų dotacijas. Vidutiniai PPV ir KPV rangai yra pateikti 3.4 lentelèje. Jie itin koreliuoja su Pearson koreliacija ties 0,83 ir Spearman koreliacija ties 0,84. Penki aukščiausią reitingą turintys valstybiniai universitetai, pasižymintys aukštu techniniu efektyvumu, atitinkamai yra $\mathrm{AM}_{8}, \mathrm{AM}_{4}, \mathrm{AM}_{9}, \mathrm{AM}_{10}$ ir $\mathrm{AM}_{3}$. Patys neefektyviausi valstybiniai universitetai, užimantys vietas nuo 11 iki 13 , atitinkamai yra $\mathrm{AM}_{2}, \mathrm{AM}_{12}$ ir $\mathrm{AM}_{7}$. Reitingai pateikiami toliau pateiktoje S3.4 lentelëje.

Penki patys efektyviausi valstybiniai universitetai atitinkamai yra $\mathrm{AM}_{8}, \mathrm{AM}_{4}, \mathrm{AM}_{9}$, $\mathrm{AM}_{10}$ ir $\mathrm{AM}_{3}$, o penki mažiausiai efektyvūs valstybiniai universitetai atitinkamai yra $\mathrm{AM}_{2}$, $\mathrm{AM}_{12}$ ir $\mathrm{AM}_{7}$. Tai ịdomu, kadangi visi penki neefektyviausi valstybiniai universitetai yra 
dideli (kai kurie taip pat yra ir specializuoti), išskyrus $\mathrm{AM}_{10}$, kuri yra specializuota AMI, turinti vos 2000 studentu. Todèl šio darbo pradžioje pateiktos prielaidos, kad mažesni ir labiau specializuoti valstybiniai universitetai yra neefektyvūs našumo prasme, palyginti su jų sąnaudomis, nè vienu atveju nepasitvirtinimo. Iš trijų mažiausiai efektyvių valstybinių universitetų du yra specializuoti valstybiniai universitetai, tuo tarpu $\mathrm{AM}_{12}$ yra didžiausia valstybinè ir nespecializuota AMI Lietuvoje, kuri šias prielaidas taip pat paneigia.

S3.3 lentelè. Kintamujų apibrèžimai ir modelio specifikacijos (sudaryta autoriaus)

\begin{tabular}{|c|c|c|c|c|c|c|c|c|c|c|c|c|}
\hline \multirow{2}{*}{ 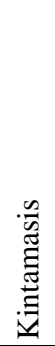 } & \multirow{2}{*}{ 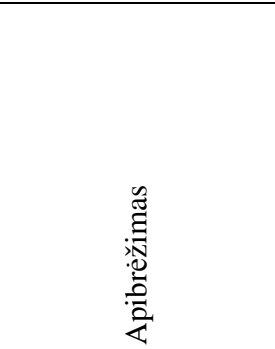 } & \multicolumn{3}{|c|}{ 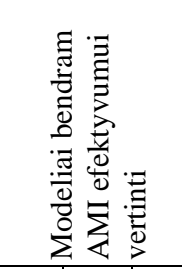 } & \multicolumn{2}{|c|}{ 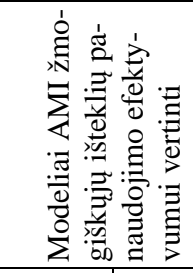 } & \multicolumn{3}{|c|}{ 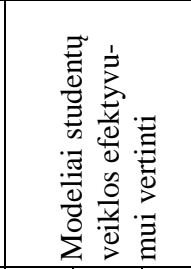 } & \multicolumn{3}{|c|}{ 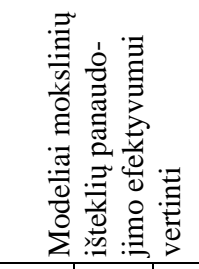 } \\
\hline & & 1a & $1 b$ & 1c & $2 \mathrm{a}$ & $2 b$ & 3a & $3 \mathrm{~b}$ & 3c & $4 a$ & $4 b$ & $4 c$ \\
\hline I1 & $\begin{array}{l}\text { Valstybinès lèšos } \\
\text { studijoms }\end{array}$ & + & + & & & & + & + & + & & & \\
\hline I2 & $\begin{array}{l}\text { Lėšos, skirtos sti- } \\
\text { pendijoms }\end{array}$ & + & + & & & & + & + & + & & & \\
\hline I3 & $\begin{array}{l}\text { Valstybės dotacijos } \\
\text { moksliniams tyrimas }\end{array}$ & + & + & & & & & & & + & + & + \\
\hline I4 & Administravimas & + & + & & & & & & + & & & + \\
\hline I5 & Kitos pajamos & + & + & & & & & & + & & & + \\
\hline I6 & Bendros pajamos & & & + & + & + & & & & & & \\
\hline I7 & $\begin{array}{l}\text { Akademinis perso- } \\
\text { nalas }\end{array}$ & & & & + & + & & & + & + & + & + \\
\hline I8 & $\begin{array}{l}\text { Administracinis per- } \\
\text { sonalas }\end{array}$ & & & & + & + & & & + & & & + \\
\hline O1 & $\begin{array}{l}\mathrm{BVP} * \text { našumo } \\
\text { koeficiento }\end{array}$ & + & + & + & + & + & & + & & & + & \\
\hline $\mathrm{O} 2$ & $\begin{array}{l}\text { Baigusiujjų ab- } \\
\text { solventų skaičius }\end{array}$ & & + & + & & & + & & + & & & \\
\hline $\mathrm{O} 3$ & $\begin{array}{l}\text { Gauta taškų suma už } \\
\text { mokslo produkciją } \\
\text { (11 lygmeniui - } \\
\text { mokslinis (meninis) } \\
\text { darbas) }\end{array}$ & & + & + & + & & & & & + & & + \\
\hline
\end{tabular}


S3.4 lentelè. Aukštojo mokslo institucijų kryžminio efektyvumo vertinimas rangais (remiantis bendrais 2010-2016 duomenimis) (sudaryta autoriaus)

\begin{tabular}{|c|c|c|c|}
\hline AMI & PPV Rangas & KPV Rangas & Vidutinis rangas \\
\hline $\mathrm{AM}_{8}$ & 1 & 1 & 1 \\
\hline $\mathrm{AM}_{4}$ & 2 & 3 & 2.5 \\
\hline $\mathrm{AM}_{9}$ & 4 & 2 & 3 \\
\hline $\mathrm{AM}_{10}$ & 3 & 5 & 4 \\
\hline $\mathrm{AM}_{3}$ & 5 & 4 & 4.5 \\
\hline $\mathrm{AM}_{5}$ & 7 & 6 & 6.5 \\
\hline $\mathrm{AM}_{13}$ & 6 & 7 & 6.5 \\
\hline $\mathrm{AM}_{6}$ & 8 & 8 & 8 \\
\hline $\mathrm{AM}_{11}$ & 9 & 9 & 9 \\
\hline $\mathrm{AM}_{1}$ & 12 & 10 & 11 \\
\hline $\mathrm{AM}_{2}$ & 11 & 11 & 11 \\
\hline $\mathrm{AM}_{12}$ & 10 & 12 & 13 \\
\hline $\mathrm{AM}_{7}$ & 13 & 13 & \\
\hline
\end{tabular}

Kryžminio efektyvumo matricos duomenų regresijos įvertinimas (S3.4 paveikslas) leido atlikti palyginimus skirtingais laiko momentais, tai buvo esminis aspektas vertinant efektyvumo pokyčių dinamiką valstybiniuose universitetuose. Per šešerių metų laikotarpi $\mathrm{AM}_{13}$ efektyvumas sumažèjo 33,9 proc., o $\mathrm{AM}_{9}$ padidėjo 37,1 proc. Daugumos valstybinių universitetų efektyvumas svyravo, t. y. didejo arba mažèjo daugiau nei $10 \%$, tik $\mathrm{AM}_{1}$, $\mathrm{AM}_{2}, \mathrm{AM}_{7}, \mathrm{AM}_{3}$ ir $\mathrm{AM}_{6}$ rodikliai išliko santykinai stabilūs nepasiekiant šios svyravimų ribos. Čia taip pat galima paminèti, kad $\mathrm{AM}_{13}$ padètis iš esmès pakito iš pačios efektyviausios institucijos 2010 m. ị mažiausiai efektyvią 2016 m.

Efektyvumo priklausomybės nuo poveikio konkrečiu laiko momentu vertinimas leidžia patikrinti nulinę hipotezę: „Tam tikrų metų efektyvumas dèl išorinių veiksnių nebuvo neịprastai mažas arba neịprastai didelis“. Vertinant kiekvienus metus, nė vienas iš poveikių, susijusių su laiku, nesukūrè reikšmingo modelio rezultato, kadangi nė vienas iš rezultatų neviršijo 95 proc. patikimumo lygio, todèl hipotezè negali būti atmesta. Tai rodo šio laikotarpio efektyvumo stabilumą.

Konkretūs valstybinių universitetų poveikiai yra reikšmingi, tai rodo, kad kiekvienos AMI efektyvumo lygis nèra vienodas. $\mathrm{AM}_{1}$ yra žymiai efektyvesnè už $\mathrm{AM}_{5}, \mathrm{AM}_{4}$ ir $\mathrm{AM}_{7}$; tačiau šios isstaigos yra žymiai mažiau efektyvios už $\mathrm{AM}_{13}$ ir $\mathrm{AM}_{8} . \mathrm{AM}_{5}, \mathrm{AM}_{4}$ ir $\mathrm{AM}_{7}$, kurios yra specializuoti valstybiniai universitetai. Nepaisant to, tyrimo rezultatai rodo, kad šiame instituciniame lygmenyje valstybinių universitetų tipai pasižymi tam tikrais skirtumais, kurie preliminariose išvadose galèjo būti neįvertinti. 


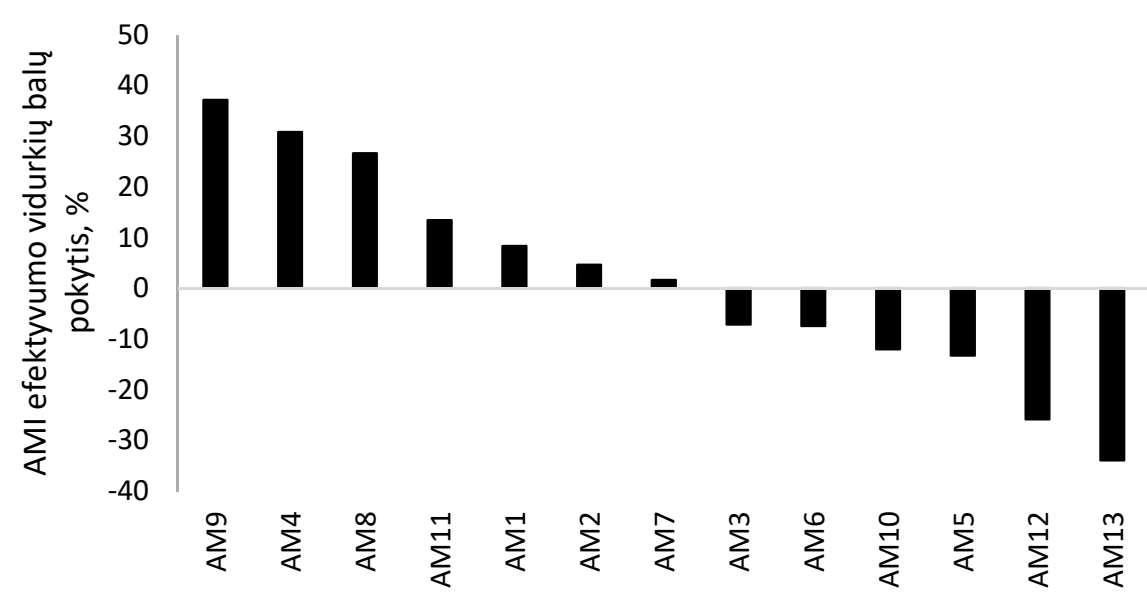

S3.4 pav. Aukštojo mokslo institucijų efektyvumo vidurkių balų pokytis, 2010-2016 m. (sudaryta autoriaus)

Šiame skyriuje išnagrinètas valstybinių universitetu poveikis Lietuvos ekonomikai ir kaip efektyviai jie panaudoja savo išteklius, kad sukurtų rezultatus, kurie atitinka AMI nustatytus tarptautinius standartus. Leontjevo modelis buvo naudojamas stebėti valstybinių universitetų sąnaudoms ir rezultatams, kuriuos jie sukuria Lietuvoje. Su valstybiniais universitetais susiję duomenys buvo sujungti i DAA modeli, kuris buvo panaudotas apskaičiuojant šių institucijų efektyvumą. Lietuvos AM sistema šiuo metu susiduria su įvairiais iššūkiais ir problemomis, kurios kenkia AMI našumui ekonomikoje bei tarptautiniame švietimo sektoriuje. Todèl tyrimas nagrinejja problemas labiau moksline prasme. Tyrimas yra reikšmingas ne tik moksliniu lygmeniu dèl naujo modelio sukūrimo, bet ir empiriniu lygmeniu, nes yra pateikiama Lietuvos valstybinių universitetų ekonominio poveikio ir efektyvumo analizè.

\section{Bendrosios išvados}

1. Atlikus AMI poveikio ekonomikai ir veiklos efektyvumo koncepcijų literatūros apžvalgą paaiškèjo trys pagrindinès problemos su kuriomis susiduria AMI. Pirma, nepakankamai efektyviai naudojami finansiniai ištekliai, kurie ne visada aiškiai susieti su AMI išsikeltų strateginių tikslų igyvendinimu. Antra, pasigendama įrankių ir priemonių skirtų aukštojo mokslo institucijų ekonominiam poveikiui ir efektyvumui ịvertinti. Trečia, trūksta metodų, kurių pagalba būtų galima ịvertinti žmogiškụjų resursų poveikị kitiems ekonominiams sektoriams. Didžioji dalis mokslininkų sutinka, kad AMI labai prisideda prie vietos ir regiono ekonominės plètros, tačiau nuomonès išsiskiria vertinant, kaip tinkamai įvertinti AMI sukuriama ekonominį efektą šalei, ar regioniui, kuriame šios institucijos veikia. 
2. Pasiūlyta metodika, skirta įvertinti AMI ekonominị poveiki ir efektyvumą bendroje sistemoje. Integruota metodika leidžia vertini AMI veiklos ekonominius efektus tiek išoriniu (poveikio ekonomikai) tie vidiniu (veiklos efektyvumo) požiūriu.

3. Pasiūlytame modelyje panaudota sąnaudų-rezultatų vertinimo matrica kartu su duomenų apgaubimo analizès metodu leidžia ịvertinti ne tik konkrečios institucijos poveiki ar efektyvumą, bet ir palyginti institucijas tarpusavyje t. y. atlikti AMI sistemini vertinimą. Pasiūlyto algoritmo pagalba AMI poveikio ekonomikai ir efektyvumo vertinimo rezultatai gali būti panaudoti ekonominės plètros kontekste atsižvelgiant ne tik ì gautus momentinius rezultatus, bet ir laiko eilutès.

4. Atliktu empiriniu tyrimu Lietuvos AMI pavyzdžiu ịrodyta, kad pasiūlyto modelio atskiros dalys suderinamos ir padeda geriau suprasti koki poveiki ekonomikai AMI sukuria. Pasiūlytas modelis yra tinkamas poveikio ekonomikai ir efektyvumui vertinti. Trijų valstybinių universitetų II tipo našumo koeficientai lyginant su kitais švietimo sektoriais buvo vieni iš didžiausių. Valstybinių universitetų efektyvumo palyginimas ịvairiais laiko momentais suteikè naujų ižvvalgų apie universitetų veiklos efektyvumą instituciniu lygmeniu. Tyrimu taip pat paneigiamos ankstesnès prielaidos, kad smulkieji valstybiniai universitetai, lyginant su didesnėmis institucijomis, yra mažiau efektyvūs. Vienas iš smulkiausių valstybinių universitetų yra vienas iš penkių efektyviausių, o didžiausias valstybinis universitetas užima vos 12-ą vietą iš 13 tarp mažiausiai efektyvių valstybinių universitetų. Gauti kiekybiškai ir kokybiškai išreikšti rezultatai, tokie kaip poveikio ekonomikai našumo koficientai bei AMI efektyvumo vertinimas bendroje sistemoje, yra nauji ir reikšmingi ekonomikos mokslui. 



\section{Annexes $^{1}$}

Annex A. Data of Public Universities in Lithuania (2010-2016)

Annex B. Input-Output Table Disaggregation

Annex C. Public Universities Output Multiplier Calculations

Annex D. Cross Efficiency and Dynamic Data Envelopment Analysis Calculations ( $R$ package)

Annex E. Author's Declaration of Academic Integrity

Annex F. The Co-Authors' Agreements to Present the Material of Publications as a Part of the Doctoral Dissertation

Annex G. Copies of Scientific Publications by the Author on the Topic of the Dissertation

${ }^{1}$ The annexes are supplied in the attached compact disc. 
Agnè VAICIUKEVIČIŪTĖ

ASSESSING ECONOMIC IMPACT AND EFFICIENCY OF HIGHER EDUCATION INSTITUTIONS

Doctoral Dissertation

Social Sciences, Economics (S 004)

AUKŠTOJO MOKSLO INSTITUCIJU EKONOMINIO POVEIKIO IR EFEKTYVUMO VERTINIMAS

Daktaro disertacija

Socialiniai mokslai, Economics (S 004)

201905 16. 13,5 sp. I. Tiražas 20 egz.

Vilniaus Gedimino technikos universiteto

leidykla „Technika“,

Saulètekio al. 11, 10223 Vilnius,

http://leidykla.vgtu.It

Spausdino UAB „BMK leidykla“,

A. Mickevičiaus g. 5, LT-08119 Vilnius 